\title{
BRÚQUIDOS (COLEOPTERA: BRUCHIDAE) DEL ESTADO DE TABASCO, MÉXICO
}

\author{
ARACELY DE LA CRUZ PÉREZ, ${ }^{1}$ JESÚS ROMERO NÁPOLES, ${ }^{2}$ JosÉ LUIS \\ CARRILLO SANCHEZ, ${ }^{2}$ EUSTOLIA GARCÍA LÓPEZ, ${ }^{2}$ ROSAURA GRETHER \\ GONZALEZ, ${ }^{3}$ SAÚl SANCHEZ SOTO, ${ }^{2}$ \& MANUEL PÉREZ DE LA CRUZ ${ }^{1}$ \\ ${ }^{1}$ Universidad Juárez Autónoma de Tabasco- DACBIOL < aracely.delacruz@ujat.mx> \\ Carretera Villahermosa-Cárdenas Km. 0.5 S/N entronque a bosques de saloya C.P. 86150 \\ ${ }^{2}$ Colegio de Postgraduados. Carretera México-Texcoco, Km 36.5 Montecillo, Texcoco, Estado de \\ México C.P. 56230 \\ 3Universidad Autónoma Metropolitana. Av. San Rafael Atlixco No.186, Col.Vicentina Del. \\ Iztapalapa, México D.F. C.P. 09340
}

de la Cruz Pérez, A., Romero Nápoles, J., Carrillo Sánchez, J. L., García López, E., Grether González, R. G., Sanchez Soto, S. \& Pérez de la Cruz, M. 2013. Brúquidos (Coleoptera: Bruchidae) del estado de Tabasco, México. Acta Zoológica Mexicana (n. s.), 29(1): 1-95.

RESUMEN. Con el fin de determinar la diversidad de especies de Bruchidae del estado de Tabasco, se realizaron colectas a través de (1) muestras de semillas secas, y (2) colecta manual directa. Un total de 3578 ejemplares en 14 géneros y 49 especies fueron registradas de las cuales 37 especies son nuevas para Tabasco. De las 35 plantas hospederas colectadas, nueve fueron registradas como nuevas hospederas asociadas. Se presenta una diagnosis y clave con esquemas de genitalia para las especies de Bruchidae de Tabasco.

Palabras clave: Gorgojos, taxonomía, clave dicotómica, diversidad, clave para brúquidos.

de la Cruz Pérez, A., Romero Nápoles, J., Carrillo Sánchez, J. L., García López, E., Grether González, R., Sánchez Soto, S. \& Pérez de la Cruz, M. 2013. Bruchids (Coleoptera: Bruchidae) of the state of Tabasco, Mexico. Acta Zoológica Mexicana (n. s.), 29(1): 1-95.

ABSTRACT. In order to determine the species diversity of the Bruchidae of the state of Tabasco, collections were made via (1) dry seeds samples, and (2) direct hand collections. A total of 3578 specimens in 14 genera and 49 species were recorded of which 37 species are new for Tabasco. Of the 35 host plants collected, 9 were recorded as new host associations. A diagnostic key to bruchid species of Tabasco is presented.

Key words: Weevils, taxonomy, dichotomic key, diversity, diagnostic key for bruchids.

\section{INTRODUCCIÓN}

Los brúquidos son coleópteros conocidos como "gorgojos” o “escarabajos de las semillas” y sus estados inmaduros se alimentan de semillas de alrededor de 34 familias

Recibido: 04/04/2011; aceptado: 11/10/2012. 
de plantas, principalmente de leguminosas (Romero \& Johnson 2004); este grupo de plantas destaca entre las angiospermas por su diversidad debido a sus hábitos, encontrándose desde hierbas, arbustos, lianas y árboles, se encuentran en la mayoría de los tipos de vegetación del mundo y colonizan áreas marginales o perturbadas (Grether 2005). Incluso algunas especies del género Aeschynomene y Andira se han adaptado a ambientes acuáticos (Weaver 1989). En México se reporta a las leguminosas como la cuarta familia más diversa después de las Asteraceae, Poaceae y Orchidaceae (Villaseñor 2003, 2004). Debido a la relación estrecha de los brúquidos y sus plantas hospederas, principalmente leguminosas, estos insectos tienen impacto en las áreas agroalimentaria, medicinal, industria confitera, textil y forestal al tener un amplio rango de hospederos de utilidad para el hombre, como es el caso de Caryedon serratus que se alimenta de semillas de los géneros Acacia, Bauhinia, Cassia, Piliostigma, Prosopis y Tamarindus; Callosobruchus maculatus ataca especies de Abelmoschus, Acacia, Arachis, Cajanus, Cercis, Cicer, Dolichos, Ebenus, Glycine, Gossypium, Lablab, Lathyrus, Lens, Macrotyloma, Medicago, Phaseolus, Pisum, Pueraria, Sphenostylis, Vicia, Vigna y Voandzeia; Acanthoscelides obtectus y Zabrotes subfasciatus se alimentan de semillas de Phaseolus y Vigna, por mencionar algunas. Estos insectos a pesar de afectar a más de un género de diferente familia de planta no se ha evaluado en todos los casos el daño e impacto que pueden tener, ya que también más de una especie de brúquido se alimenta de las semillas de una misma especie de planta; por ejemplo, se ha registrado más de una especie de brúquido afectando las semillas de un hospedero, causando daños del $50 \%$ y en casos extremos de hasta $90 \%$ e incluso 100\% (Romero 2002b); tienen impacto sobre colecciones de semillas, en el almacenamiento de granos comestibles o afectando la germinación. Económicamente este grupo destaca como una plaga primaria o secundaria al producir daños leves e incluso la pérdida total. Aunque la mayoría de las especies de esta familia de insectos se encuentra regulando las poblaciones de plantas silvestres, con toda seguridad en el futuro se incorporan algunas de ellas al ámbito productivo, por lo que el conocimiento y grado de daño de sus insectos asociados es muy importante para la toma de decisiones en el manejo de los productos o subproductos generados (Romero et al. 2005); sobre todo cuando se desean establecer bancos de germoplasma o de alimentos ya sea con fines de conservación o mejoramiento de especies, por tal motivo, la finalidad del trabajo fue obtener una lista de las especies de Bruchidae y de sus hospederos; conocer la diversidad de brúquidos en las subregiones Centro, Chontalpa, Ríos, Pantanos y Sierra del estado de Tabasco y elaborar una clave dicotómica para la identificación de los géneros y especies para el estado.

\section{MATERIAL Y MÉTODOS}

El estado de Tabasco se localiza al sureste de la República Mexicana (SEDESPA 2001), sus coordenadas geográficas son $17^{\circ} 15^{\prime}$ y $18^{\circ} 39^{\prime}$ de latitud norte y $91^{\circ} 00^{\prime}$ y 
94¹7’ de longitud oeste, colinda al norte con el Golfo de México y Campeche; al este con Campeche y la República de Guatemala; al sur con Chiapas y al oeste con Veracruz. Tabasco se encuentra integrado por 17 municipios que se reparten en dos grandes regiones, la región del Grijalva y la Región del Usumacinta. La región del Grijalva se divide en tres subregiones: la subregión del Centro integrada por los municipios de Villahermosa, Jalpa de Méndez y Nacajuca, la subregión de la Chontalpa formada por los municipios de Huimanguillo, Cárdenas, Cunduacán, Comalcalco y Paraíso y la subregión Sierra por los municipios de Teapa, Jalapa y Tacotalpa. La región del Usumacinta se divide en dos subregiones, la subregión de los Ríos, formada por los municipios de Balancán, Centla, Emiliano Zapata, Jonuta y Tenosique y la subregión de los Pantanos, integrada por los municipios de Macuspana, Jonuta y Centla (Fig. 1).

Colecta directa. Se realizaron recorridos al azar entre la vegetación a campo abierto con la finalidad de capturar formas adultas de brúquidos; para tal efecto se utilizó una red entomológica, después de 10 a 20 redadas los organismos fueron colocados en bolsas de plástico transparente para facilitar su separación, posteriormente se colocaron en tubos de ensayo de plástico con alcohol al 70\% con sus respectivos datos de colecta.

Colecta indirecta. La colecta de semillas fué dirigida a la recolección de frutos secos, los cuales fueron colocados en bolsas de papel con sus respectivos datos georeferenciados; el material se conservó en el laboratorio de entomología del Colegio de Postgraduados Campus Tabasco, donde se revisaron cada tercer día hasta observar

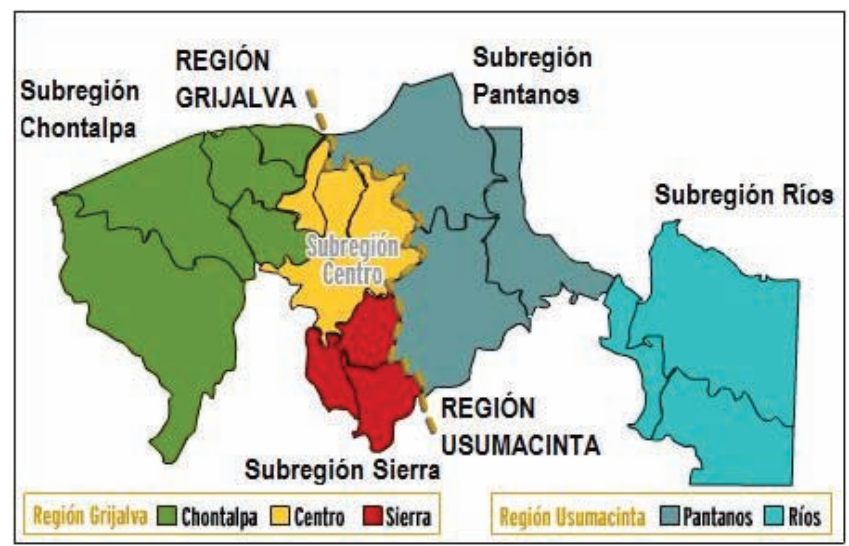

Figura 1. Mapa de Tabasco indicando las cinco subregiones en las que se agrupan los 17 municipios. 
la emergencia de las formas adultas de los insectos las cuales fueron preservados en alcohol al 70\%. Durante este mismo período se realizó un estudio a la par sobre insectos en cacao en Tabasco, los brúquidos que eran colectados en las trampas de alcohol se integraron a este trabajo.

Colecta, procesamiento y determinación de plantas hospederas. Para la identificación de los hospederos se hicieron colectas botánicas, cortando una parte de la planta (rama, flor y fruto) o la planta completa (herbáceas), las muestras fueron colocadas en una prensa botánica y etiquetadas con sus datos georeferenciados, posteriormente se mantuvieron en la secadora de 3 a 4 días en el Herbario Centro Superior de Agrícultura Tropical (CSAT) del Campus Tabasco, siguiendo la metodología de Lot \& Chiang (1986); el material fue identificado con la ayuda de literatura taxonómica y florística para las familias, géneros y especies, así como por comparación con la Colección del Herbario CSAT (Centro Superior de Agrícultura Tropical).

Procesamientos y determinación del material entomológico. Los insectos capturados en la colecta directa y aquellos emergidos de las semillas se transportaron al laboratorio de Taxonomía del Colegio de Postgraduados, Campus Montecillo para su determinación taxonómica; para tal efecto fue necesario la extracción de la genitalia del macho, para esto se utilizó la metodología propuesta por Kingsolver \& Whitehead (1974a) y Kingsolver (1970). Para la interpretación de las estructuras de la genitalia se siguió la nomenclatura propuesta por Romero \& Johnson (1999). Los datos de las especies determinadas se incorporaron a la base de datos de Bruchidae (BRUCOL) (Romero \& Johnson 2002a). Todo el material fue depositado en la Colección Entomológica del Colegio de Postgraduados (CEAM).

Para la elaboración de los esquemas de las genitalias, se utilizaron las ilustraciones originales y se modificaron; para esto se usaron las siguientes fuentes: Acanthoscelides (Johnson 1990), Amblycerus (Romero et al. 1996), Callosobruchus (Kingsolver 2004), Caryedes (Kingsolver \& Whitehead 1974b), Caryedon (Johnson et al. 2004), Ctenocolum (Kingsolver \& Whitehead 1974a), Gibbobruchus (Whitehead \& Kingsolver 1975), Megacerus (Teran \& Kingsolver 1977), Meibomeus (Kingsolver \& Whitehead 1976), Merobruchus (Kingsolver 1988), Mimosestes (Kingsolver \& Johnson 1978), Sennius (Johnson \& Kingsolver 1973), Stator (Johnson \& Kingsolver 1976), Zabrotes (Romero \& Johnson 2000).

Analisis de la diversidad. Se analizó la diversidad alfa y beta en las subregiones del estado, para cuantificar a las especies se utilizó la riqueza especifica, para conocer la estructura de las comunidad se aplicaron los índices de Shannon-Wiener $\left(\mathrm{H}^{\prime}\right)$ y Pieou ( $\left.\mathrm{J}^{\prime}\right)$; para conocer la similitud o disimilitud entre las subregiones se utilizó el índice de Morisita de Horn (IM-Horn) utilizando el programa Bio-dap (Thomas \& Clay 2005). 


\section{RESULTADOS}

Durante los años 2007 a 2009 se realizaron recorridos en el estado de Tabasco lográndose colectar en 11 municipios un total de 58 puntos de colecta, mismos que cubrieron la mayor parte de la superficie del estado, como se muestra en la Figura 2.

Se obtuvieron en total 3,578 brúquidos agrupados en 14 géneros y 49 especies, de las cuales 37 constituyeron nuevos registros para el estado de Tabasco; a este número de especies se incorporaron los registros provenientes de la base de datos BRUCOL, mismos que se obtuvieron de revisar las siguientes colecciones: CEAM (Colección Entomológica del Colegio de Postgraduados, Montecillo, Estado de México, México), CECT (Colección Entomológica del Campus Tabasco, Colegio de Postgraduados, Cárdenas, Tabasco, México), MIFA (Museo de Insectos de la Facultad de Agronomía, Universidad Autónoma de Tamaulipas, México), TAMU (Colección de

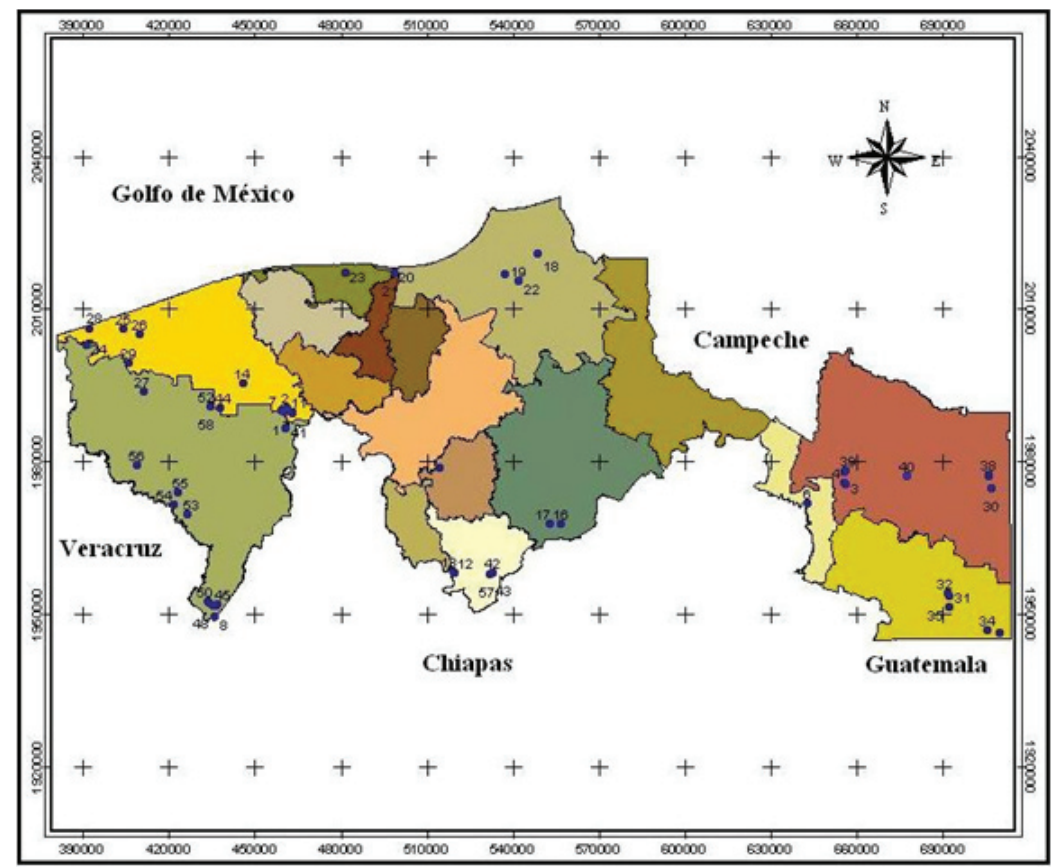

Puntos de Colecta

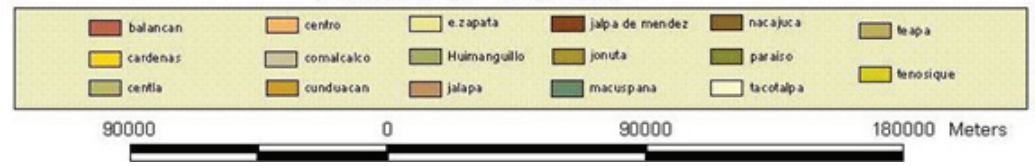

Figura 2. Ubicación de los puntos de colecta realizados durante el 2007-2009 en los municipios de Tabasco. 
Insectos de la Universidad de Texas A \& M, EUA), USNM (Colección de Insectos del Museo de Historia Natural, EUA), CAS (Colección de la Academia de Ciencias de California, EUA); el total de especies para el estado fue de 49 (Cuadro 1). El género con el mayor número de especies del total colectado fue Acanthoscelides Schilsky con 17 especies (34.69\%).

Los análisis de diversidad indicaron que la subregión Chontalpa fue la más diversa y la que registró el mayor numero de especies; Zabrotes subfasciatus fue abundante en la subregión Sierra; en la subregión Pantanos la abundancia de las especies fue más equitativa, por otro lado la menor diversidad se observo en la subregión Centro, esto se debe a la diferencia existente entre el número de especies y la abundancia relativa entre las cinco subregiónes, ya que esta zona fue afectada por fenómenos climatológicos durante los años de realización de la investigación (Cuadro 2). Las subregiones con el mayor grado de similitud fueron Centro-Pantanos al obtener el valor de 0.724 a diferencia de las otras subregiones que obtuvieron valores menores a 0.1 (Cuadro 3).

Se listan 35 plantas de las cuales 29 se determinaron hasta especie y tres a género; en el Cuadro 4, se listan las especies de brúquidos y las plantas hospederas registradas para cada especie, de las cuales 9 registros son nuevos hospederos; se confirmó el hospedero Calopogonium caeruleum para las especies del género Caryedes; Albizia lebbeck como hospedera de Amblycerus cistelinus (Cuadro 4).

Clave para especies de la familia Bruchidae. A continuación se proporciona una clave dicotómica, mediante la cual se pueden determinar las 49 especies para el estado de Tabasco, para mayor comprensión de ésta en la Figura 3 se muestra la morfología básica de este grupo de insectos.

11 Primer segmento metatarsal cuando menos 1.5 veces más largo que el segundo, antena serrada o pectinada; generalmente con carina frontal, cuerpo pubescente, pigidio expuesto . . . . . Familia Bruchidae. . . . . 2

11' Primer segmento metatarsal más o menos de la misma longitud que el segundo, antena filiforme; generalmente sin carina frontal, cuerpo generalmente glabro, pigidio no expuesto ........ Familia Chrysomelidae

12 (1) Metatibia con un par de espinas móviles largas, localizadas apicalmente ..... Subfamilia Amblycerinae. ................. 3

12' Metatibia sin espinas apicales $\ldots \ldots \ldots \ldots \ldots \ldots \ldots \ldots \ldots$

13 (2) Ojos emarginados, sinus ocular cuando más $1 / 3$ de su longitud, surco metepisternal presente ...... Amblycerus Thunberg . . . . . . . . 15

13' Ojos emarginados en cuando menos la mitad de su longitud, sin surco metepisternal, pigidio amarillento con una raya media longitudinal blanca, cuerpo negro, cabeza blanca, excepto por unos puntos marrón amarillentos sobre el vértex, metacoxa marrón, lisa, sin un 


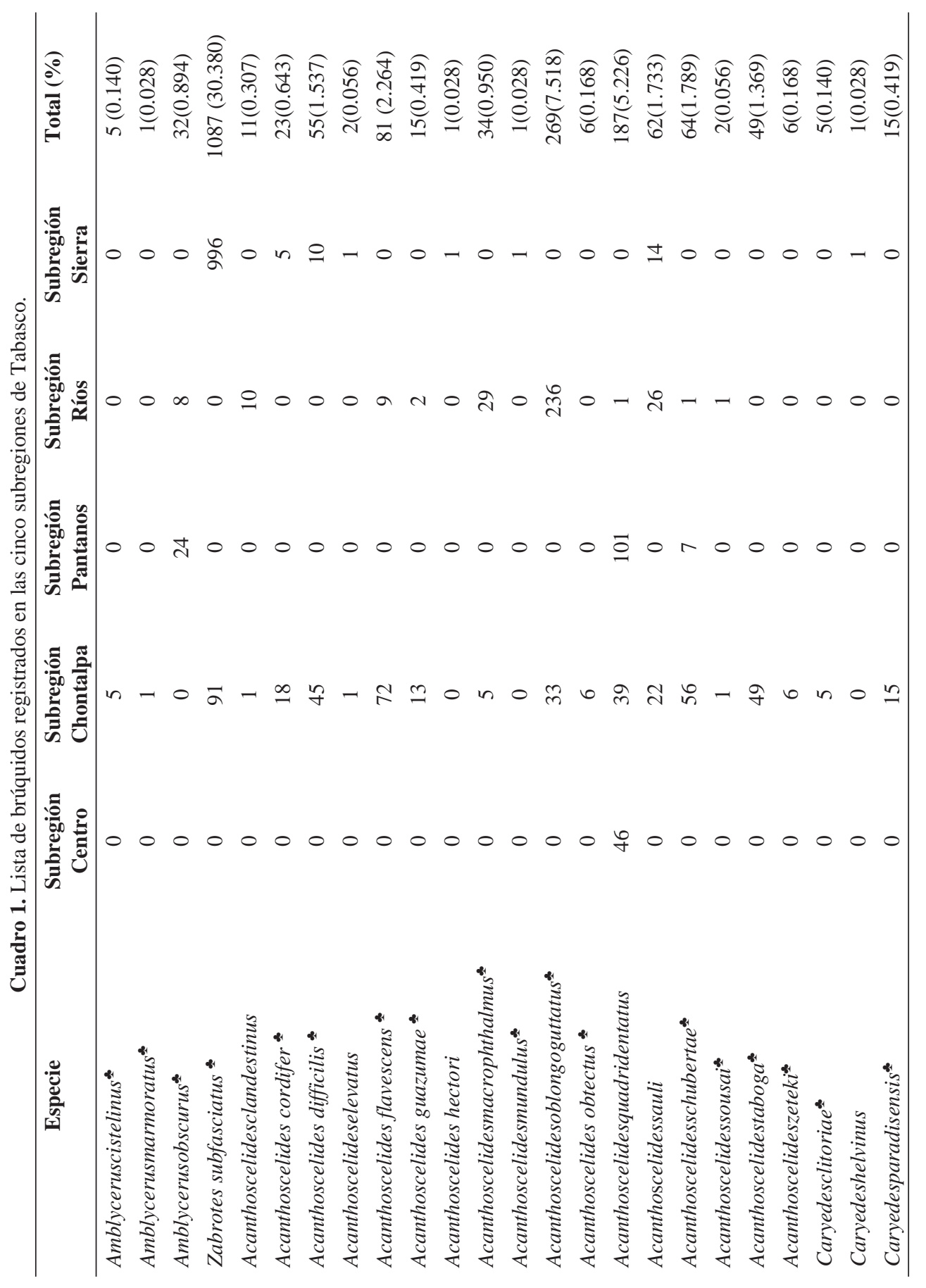




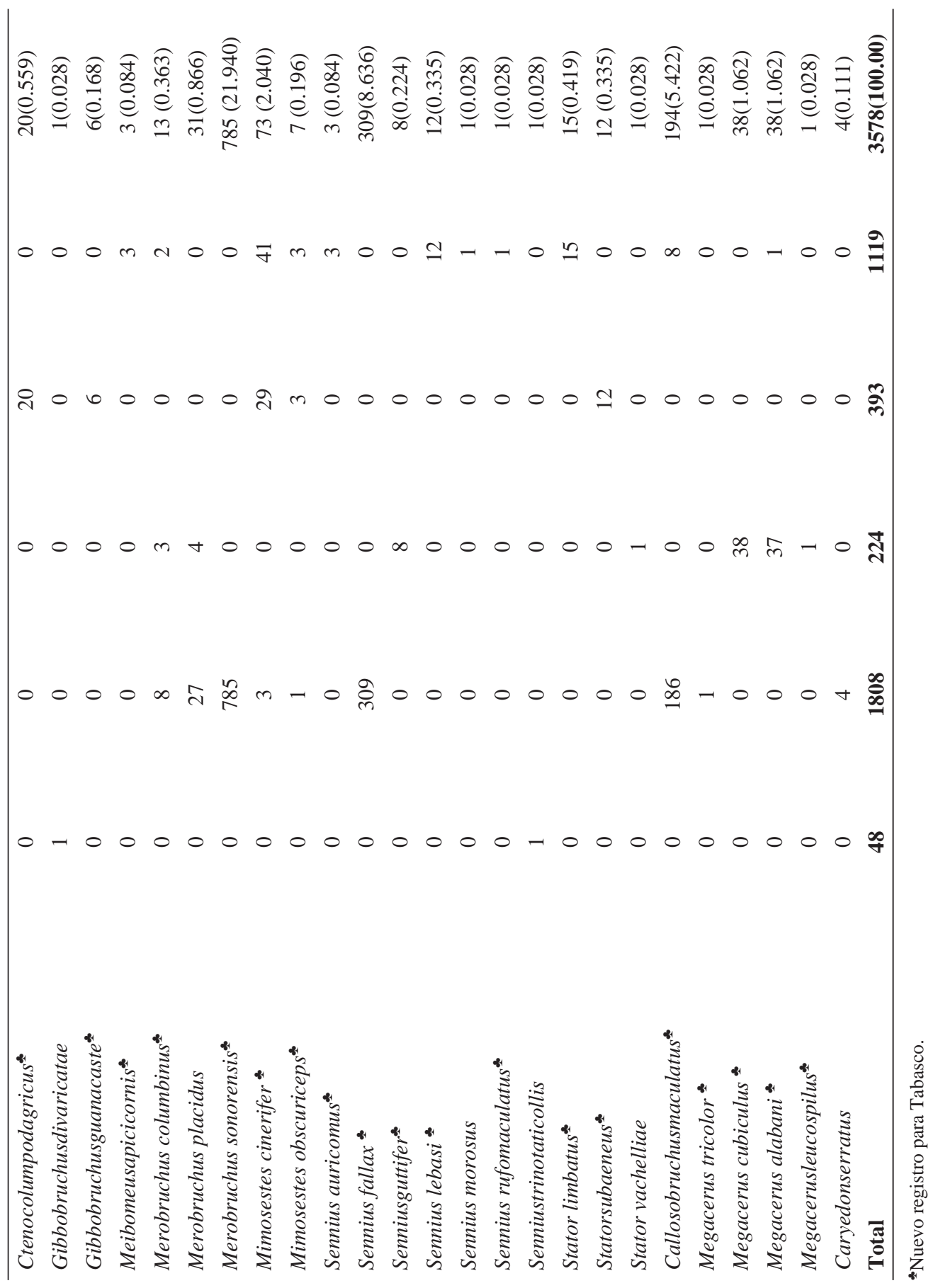


Cuadro 2. Análisis de la diversidad en las cinco subregiones de Tabasco, México.

\begin{tabular}{lcccccc}
\hline $\begin{array}{c}\text { Subregiones } \\
\text { de Tabasco }\end{array}$ & $\begin{array}{c}\text { Riqueza } \\
\text { de especies }\end{array}$ & $\begin{array}{c}\text { Número de } \\
\text { individuos }\end{array}$ & $\begin{array}{c}\text { Abundancia } \\
\text { máxima }\end{array}$ & $\begin{array}{c}\text { Índice de } \\
\text { Shanon (H') }\end{array}$ & $\begin{array}{c}\text { Equidad } \\
(\mathbf{J})\end{array}$ & Var $\mathbf{H}^{\prime}$ \\
\hline Centro & 3 & 48 & 46 & 0.20 & 0.18 & 0.01198 \\
Chontalpa & 29 & 1808 & 785 & 2.03 & 0.60 & 0.00102 \\
Pantanos & 10 & 224 & 101 & 1.60 & 0.70 & 0.00395 \\
Ríos & 15 & 393 & 236 & 1.56 & 0.58 & 0.00474 \\
Sierra & 19 & 1119 & 996 & 0.59 & 0.20 & 0.00173 \\
\hline
\end{tabular}

Cuadro 3. Valores del índice de similitud de Morisita-Horn (IM-H) cuantitativo entre las cinco subregión del estado de Tabasco, México.

\begin{tabular}{lc}
\hline \multicolumn{1}{c}{ SUBREGIONES } & SIMILITUD (IM-H) \\
\hline Centro-Chontlapa & 0.036 \\
Centro-Pantanos & 0.724 \\
Centro-Ríos & 0.004 \\
Centro-Sierra & 0.000 \\
Chontalpa-Pantanos & 0.043 \\
Chontalpa-Ríos & 0.043 \\
Chontalpa-Sierra & 0.089 \\
Pantanos-Ríos & 0.010 \\
Pantanos-Sierra & 0.000 \\
Ríos-Sierra & 0.006 \\
\hline
\end{tabular}

grupo de puntuaciones cerca de la articulación trocanteral, élitros con una banda blanca mesal y transversal, metasterno con una fosa, con un par de carinas sobre la parte externa de la metatibia, pronoto con pequeñas depresiones laterales, con puntos marrón sobre la frente..................... Zabrotes subfasciatus (Boheman)

14 (2') Metafémur con pecten y a menudo también con espinas, disco del pronoto generalmente circundado por una carina o línea marginal, borde elitral posterior glabro, proceso prosternal corto, sin separar a las coxas por completo, si las llega a separar entonces el proceso es muy delgado y agudo, carina lateral del pronoto indistinta lateralmente ..... . Subfamilia Pachymerinae....... Caryedon serratus (Olivier)

14' Metafémur sin pecten, con o sin espinas, disco del pronoto no circundado por una línea marginal, borde elitral posterior delineado con pequeñas setas . . . . Subfamilia Bruchinae . . . . . . . . . . . . . . . . 5 
de la Cruz Pérez et al.: Brúquidos de Tabasco

Cuadro 4. Especies de brúquidos y sus plantas hospederas colectadas en Tabasco, México.

Durante el 2007 al 2009. Nuevo hospedero ( $\Delta$ ) (9); hospederos confirmados ( $\downarrow)$ (2);

hospederos no conocidos (ND) (7).

\begin{tabular}{|c|c|}
\hline Especie & Hospedero \\
\hline Amblycerus cistelinus & $\begin{array}{l}\text { Guazuma ulmifolia Lam. (Leguminosae) } \\
\text { Albizialebbeck (L.) Benth. (Leguminosae) } \\
\text { Trampas de alcohol }\end{array}$ \\
\hline Amblycerus marmoratus & ND \\
\hline Amblycerus obscurus & $\begin{array}{l}\text { Senna occidentalis (L.) Link. (Leguminosae) } \\
\text { Senna bicapsularis (L.) Roxb. (Leguminosae) }\end{array}$ \\
\hline Zabrotes subfasciatus & Phaseolus vulgaris L. (Leguminosae) \\
\hline Acanthoscelides clandestinus & $\begin{array}{l}\text { Vigna adenantha (G. Mey.) Marechal, Mascherpa y Stainier } \\
\text { (Leguminosae) }\end{array}$ \\
\hline Acanthoscelides cordifer & Mimosa albida var. strigosa (Willd.) B.L. Rob (Leguminosae) \\
\hline Acanthoscelides difficilis & $\begin{array}{l}\text { Mimosa pudica L. (Leguminosae) } \\
\text { Mimosa albida var. strigosa (Willd.) B.L. Rob (Leguminosae) }\end{array}$ \\
\hline Acanthoscelides elevatus & A Pavonia sp. (Malvaceae) \\
\hline Acanthoscelides flavescens & $\begin{array}{l}\text { A Crotalaria mollicula Kunth (Leguminosae) } \\
\text { Rhynchosia minima L. (D.C.) (Leguminosae) }\end{array}$ \\
\hline Acanthoscelides guazumae & $\begin{array}{l}\text { Guazuma ulmifolia Lam. (Leguminosae) } \\
\text { Trampas de alcohol } \\
\Delta \text { Leucaena leucocephala (Lam.) De Wit (Leguminosae) }\end{array}$ \\
\hline Acanthoscelides hectori & Calopogonium caeruleum (Leguminosae) \\
\hline Acanthoscelides macrophthalmus & Leucaena leucocephala (Lam.) De Wit (Leguminosae) \\
\hline Acanthoscelides sp. & $\boldsymbol{\Delta}$ Aeschynomene scabra G. Don (Leguminosae) \\
\hline Acanthoscelides mundulus & Nissolia fructicosa Jacq. (Leguminosae) \\
\hline Acanthoscelides oblongoguttatus & $\begin{array}{l}\text { Acacia cornígera }(\mathrm{L} .) \text { Willd (Leguminosae) } \\
\text { Acacia collinsii Saff (Leguminosae) }\end{array}$ \\
\hline Acanthoscelides obtectus & Phaseolus vulgaris L. (Leguminosae) \\
\hline Acanthoscelides quadridentatus & $\begin{array}{l}\text { Redeo sobre malváceas } \\
\text { Mimosa pigra L. (Leguminosae) }\end{array}$ \\
\hline Acanthoscelides sauli & $\begin{array}{l}\text { Acacia cornigera (L.) Willd. (Leguminosae) } \\
\text { Acacia collinsi Saff. (Leguminosae) }\end{array}$ \\
\hline Acanthoscelides schubertae & $\begin{array}{l}\text { Desmodium incanum DC. (Leguminosae) } \\
\text { Hospedero \# } 46 \text { (Leguminosae) } \\
\text { Hospedero \# } 213 \text { (Leguminosae) }\end{array}$ \\
\hline Acanthoscelides sousai & $\begin{array}{l}\text { Acacia cornigera (L.) Willd (Leguminosae) } \\
\text { Acacia collinsii Saff (Leguminosae) }\end{array}$ \\
\hline Acanthoscelides taboga & Calopogonium caeruleum (Benth.) Sauvalle (Leguminosae) \\
\hline Acanthoscelides zeteki & Rhynchosia minima (L.) DC. (Leguminosae) \\
\hline
\end{tabular}




\begin{tabular}{|c|c|}
\hline Caryedes clitoriae & Calopogonium caeruleum (Benth.) Sauvalle (Leguminosae) \\
\hline Caryedes helvinus & ND \\
\hline Caryedes paradisensis & Calopogonium caeruleum (Benth.) Sauvalle (Leguminosae) \\
\hline Ctenocolum podagricus & $\begin{array}{l}\text { Piscidia piscipula (L.) Sarg. (Leguminosae) } \\
\text { Lonchocarpus rugosus Benth (Leguminosae) }\end{array}$ \\
\hline Gibbobruchus divaricatae & Bauhinia divaricata L. (Leguminosae) \\
\hline Gibbobruchus guanacaste & $\boldsymbol{\Delta}$ Lonchocarpus rugosus Benth (Leguminosae) \\
\hline Meibomeus apicicornis & $\begin{array}{l}\text { Redeo sobre malváceas } \\
\text { Desmodium sp. (Leguminosae) }\end{array}$ \\
\hline Merobruchus columbinus & $\begin{array}{l}\text { Samanea saman (Jacq) Merrill (Leguminosae) } \\
\text { Trampas en alcohol }\end{array}$ \\
\hline Merobruchus placidus & $\begin{array}{l}\text { ND Acaciella angustissima var. angustissima (Mill.) Kuntze } \\
\text { (Leguminosae) }\end{array}$ \\
\hline Merobruchus sonorensis & Albizia lebbeck (L.) Benth. (Leguminosae) \\
\hline Mimosestes cinerifer & $\begin{array}{l}\text { A Acacia collinsii Saff. (Leguminosae) } \\
\text { Acacia cornigera }(\mathrm{L} .) \text { Willd (Leguminosae) }\end{array}$ \\
\hline Mimosestes obscuriceps & $\begin{array}{l}\text { Hospedero \#340 (Leguminosae) } \\
\text { வ Acacia collinsii Saff. (Leguminosae) } \\
\text { Acacia cornigera (L.) Willd. (Leguminosae) }\end{array}$ \\
\hline Sennius auricomus & $\boldsymbol{\Delta}$ Senna multijuga (L. C. Rich) Irwin y Barneby (Leguminosae) \\
\hline Sennius fallax & Senna occidentalis (L.) Link (Leguminosae) \\
\hline Sennius guttifer & Senna bicapsularis (L.) Roxb. (Leguminosae) \\
\hline Sennius lebasi & $\begin{array}{l}\text { Senna occidentalis (L.) Link. (Leguminosae) } \\
\text { Hospedero \#314 (Leguminosae) }\end{array}$ \\
\hline Sennius morosus & ND \\
\hline Sennius rufomaculatus & Hospedero \# 314 (Leguminosae) \\
\hline Sennius trinotaticollis & ND \\
\hline Stator limbatus & Albizia lebbeck (L.) Benth.(Leguminosae) \\
\hline Stator subaeneus & $\begin{array}{l}\text { Acacia cornigera (L.) Willd. (Leguminosae) } \\
\text { Acacia collinsii Saff. (Leguminosae) }\end{array}$ \\
\hline Stator vachelliae & ND \\
\hline Callosobruchus maculatus & Vigna sp. (Leguminosae) \\
\hline Megacerus tricolor & A Ipomea purpurea (L.) Roth (Convolvulacea) \\
\hline Megacerus cubiculus & Hospedero \# 180 (Convolvulacea) \\
\hline Megacerus alabani & $\begin{array}{l}\text { AIpomea seducta House } \\
\text { Hospedero \# } 180 \text { (Convolvulacea) }\end{array}$ \\
\hline Megacerus leucospilus & ND \\
\hline Caryedon serratus & Tamarindus indica L. (Leguminosae) \\
\hline
\end{tabular}


a)
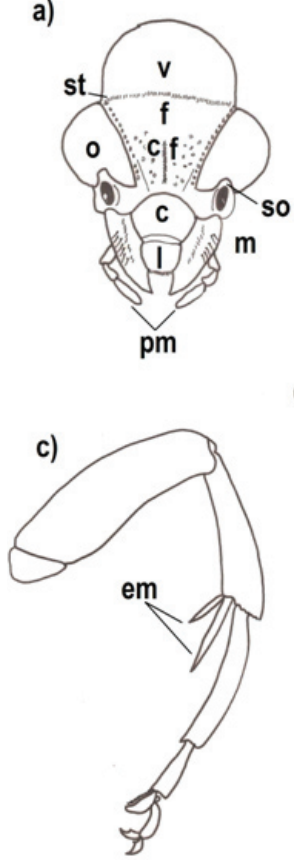

b)

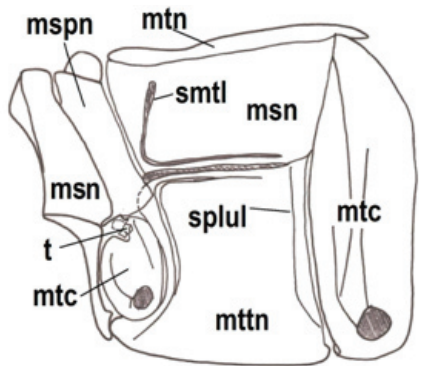

d)

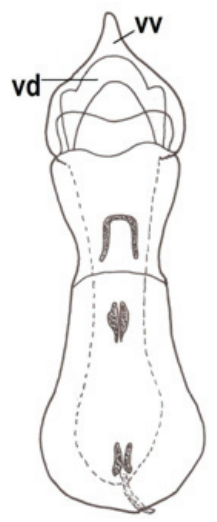

e)

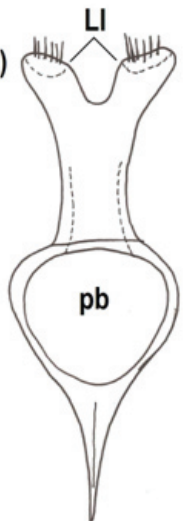

Figura 3. Cabeza de un Bruchidae, a): vertex (v); sulcus transversal (st); frente (f); carina frontal (cf); ojos (o); sinus ocular (so); clípeo (c); labro (l); mandíbula (m); palpo maxilar (pm). Mesotórax y metatórax, b): metepimeron (mtn); mesepisternon (msn); sulcus metepisternal (smtl); mesepimeron (mspn); trocantina (t); sutura pleurosternal (splul); metasternon (mttn); metacoxa (mtc). Pata posterior, c): espinas móviles en metatibia (em). Genitalia del macho: edeago ó lóbulos medios, d): valva ventral

(vv) y valva dorsal (vd). Tegmen e): lóbulos laterales ó párameros (Ll) y pieza basal (pb).

15 (4’) Décima estría elitral extendiéndose cerca de la mitad del élitro ...... Megacerus Fahraeus .................. 17

15 Décima estría elitral extendiéndose cerca del ápice del élitro . . . . . . 6

16 (5’) Fémur posterior con espinas o dientes en el margen ventral interno y externo, pronoto rojo oscuro a negro, carece de líneas longitudinales; patrones elitrales variables ..... Callosobruchus maculatus (Fabricius)

16’ Fémur posterior con espinas o dientes sólo en el margen ventral interno

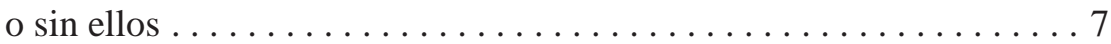

17 (6’) Fémur posterior sin espinas o con sólo una espina subapical . . . . . 8 8

17' Fémur posterior con al menos dos espinas. . . . . . . . . . . 9

18 (7) Carina lateral del pronoto completa, misma que se extiende hasta la cavidad coxal, carina lateral ventral en el metafémur alcanzando el margen 
distal, genitalia sin un par de escleritos lineales en la parte anterior del lóbulo medio ...... Stator Bridwell. ................. 20

18 Carina lateral del pronoto incompleta, carina lateral ventral en el metafémur sin alcanzar el margen distal o ausente, genitalia con un par de escleritos lineales en la parte anterior del lóbulo medio ...... Sennius Bridwell . .................... 22

19 (7’) Fémur posterior notablemente agrandado con al menos cuatro espinas; si presenta tres espinas, entonces la tibia posterior está arqueada . . . . 10

19' Fémur posterior no agrandado cuando más con tres espinas; si presenta más de tres espinas, entonces la tibia posterior es recta. . . . . . . . 14

10 (9) Pronoto con gibas........................... 11

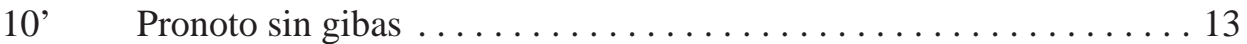

11 (10) Pigidio o esternitos abdominales con áreas glabras . . . . . Gibbobruchus Pic.................................. 28

11' Pigidio o esternitos abdominales sin áreas glabras . . . . . . . . . 12

12 (11') Pecten del fémur posterior con 3 a 6 espinas y con 2 o más espinas pequeñas antes del pecten, genitalia con los lóbulos laterales fusionados . . . . . Caryedes Hummel . . . . . . . . . . . . . . . . . 29

12' Pecten del fémur posterior con 7 a 9 espinas, sin espinas antes del pecten, genitalia con los lóbulos laterales divididos cuando menos en la mitad de su longitud, base de la muesca entre los dientes del gibosito basal elitral más cerca del ápice del diente interno que cerca de la base elitral. ....................... tenocolum podagricus (Fabricius)

13 (10’) Vestidura elitral densa, con patrones contrastantes, generalmente estrías elitrales 3 y 4 originándose basalmente en un tubérculo bidentado, generalmente genitalia con lóbulo medio no tan alargado, los lóbulos laterales profundamente divididos ...... Merobruchus Bridwell ........ 31

13' Vestidura elitral poco densa, con pocas manchas de pubescencia densa, generalmente sólo estría elitral 4 originándose basalmente en un diente, generalmente genitalia con lóbulo medio muy alargado, los lóbulos laterales hendidos ligeramente; antena corta, élitros con parches blanco intensos sobre el intervalo $3 . . . \ldots \ldots$.... Meibomeus apicicornis (Pic)

14 (9) Cabeza con un área glabra en la frente que se extiende hacia el vértex, fémur posterior profundamente acanalado en el macho . . . . . Mimosestes Bridwell . . . . . . . . . . . . . . . . 33

14' Cabeza sin un área glabra en la frente que se extienda hacia el vértex, fémur posterior en el macho sin tal canaladura, longitud del escutelo no más de 1.5 veces su anchura, hembras sin un par de surcos subapicales glabros en el pigidio . . . . . Acanthoscelides Schilsky . . . . . . . . 34 
15 (3) Frente con carina linear media, pigidio con una mancha central grande, rodeado de vellos blancos sin pequeñas depresiones. ................... Amblycerus cistelinus (Gyllenhal)

15 Frente sin carina linear media o con una línea no punteada, sin las otras características del pigidio.................... 16

16 (15’) Eje transversal del sulcus metepisternal recto . . . . Amblycerus obscurus (Sharp)

16' Eje transversal del sulcus metepisternal encorvado........ Amblycerus marmoratus (Sharp)

17 (5) Borde interno de la cara ventral del fémur posterior liso, estrías elitrales con puntos grandes que ondulan los bordes de las interestrías, éstas semejando costillas y marcadas a veces con una hilera de puntos, mucro de la tibia posterior tan largo como la mitad del ancho de ésta en el ápice hasta más largo que el ancho de la misma, carina lateral de la tibia III terminando junto a la base del mucro o muy próximo a ella, ápice de la tibia posterior del macho con un gancho ...... Subgénero Pachybruchus Pic . . . . . . . . . . . . 19

17' Borde interno de la cara ventral del fémur posterior liso o con un dientecito, estrías elitrales con puntos de tamaño variable que deforman o no a las interestrías, éstas sin hileras de puntos en su superficie, mucro de la tibia III no tan largo como la mitad del ancho del ápice tibial, carina lateral de esta tibia terminando en un dientecito del borde apical, machos sin apéndices peculiares en las patas I o II . . . . . Subgénero Megacerus Fahraeus . . . . . . . . . . . . 18

18 Élitros con estrías que llevan puntos profundos cuyo diámetro es ligeramente mayor que el ancho de aquellas; interestrías elevadas, con bordes sinuosos; pigidio con dos áreas glabras periapicales pequeñas y dos más en el tercio medio, a veces ocultas por la pubescencia blanca; genitalia del macho con el spiculum gastrale con brazos largos, ampliamente abiertos. Parámeros apicalmente redondeados, con unas 14 cerdas a cada lado en su borde distal; lóbulo anterior con escasos pelos en su cara ventral; lengüeta subtríangular, con pelos en su borde libre; a cada lado existen, detrás de la lengüeta, unos nueve sensorios alargados. Edeago con el tubo más corto que el lóbulo basal; placa apical alargada; saco interno con un grupo de dientes flanqueados en su parte anterior por un diente de mayor tamaño a cada lado y después de un espacio, un par casi superpuesto de dientes a cada lado. ..... . Megacerus tricolor (Suffrian) 18' Élitros con estrías que llevan puntos poco profundos, cuyo diámetro es igual o ligeramente mayor que aquellas; interestrías no elevadas; pigidio con pubescencia densa, blanca y uniforme, ojos del macho escotados 
hasta la mitad de su longitud, spiculum gastarle con brazos estrechos; dientes del saco interno alineados hacia atrás en filas subparalelas superponiéndose unos con otros parcialmente . Megacerus cubiculus (Casey)

19 (17) Pigidio totalmente pubescente o con sólo las áreas espiraculares glabras, cuerpo totalmente negro, antenas de la hembra moderadamente flabeladas; élitros con estrías profundamente marcadas en el fondo de las cuales se observan puntos grandes no confluentes, interestrías sinuosas, la primera más dilatada en su parte media, donde se halla una mecha de pelo; siendo la superficie de todas punteada y finamente rugosa; mucro en la tibia III más largo que el ancho de ésta en el ápice $\ldots \ldots \ldots \ldots \ldots$.......... Megacerus (P.) alabani Teran y Kingsolver

19' Pigidio no totalmente pubescente, con otras áreas glabras además de los espiraculares, cuerpo con la cabeza negra y el resto rojo, élitros con bandas de pelos densos sobre algunas interestrías, o casi glabros, pronoto ligeramente señalado en la línea media, mucro de la tibia III más largo que el ancho apical de ese segmento......................... Megacerus (P.) leucospilus (Sharp)

20 (8) Élitros completamente rojos, con los márgenes lateral, basal y sutural negros; o los élitros pueden presentar pequeñas máculas rojas en la parte basal y apical sobre una mancha negra, tamaño pequeño, longitud del pronoto a los élitros de 1.6-2.7 mm; fémur posterior completamente

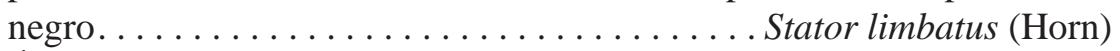

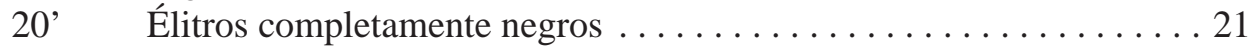

21 (20’) Ojos aplanados, muy cerca al margen lateral de la cabeza, margen posterior expandiéndose y emergiendo en la parte lateral del vértex..................................... stor subaeneus (Schaeffer)

21' Ojos no aplanados, el margen posterior proyectándose lateralmente y bien separado del vertex.............. Stator vachelliae Bottimer

22 (8’) Espina cerca del ápice del fémur posterior aproximadamente tan larga o más larga que el ancho de la base de la tibia posterior . . . . . . . 23

22' Espina cerca del ápice del fémur posterior 1/3 a 3/4 tan larga como el ancho de la base de la tibia. ...................... 27

23 (22) Con bandas densas de pelos blancos extendiéndose en casi la totalidad de la longitud de los élitros, entre los intervalos del margen medio de la estría tres; pronoto en la base usualmente con tres manchas de pelos densos dorados y blancos; espina subapical del fémur posterior 1.3 veces más larga que el ancho de la base de la tibia, margen posterior de la espina serrado; mucro de 1 a 6 veces más largo que el primer tarsomero, usualmente la región apical de pigidio más oscura que la base del pigidio.................... Sennius trinotaticollis (Pic) 
23’ No como en la descripción anterior . . . . . . . . . . . . 24

24 (23’) Estrías 2- 3 y 4 - 5 más cercanas unas de otras en la base que las estrías adyacentes; con una espina pequeña en la base de la estría 2, 3, 4 y a veces en la 5; élitros con pubescencia blanca o dorada moderadamente esparcida y con mechones de densa pubescencia blanca en la base de los intervalos de las estrías 2- 3 y 4- 5, algunas veces también esta presente un mechón cerca de la base del húmero; en la parte media de los élitros se presentan mechones de pubescencia densa blanca entre las estrías 2- 3, 4- 5, 6- 7 y 8- 9, y un mechón más ubicado mesalmente pero más apicalmente que los otros. ............... Sennius guttifer (Sharp)

24' No como en la descripción anterior . . . . . . . . . . . . 25

25 Élitros negros con maculas largas rojo amarillentas las cuales alcanzan los márgenes laterales de los élitros, ocasionalmente todos negros o las maculas no alcanzan los márgenes laterales, el margen basal de cada élitro usualmente negro, la mitad apical de los élitros de marrón a negra; pigidio rojo o marrón rojizo, algunas veces con los márgenes

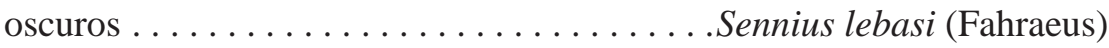

25' No como en la descripción anterior . . . . . . . . . . . . 26

26 (25’) Espina cerca del ápice del fémur posterior fuerte, algunas veces con el margen posterior serrado o crenado; los élitros varían de totalmente negros a rojo-naranja, con la base café oscuro; aunque la forma más típica es élitros negros con una banda media rojo-naranja de anchura variable; la pubescencia en los élitros varía de blanquecina para los especímenes que presentan mayormente los élitros rojo-naranja a pubescencia mezclada blanca y amarillenta con una banda de pubescencia ubicada 2/5 de la base en especímenes que presentan los élitros más

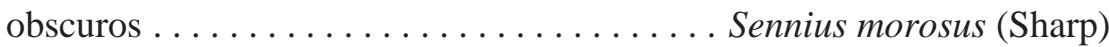

26’ Espina cerca del ápice del fémur posterior débil, con el margen posterior liso; élitros usualmente negros con máculas rojo-naranja que cubren casi la mitad de éstos y se extienden de la estría 2 a la 9 y ligeramente más cerca de la base que del ápice; húmero siempre negro de manera que la mácula se extiende hacia la base y hacia el margen lateral; élitros con pubescencia mezclada blanca y dorada en la base, frecuentemente con pequeñas maculas de pubescencia café densa sobre los intervalos entre las estrías 2 y 3, 4 y 5 apicalmente, usualmente con más pubescencia amarillenta mesalmente cubriendo la maculación; si los élitros son todos negros entonces la banda de pubescencia blanca transversa está situada más hacia la base que hacia el ápice ...................... Sennius rufomaculatus (Motschulsky) 
27 (22’) Espina cerca del ápice del fémur posterior 1/3 o menos larga que el ancho de la base de la tibia; élitros usualmente negros con una banda media rojo-naranja expandiéndose hacia el ápice o élitros negros con una mácula rojo-naranja en la base, algunas veces los élitros son totalmente negros . . . . . . . . . . . . . . . Sennius fallax (Boheman)

27 Espina cerca del ápice del fémur posterior 1/2 más larga que el ancho de la base de la tibia posterior; los élitros varían de negros a negros con una pequeña mácula medial rojo-naranja cerca de la base; en pocas oacasiones los élitros también pueden ser totalmente rojo-naranja ............... Sennius auricomus Johnson y Kingsolver

28 (11) Dorso del fémur posterior con un patrón pálido extenso; pecten del fémur posterior con 3-4 dientes posteriores bien espaciados, separados por un espacio moderado del diente grande anterior; cuerpo de 2.4-3.6 mm de longitud y 1.6-2.4 mm de ancho .......... Gibbobruchus guanacaste Whitehead y Kingsolver

28' Dorso del fémur posterior con un patrón pálido reducido; pecten del fémur posterior con 3-4 dientes posteriores poco espaciados, separados por un gran espacio del diente grande anterior; cuerpo de 2.6 - $4.1 \mathrm{~mm}$ de longitud y 1.8-2.6 mm de ancho ......... Gibbobruchus divaricatae Whitehead y Kingsolver

29 (12) Estría elitral 3 no toca el gibosito basal; lóbulo post-ocular abreviado; antena no flabelada; ojos sin dimorfismo sexual, radio interocular de más de 0.22 mm....................... Caryedes clitoriae (Gyllenhal)

29' Estría elitral 3 toca el gibosito basal, sin las otras características mencionadas. ............................. 30

30 (29’) Metasterno poco profundo, ligeramente arqueado en vista lateral; gena entre la base de la mandíbula y la fosa antenal del tamaño del diámetro de la fosa antenal; lóbulo medio de la genitalia del macho fracturado antes del ápice ........... Caryedes paradisensis Kingsolver y Whitehead

30' Metasterno profundo, fuertemente arqueado en vista lateral; gena entre la base de la mandíbula y la fosa antenal más grande que el diámetro de la fosa antenal; lóbulo medio de la genitalia del macho sin fracturar antes del ápice ................. Caryedes helvinus (Motschulsky)

31 (13) Élitros sin gibositos básales bidentados sobre la estrías 3- 4; insecto de 4.7-8.8 mm; la longitud del mucro de la metatibia de 3-4 veces el ancho del ápice de la metatibia, estrías 3-6 finamente denticuladas en la base, o con las estrías 5-6 carentes de dientecillos, estría 6-7 unidas basalmente por una carina curva; saco interno de la genitalia del macho con un esclerito largo en forma de "Y”. ........ Merobruchus columbinus (Sharp) 
31' Sin las características antes mencionadas .............. 32

32 (31’) Pigidio sin un mechón basal subtriangular de setas blanquecinas; pero con un par de manchas de color café en la parte media apical del pigidio, algunas veces también se presentan adicionalmente un par de manchas sub-basales ...................... Merobuchus placidus (Horn)

32' Pigidio con un mechón basal subtriangular de setas blanquecinas, que contrasta con el resto de la pubescencia; generalmente también está presente una línea breve de pubescencia en el ápice del subtriángulo....................... Kerobruchus sonorensis Kingsolver

33 (14) Prosternum separando la procoxa en toda su longitud; cuerpo usualmente negro.................... Mimosestes obscuriceps (Sharp)

33' Prosternum no separando la procoxa en su longitud; con pelos uniformes blancos o pelos amarillos y dorados entremezclados uniformemente, sin un patrón; cuerpo usualmente marrón rojizo................... Mimosestes cinerifer (Fahraeus)

34 (14’) Mucro en el ápice de la tibia posterior 0.16 o menos la longitud del primer tarsómero; sin sinus en la base del mucro. . . . . . . . . 35

34’ Mucro en el ápice de la tibia posterior 0.2 o más la longitud del primer tarsómero; con o sin sinus en la base del mucro . ........... 41

35 (34) Espina subapical grande del fémur posterior 1.5 a 2 veces el ancho de la base de la tibia ............................. 36

35' Espina subapical grande del fémur posterior hasta 1.4 veces el ancho de la base de la tibia ............................ 39

36 (35) Anchura de los ojos de 2 a 12 veces la anchura de la frente . . . . . . 37

36' Anchura de los ojos hasta 1.5 veces la anchura de la frente . . . . . . 38

37 (36) Anchura de los ojos de 12 veces la anchura de la frente; antena expandida lateralmente o flabelada, alcanzando de 0.5 a 0.8 la longitud de los élitros; sin un mácula negra ocupando 0.3 la parte apical de los élitros ...............Acanthoscelides macrophthalmus (Schaeffer)

37' Anchura de los ojos menos de 12 veces la anchura de la frente; antena excéntrica pero no expandida lateralmente, alcanzando de 0.3 a 0.5 la longitud de los élitros; frecuentemente con un mácula negra ocupando 0.3 la parte apical de los élitros ...... . Acanthoscelides cordifer (Sharp) 38 (36’) Hembras con mandíbulas largas y rectas cruzándose en el ápice; patrón de pubescencia de los élitros no muy contrastante; pigidio sin una mácula de pubescencia obscuros en forma de "V", longitud corporal mayor de $5.2 \mathrm{~mm}$..............Acanthoscelides oblongoguttatus (Fahraeus)

38' Ambos sexos con mandíbulas cortas y curvas, nunca se cruzan en el ápice; patrón de pubescencia de los élitros muy contrastante; pigidio con 
una mácula de pubescencia oscura en forma de "V"; longitud corporal menos de $5.2 \mathrm{~mm}$... A Acanthoscelides sauli Romero, Cruz y Kingsolver

39 (35') Élitros con pubescencia contrastante clara y obscura, aunque en ocasiones el contraste puede ser poco intenso . ............. 40

39' Élitros con pubescencia blanca o dorada uniforme, sin máculas contrastantes de pubescencia clara y obscura..............Acanthoscelides guazumae Johnson y Kingsolver

40 (39) Segmento apical de la antena café obscuro; todas las patas completamente rojo-naranja; pronoto con una mácula triangular media de pubescencia blanca muy densa en la base; pigidio con una mácula moderadamente ancha de pubescencia blanca muy densa sobre la línea media, extendiéndose de la base aproximadamente 0.5 de la longitud del pigidio y dos pequeñas máculas poco contrastantes de pubescencia café oscura cerca del ápice de la mácula blanca...... Acanthoscelides mundulus (Sharp)

40’ Segmento apical de la antena rojo-naranja; patas posteriores rojo-naranja excepto la mitad de la cara ventral del fémur posterior que es obscura; pronoto sin una mácula triangular media de pubescencia densa blanca en la base; pigidio con pubescencia moderadamente densa de color amarillento...................... Acanthoscelides obtectus (Say)

41 (34’) Mucro del ápice de la tibia posterior 0.2 a 0.33 veces tan largo como el primer tarsómero .........................4 42

41’ Mucro del ápice de la tibia posterior 0.4 veces o más largo que el primer tarsómero ...........................49

42 (41) Espina subapical del fémur posterior seguida 3 o 4 espinas más pequeñas. ............................. 43

42’ Espina subapical del fémur posterior con pequeñas serraciones sobre el margen posterior o seguida por una o dos espinas más pequeñas . . . 44

43 (42) Antenas cortas, extendiéndose cerca de la base de los élitros; anchura de la frente 1.2 veces la anchura del ojo; Espina subapical del fémur posterior seguida de 3 o 4 espinas más pequeñas. .............. Acanthoscelides quadridentatus (Schaeffer)

43' Antenas largas, extendiéndose 0.25 de la longitud de los élitros; anchura de la frente 1.4 veces la anchura del ojo; Espina subapical del fémur posterior seguida de 4 espinas más pe-

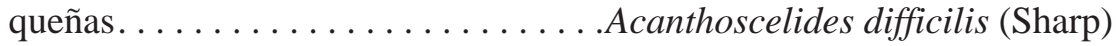

44 (42’) Mucro del ápice del fémur posterior 0.2 a 0.25 veces más largo que el primer tarsómero posterior. . ................ 45

44’ Mucro del ápice del fémur posterior 0.3 a 0.33 veces más largo que el primer tarsómero posterior..................46 
45 Antenas fuertemente aserradas, extendiéndose cerca de 0.5 de la longitud de los élitros; ojos 2.5 a 3.5 veces la anchura de la frente; espina subapical del fémur 1.5 veces la longitud del ancho de la metatibia, seguida por 2 espinas 0.3 de la longitud de la primera espina............... Acanthoscelides clandestinus (Motschulsky)

45' Antenas extendiéndose a la base de los élitros; ojos 2 veces la anchura de la frente anterior, escutelo transversal; espina subapical del fémur 1.7 veces la longitud del ancho de la metatibia, seguida por 2 espinas 0.4 de la longitud de la primera espina...... Acanthoscelides sousai Johnson

46 Pronoto usualmente marrón rojizo contrastando con élitros cafés; pigidio con pubescencia uniformemente densa blanca y amarilla, interrumpidos por pequeños parches de color café en ambos lados de la línea media, cerca de 0.4 de la base, espina subapical del fémur posterior cerca de 1.6 veces más larga que el ancho de la base de la

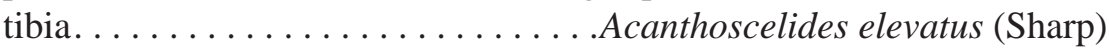

46' No exactamente como en la descripción anterior. . . . . . . . . . . 47

47 (46) Espina dorsal coronal alargada, generalmente con sinus en la base; élitro generalmente con máculas moderadamente densas de pubescencia blanca en la base de las estrías 2 y 3, 4 y 5 así como en el ápice, entre las estrías 4-7; también máculas de pubescencia café entre las estrías 2 y 3 cercas de 0.3 de la base y 0.3 de ápice ................ Acanthoscelides flavescens (Fahraeus)

47 No exactamente como en la descripción anterior. . . . . . . . . . . . 48

48 (47) Parte mesal del primer esternito abdominal del macho con una pequeña concavidad cubierta con pubescencia blanca; estrías elitrales de la 3, 4, 5 y 6 abreviadas en la base por pequeñas espinas ................... Acanthoscelides taboga Johnson

48' Parte mesal del primer esternito abdominal del macho sin una pequeña concavidad; estrías elitrales de la 3 y 4 abreviadas en la base por pequeñas espinas .................Acanthoscelides hectori Kingsolver

49 (41) Primer esternito abdominal del macho ligeramente cóncavo mesalmente, con un surco con pelos largos en el ápice; antena extendiéndose de 0.25 a 0.3 de la longitud de los

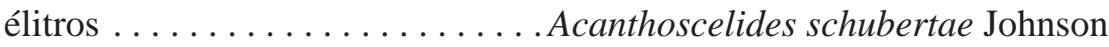

49' Primer esternito abdominal del macho no cóncavo mesalmente, sin un surco con pelos largos en el ápice; antenas extendiéndose hasta la base de los élitros o ligeramente más

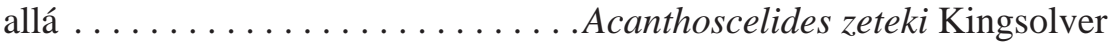




\section{Taxonomía de las especies de Bruchidae del estado de Tabasco}

\section{SUBFAMILIA AMBLYCERINAE}

Esta subfamilia está formada por los géneros Amblycerus, Zabrotes y Spermophagus. Las especies del género Amblycerus son plagas de árboles forestales, arbustos y plantas ornamentales, ninguna de estas especies afecta cultivos agrícolas. Amblycerus se reconoce porque el sinus es cuando más $1 / 3$ de la longitud del ojo y presentan un surco en el metepisterno. El género Zabrotes se caracteriza por presentar el sinus más conspicuo, por lo menos la mitad de la longitud del ojo, además no presentan surco metepisternal; con lo que respecta al género Spermophagus, éste es endémico del Viejo Mundo y no hay registros de su presencia en México (Romero et al. 1996).

\section{TRIBU AMBLYCERINI}

\section{Amblycerus cistelinus (Gyllenhal), 1833}

Diagnosis. Longitud (pronoto-élitros) 5.3-7.2 mm, ancho 3.2-4.1 mm; integumento rojo o rojo obscuro; élitros con pequeñas manchas negras; cuerpo cubierto con pubescencia blanca, amarilla y café arreglada en un patrón finamente moteado; pigidio con una mancha central grande de pubescencia café, rodeado de pubescencia blanca, sin pequeñas depresiones en el pigidio; frente con carina linear media; superficie dorsal del pronoto finamente puntuado con depresiones laterales en un tercio de cada lado; surco cervical fino, con tres setas cervicales; prosternon finamente puntuado, constreñido entre las coxas; armadura del saco interno de la genitalia del macho como en las Figs. 4-5.

Hospederos. Guazuma ulmifolia Lam. es la especie preferida; para Tabasco se registra un nuevo hospedero, Albizia lebbeck (L.) Benth., que resultó ser un hospedero marginal ya que se registró una emergencia muy reducida. La planta Apeiba tibourbou Aubl. (Tiliaceae) se registra en la literatura como hospedero (Zacher 1952), aunque se requiere su corroboración. En la colección TAMU se encuentra un especimen colectado en Venezuela (3 km S Machiques, Zulia, 27/I/1985, Johnson C.D. col.) que fue obtenido de la leguminosa Platypodium elegans Vogel (Ex: CDJ\#3811-85) y constituye también un nuevo registro de hospedero.

Distribución. Brasil, Costa Rica, Cuba, Guatemala, Honduras, México (Campeche, Chiapas, Jalisco, Morelos, Oaxaca, Quintana Roo, San Luis Potosí, Tabasco, Veracruz, Yucatán), Panamá, Venezuela. 

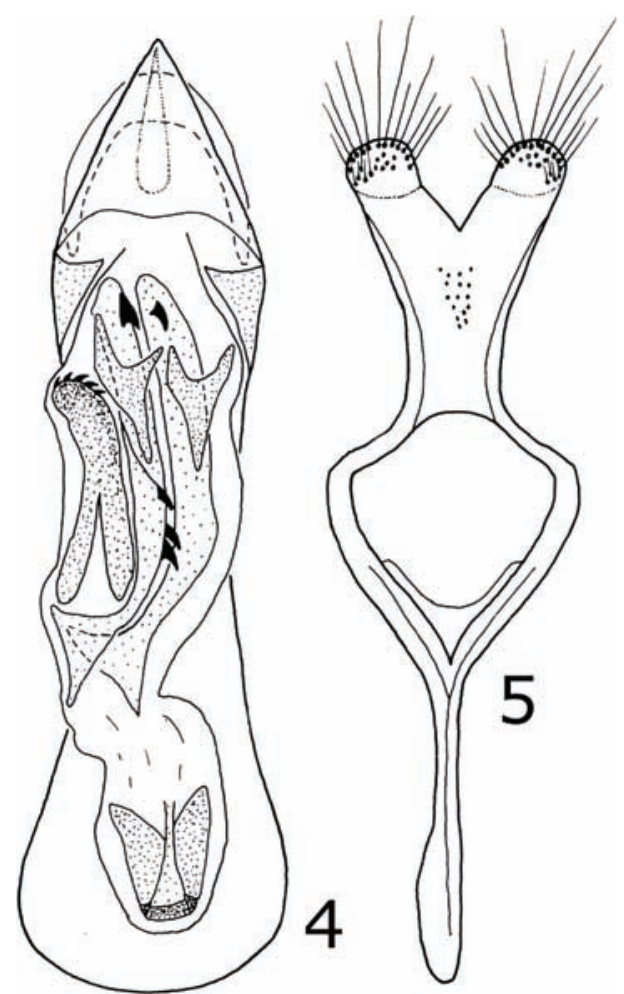

Figuras 4-5. Amblycerus cistelinus, vista ventral de la genitalia del macho: 4) lóbulo medio, 5) lóbulos laterales.

Material examinado. TABASCO. Campo Experimental COLPOS km 21 carr. fed. Cárdenas, Tabasco-Coatzacoalcos, Veracruz, 10 m, 17³7’19” N, 92²7’56” W, 29/ III/2007, Col. De La Cruz P. A., ex. Guazuma ulmifolia Lam. (Sterculiaceae) (16 ex); Ejido Río Seco, Cárdenas, 10 m, 1802’34” N, 93²2’44” W, 15/V/2007, col. Pérez De La Cruz M., capturado en trampa de alcohol en cacaotal, (1 ex); mismos datos excepto 29/VII/2007, (1 ex); El Bajío 2da sección, Cárdenas, 11 m, 1758’22” N, 93²0'53” W; 15/V/2007, col. De La Cruz P. A., capturados en trampas de alcohol en cacaotal (1 ex); Periférico Carlos A. Molina, Cárdenas, 10 m, 1758’43” N; 93²3’00” W, 2/III/2007, col. Pérez De La Cruz M. ex. Albizia lebbeck (L.) Benth. (1 ex).

Discusión. Nuevo registro para el estado de Tabasco. A. cistelinus, por lo general está asociada a las semillas de Guazuma tomentosa Kunth; aunque en la especie hermana de esta planta, Guazuma ulmifolia Lam., se registra otra especie de Amblycerus, A. 
guazumicola. Probablemente exista G. tomentosa en Tabasco; sin embargo, no se logró colectar material para su inspección.

\section{Amblycerus marmoratus (Sharp), 1885}

Diagnosis. Longitud (pronoto-élitros) 5.0-5.9 mm, ancho 3.2-3.7 mm; cuerpo con integumento amarillo excepto la cabeza, antenas, escutelo, prosterno, procoxa, mesosterno, región mesal del metasterno, parte anterior de metepisterno, metacoxa, parte basal del metafémur y los primeros tres esternitos abdominales negros o marrón oscuro; cabeza alargada y densamente punteada, frente sin una carina linear media o con una línea punteada; pronoto cubierto con pequeñas foveolas solamente en áreas laterales, surco cervical fino con tres setas cervicales; eje transversal del surco metepisternal curvado; eje transversal del sulcus metepisternal sin alcanzar los márgenes laterales; armadura del saco interno de la genitalia del macho como en las Figs. 6-7.

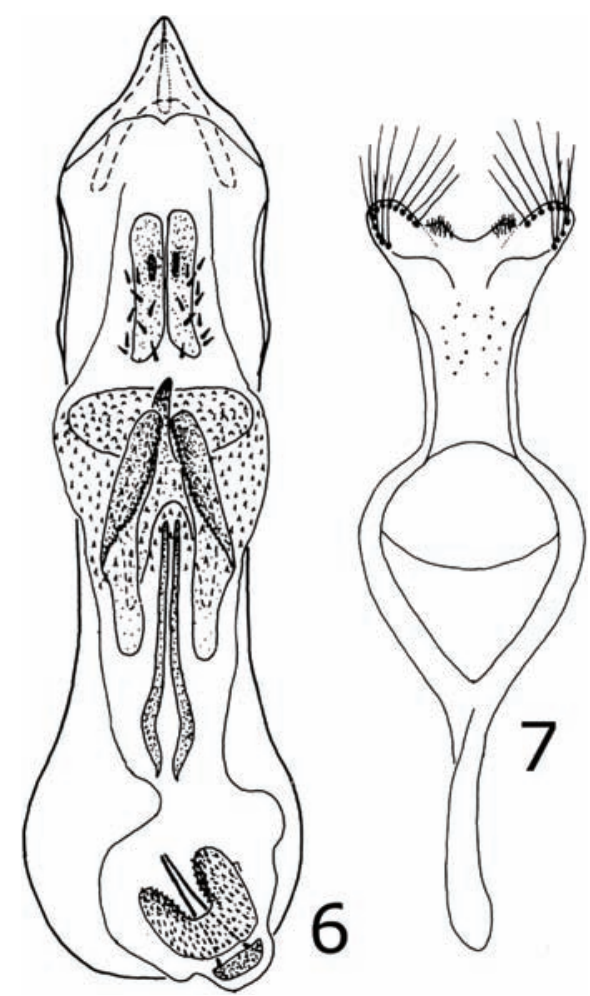

Figuras 6-7. Amblycerus marmoratus, vista ventral de la genitalia del macho: 6) lóbulo medio, 7) lóbulos laterales. 
Hospedero. No determinado.

Distribución. Costa Rica, Honduras, México (Tabasco y Veracruz) y Panamá.

Material examinado. TABASCO. 30 mi. W Cárdenas, 4/VII/1971, col. Clark, Rocan, Hart y Schaffner (1 ex).

Discusión. De esta especie nunca se ha colectado su planta hospedera; de acuerdo a Johnson \& Kingsolver (1981) su distribución es amplia, de México hasta Panamá; sin embargo no se le ha colectado en países intermedios y está pobremente representada en las colecciones.

\section{Amblycerus obscurus (Sharp), 1885}

Diagnosis. Longitud (pronoto-élitros) 4.0-5.6 mm, ancho 2.3-3.3 mm; integumento del cuerpo y apéndices rojo obscuro; ocasionalmente obscuros a casi negros; élitros con pequeñas manchas de pubescencia negra; cabeza subtriangular, cubierta con puntuaciones densas; frente sin una carina linear media o con una línea punteada; eje transversal del sulcus metepisternal formando un ángulo recto; superficie dorsal del pronoto con foveolas concentradas solamente en las áreas laterales, surco cervical fino con dos setas cervicales; armadura del saco interno de la genitalia del macho como en las Figs. 8-9.

Hospederos. Senna alata, Senna bicapsularis, Senna indecora, Senna leptocarpa, Senna obtusifolia, Senna occidentales, Senna uniflora, Senna pendula.

Distribución. Belice, Colombia, Costa Rica, Guatemala, México (Campeche, Chiapas, Guerrero, Michoacán, Morelos, Nayarit, Oaxaca, Sinaloa, Tabasco, Veracruz) y Panamá.

Material examinado. TABASCO. Laguna Colorada, Balancan, 1744’30” N, 9131'34”'W, 8/II/2007, col. De La Cruz P. A., ex. Senna occidentalis (L.) Link (Leguminoseae: Caesalpinioideae) (8 ex); Pozo Costero 24, Frontera, Centla, 1/IV/2009, UTM X-552474, Y-2059548, col. Pérez De La C. M., ex. Senna bicapsularis (L.) Roxb. (14 ex).

Discusión. Esta especie está relacionada con Amblycerus nigromarginatus, ambas forman el grupo obscurus. Presentan el mismo tipo y patrón de vestidura y la morfología externa es muy similar; sin embargo, $A$. obscurus presenta en el saco interno la espina basal más ancha y la cantidad de espínulas es mayor (Romero et al. 1996). 

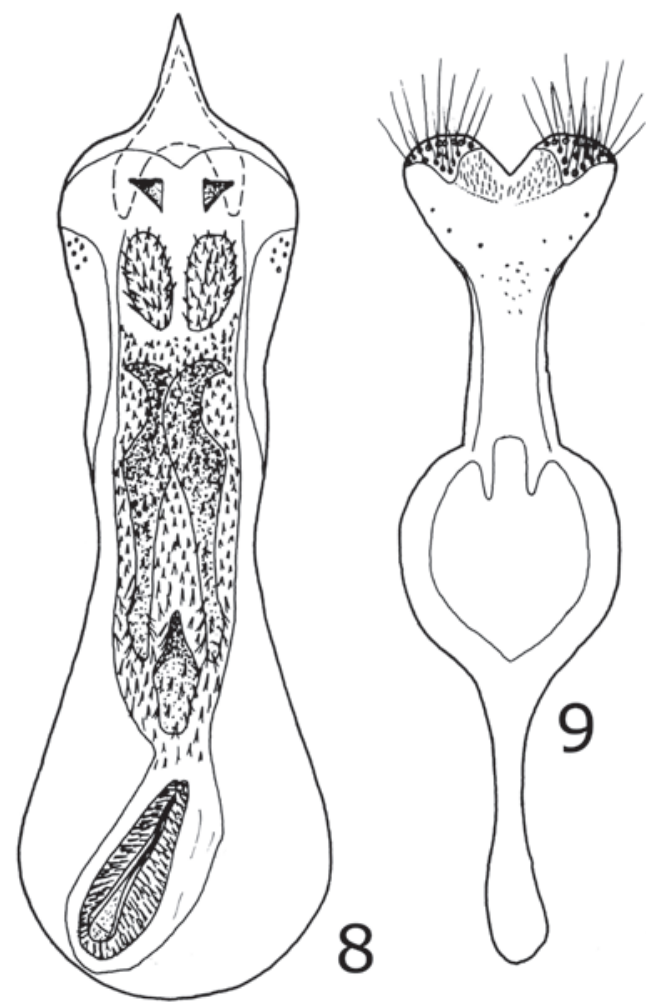

Figuras 8-9. Amblycerus obscurus, vista ventral de la genitalia del macho: 8) lóbulo medio, 9) lóbulos laterales.

\section{TRIBU SPERMOPHAGINI}

\section{Zabrotes subfasciatus (Boheman), 1833}

Diagnosis. Longitud (pronoto-élitros) 2.28-2.46 mm, ancho 1.74-1.86 mm; integumento del cuerpo y apéndices negros; cabeza cubierta con una pubescencia blanca, excepto por unos puntos marrón amarillentos sobre el vértex; élitros con una banda de pubescencia blanca mesal y otra transversal; metasterno con una fosa cubierta de pubescencia castaña; metacoxa cubierta con una pubescencia marrón; pigidio con pubescencia amarillenta con una línea media longitudinal de pubescencia blanca; ojos emarginados, cuando menos la mitad de su longitud; sin surco metepisternal; coxa lisa, sin un grupo de puntuaciones cerca de la articulación trocanteral; con un par de carinas sobre la parte externa de la metatibia; armadura del saco interno de la genitalia del macho como en las Figs. 10-11. 


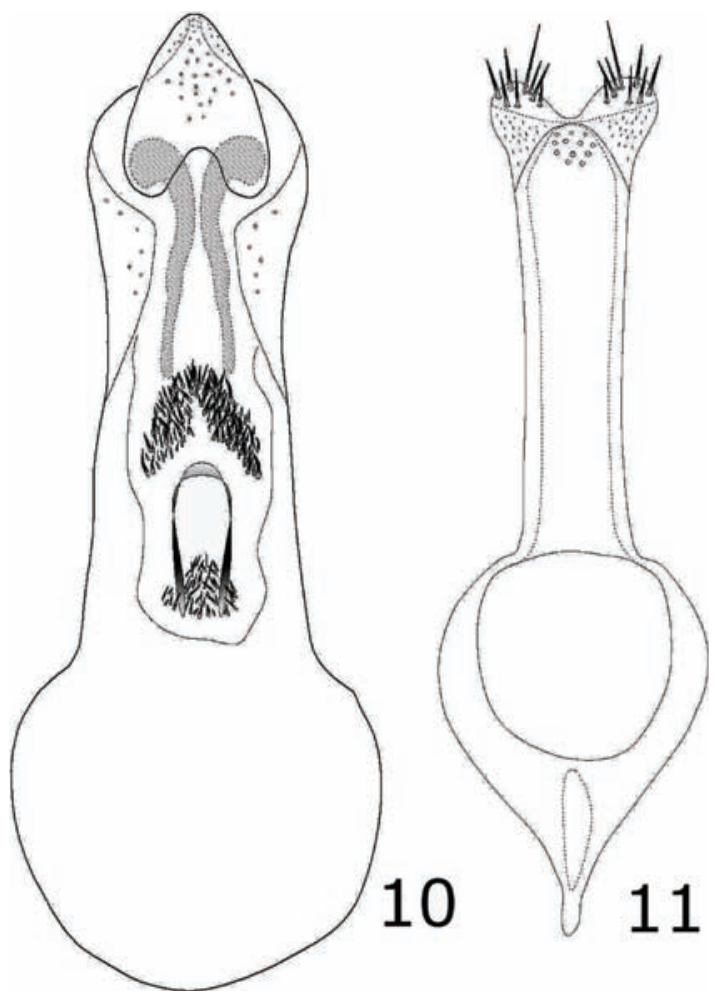

Figuras 10-11. Zabrotes subfasciatus, vista ventral de la genitalia del macho: 10) lóbulo medio, 11) lóbulos laterales.

Hospederos. Cajanus cajan, C. indicus, Cicer arietinum, Dipogon, Dolichos lablab, D. lignosus, D. sesquipedalis, Glycine hispida, G. max, Lablab níger, L. purpureus, Phaseolus acutifolius, $P$. angulares, $P$. articulatus, $P$. coccineus, $P$. lunatus, $P$. multiflorus, $P$. mungo, P. vulgaris, Pisum arvense, $P$. sativum, Vicia faba, V. sebastiana, Vigna mungo, $V$. sinensis, $V$. subterranea, $V$. unguiculata, Voandzeia subterranea.

Distribución. Originaria del Nuevo Mundo, pero ahora es una plaga cosmopolita.

Material examinado. TABASCO. Cárdenas, 17/IX/2007, col. De La Cruz P. A., ex. Phaseolus vulgaris L. (Leguminosae: Papilionoideae) (91 ex); Teapa, 29/VII/2007, col. De La Cruz P. A., ex. Phaseolus vulgaris (Leguminosae: Papilionoideae) (996 ex).

Discusión. Esta especie está relacionada con Z. silvestris, ambas son similares en la morfología externa y presentan dimorfismo sexual (Romero \& Johnson 1999), pero 
es fácil separarlas por las genitalias tanto de machos como de hembras; aunque es muy común encontrar $Z$. subfasciatus en frijol almacenado, a las dos especies se les puede encontrar en frijol silvestre.

\section{SUBFAMILIA BRUCHINAE}

Esta subfamilia es la más grande, está formada por 46 géneros, de los cuales Acanthoscelides es el más diverso en el nuevo mundo, contiene cerca de 250 especies. Este género ha sido usado para incluir a las especies que no entran en los límites de otros géneros de la subfamilia (Johnson 1983). El género Sennius se distingue porque presentar la carina lateral del pronoto incompleta ya que el lóbulo medio de la genitalia del macho presenta un par de escleritos lineales en la parte anterior (Johnson \& Kingsolver 1973). Stator se distingue por presentar la carina lateral del pronoto completa y a que el lóbulo medio de la genitalia del macho carece de un par de escleritos lineales en la parte anterior (Johnson \& Kingsolver 1976). En el género Mimosestes, la cabeza tiene un área glabra en la frente, que se extiende hacia el vértex; el fémur posterior está profundamente acanalado en el macho, la valva dorsal del lóbulo medio de la genitalia del macho no está articulada (Kingsolver \& Johnson 1978). Meibomeus se distingue porque el pronoto acampanado con lados cóncavos, fémur posterior grande con pecten de 4-8 espinas grandes y 1 a 3 más pequeñas anteriores al pecten y el lóbulo medio es muy largo y delgado (Kingsolver \& Whitehead 1976, Romero 2002a). Gibbobruchus se caracteriza porque presenta un pronoto campaniforme con gibas, tibia posterior muy arqueada y carinada, y áreas glabras en pigidio y esternitos abdominales (Whitehead \& Kingsolver 1975). Caryedes presenta un pronoto con gibas y con lados cóncavos, fémur posterior con pecten de 3-6 espinas grandes y 2 o más espinas pequeñas antes del pecten, tibia posterior muy arqueada, carinada y mucronada apicalmente (Kingsolver \& Whitehead 1974b). Se distingue de Ctenocolum porque éste tiene de 7-16 espinas grandes y 2 o más espinas pequeñas antes del pecten (Kingsolver \& Whitehead 1974a). El género Merobruchus presenta el pronoto campaniforme, con el disco sin gibas y carina lateral obsoleta; estría 3-4 o 3-6 con pequeñas gibas o dentículos; fémur posterior grande conuna espina grande seguida de 2-3 espinas más pequeñas; tibia posterior arqueada basalmente, carinada, mucro más largo que el dentículo coronal lateral (Kingsolver 1988).

\section{TRIBU ACANTHOSCELIDINI}

\section{Acanthoscelides clandestinus (Motschulsky), 1874}

Diagnosis. Longitud (pronoto-élitros) 2.2-2.9 mm, ancho 1.5-1.9 mm; cabeza usualmente con el integumento negro con máculas postoculares rojo-naranja, algunas 
veces rojo-naranja con una mácula negra alargada sobre el vertex; élitro con pubescencia densa blanca, interrumpida por máculas grandes de pubescencia café sobre el húmero cerca de la base, cerca de 0.5 de la base hasta el margen de la estría 4 y en el ápice; cabeza elongada, densamente punteada; frente con una carina fuerte media extendiéndose de la sutura frontoclipeal al vértex; ojos 2.5 a 3.5 veces la anchura de la frente; las antenas llegan ligeramente más de 0.5 la longitud de los élitros; genitalia del macho con la base de la valva ventral cerca de 0.7 veces más ancha que el ápice del lóbulo medio; armadura del saco interno de la genitalia del macho como en las Figs. 12-13.

Hospederos. Cajanus cajan, Mysanthus uleanus, Phaseolus vulgaris, Vigna adenantha.

Distribución. Brasil, Colombia, Guatemala, Hondura, México (Campeche, Michoacán, Morelos, Oaxaca, Tabasco) y Panamá, Surinam y Venezuela.

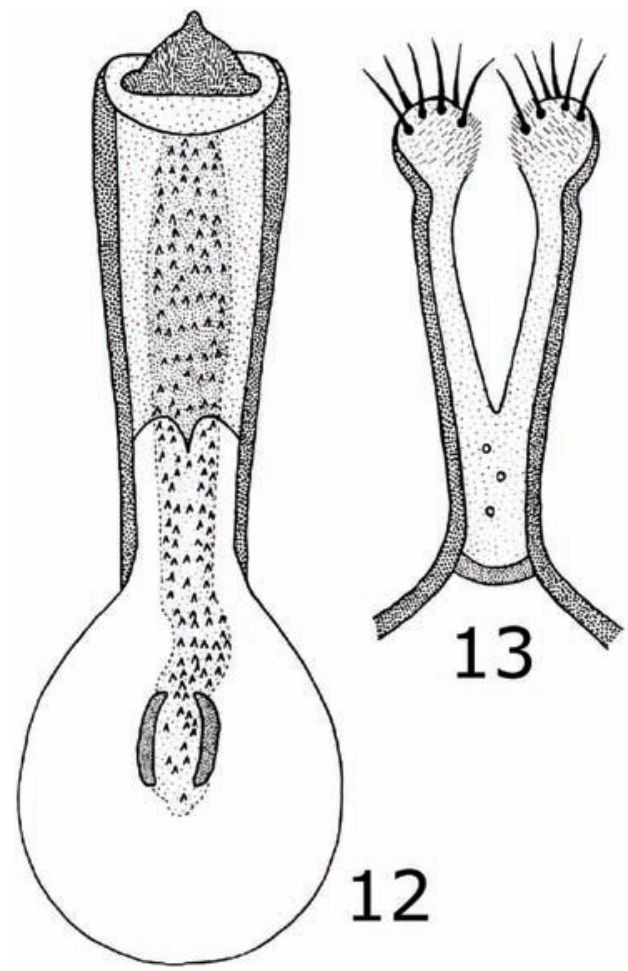

Figuras 12-13. Acanthoscelides clandestinus, vista ventral de la genitalia del macho: 12) lóbulo medio, 13) lóbulos laterales. 
Material examinado: TABASCO. 16 mi. N Cárdenas, 3/VIII/1974, col. O’Brien C.W., L.B. O’Brien, G.B. Marshall (1 ex, CEAM); Laguna Colorada, Balancan, 1802’34” N, 93²2’44” W, 8/II/2007, col. De La Cruz P. A., Vigna adenantha (G. Mey.) Marechal, Mascherpa y Stainier (Leguminosae: Papilionoideae) (10 ex).

Discusión. Esta especie se encuentra emparentada con A. amabilis, A. chiapas, A. clandestinus, A. jardin, A. palmasola, A. surrufus y A. rhynchosiestes; sin embargo, se distingue de éstas por el patrón de la vestidura en la superficie dorsal y que los ojos son al menos 2.5 veces tan amplios como la frente.

\section{Acanthoscelides cordifer (Sharp), 1885}

Diagnosis. Longitud (pronoto-élitros) 1.7-2.5 mm, ancho 1.0-1.6 mm; integumento de la cabeza marrón rojizo o marrón oscuro, sin mancha postocular obscura; cabeza corta y ancha, densamente punteado; frente con una carina media fuerte extendiéndose de la sutura frontoclipeal al vertex, terminando en un área glabra formando una "V"; la antena se extiende de 0.3 a 0.5 la longitud de los élitros; frecuentemente una mácula de pubescencia negra semicircular entre la estría 1-4, ocupando 0.3 la parte apical de los élitro; armadura del saco interno de la genitalia del macho como en las Figs. 14-15.

Hospederos. Mimosa albida Humb. \& Bonpl. ex Willd., M. guanacastensis Standl., M. albida var. strigosa (Willd.) B.L. Rob., M. xanti A. Gray, M. velloziana Mart. En la colección CEAM se encuentra un especimen colectado en Veracruz (10 mi. E Acayucan, 15/VI/1968, Johnson C.D. col.) que fue obtenido de la leguminoas Leucaena esculenta (Moc. \& Sesse ex DC.) Benth. (Ex: CDJ\#115-68) y constituye un nuevo registro de hospedero, aunque éste se puede considerar como un hospedero marginal.

Distribución. Costa Rica, Guatemala, Honduras, México (Chiapas, Guerrero, Jalisco, Michoacán, Morelos, Oaxaca, Tabasco Tlaxcala y Veracruz).

Material examinado. TABASCO. La Candelaria, Huimanguillo, 17²19'39” N, 93³6’08” W, 13/III/2007, col. De La Cruz P. A., ex. Mimosa albida var. Strigosa (Willd.) B.L. Rob. (Leguminosae: Mimosoideae), (18 ex); Poblado Zúnu y Patasta, Tacotalpa, 17²7’57” N, 9248’57’ W, 3/IV/2007, col De La Cruz P. A., Mimosa albida var. strigosa, (5 ex).

Discusión. Esta especie está integrada en el grupo Mexicanus, con las especies $A$. mexicanus, A. speciosus, A. lapsanae, A. piceoapicalis, A. leucaenicola, A. clitella- 


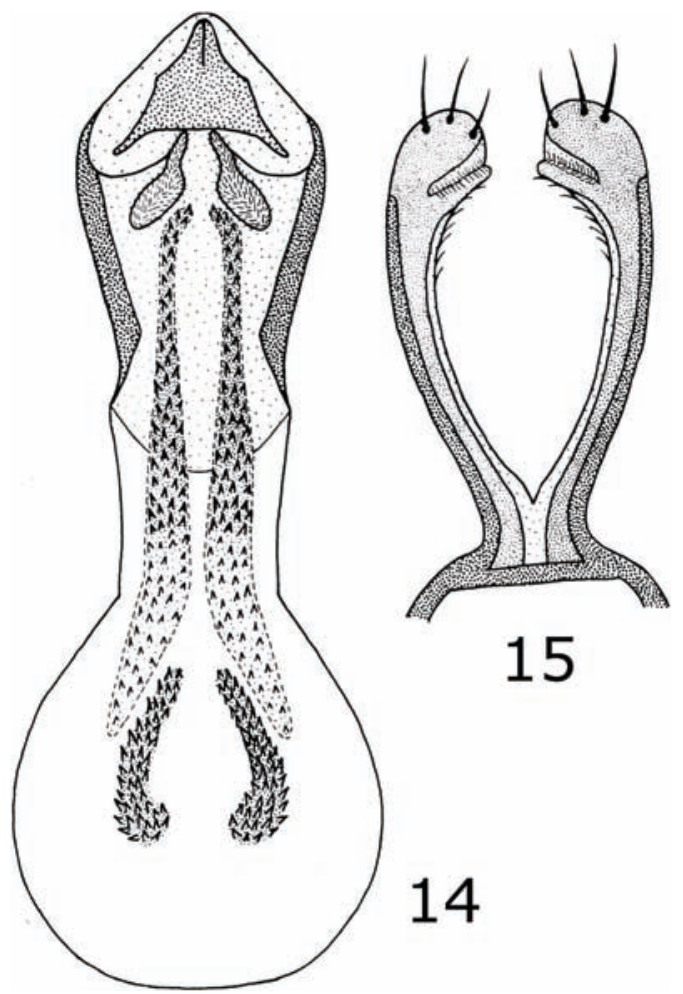

Figuras 14-15. Acanthoscelides cordifer, vista ventral de la genitalia del macho: 14) lóbulo medio, 15) lóbulos laterales.

rius, A. mankinsi y A. cordifer. Se distingue de estás especies por la genitalia del macho que tiene la valva ventral acuminada en el ápice y la armadura del saco interno de la genitalia del macho.

\section{Acanthoscelides difficilis (Sharp), 1885}

Diagnosis. Longitud (pronoto-élitros) 1.5-2.4 mm, ancho 1.1-1.7 mm; cabeza con integumento negro con manchas postoculares rojo-naranja; frente con una línea glabra media o carina extendiéndose de la sutura frontoclipeal al vertex; ojos 1.4 veces el ancho de la frente; sinus ocular 0.7 el ancho del ojo; fémur posterior constreñido basal y apicalmente, armado sobre el borde interno con espinas subapical acuminada cerca de 1.3 veces tan larga como el ancho de la base tibial seguido por 3 a 4 espinas cerca de 0.5 tan larga como la primera espina; armadura del saco interno de la genitalia del macho como en las Figs. 16-17. 


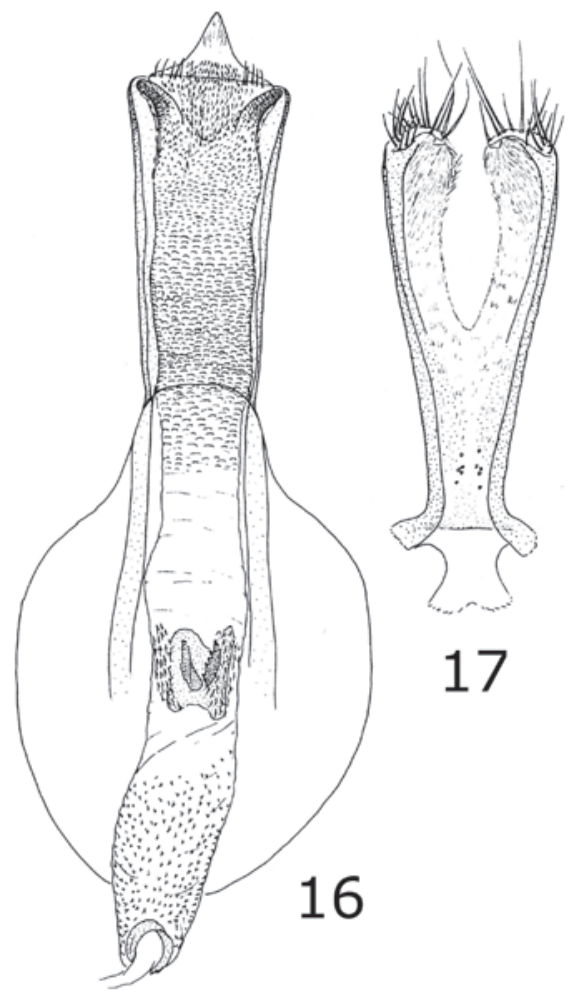

Figuras 16-17. Acanthoscelides difficilis, vista ventral de la genitalia del macho: 16) lóbulo medio, 17) lóbulos laterales.

Hospedero. Mimosa albida, M. albida var. strigosa, M. arenosa, M. arenosa var. arenosa, M.camporum, M. casta, M. guanacastensis, M. pigra, M. polycarpa, $M$. pudica, $M$. quadrivalvis, $M$. quadrivalvis var. leptocarpa, $M$. sensitiva, $M$. velloziana, M. xanti. En la colección TAMU se encuentra varios especímenes colectados en Venezuela (Estación Biológica de los Llanos, Calabozo, 15/IX/1979, Ramirez N. col.) que fue obtenido de la malvácea Sida sp., ésta constituye un nuevo registro de hospedero, aunque se puede considerar como un hospedero marginal.

Distribución. Belice, Colombia, Costa Rica, El Salvador, Guatemala, Honduras, México (Baja California Sur, Chiapas, Guerrero, Jalisco, Morelos, Nayarit, Oaxaca, Puebla, Tabasco y Veracruz), Montserrat, Nicaragua, Panamá y Venezuela.

Material examinado. TABASCO. La Candelaria, Huimanguillo, 17²19’39” N, 93³6’08” W, 13/III/2007, col. De La Cruz P. A., ex. Mimosa pudica L. (Legumino- 
sae: Mimosoideae) (44 ex); La Candelaria, Huimanguillo, 17 19’ 39” N, 93 36’ 08” W, 3/III/2007, col. De La Cruz P. A., ex. Mimosa pudica L. (Leguminosae: Mimosoideae) (1 ex); Poblado Zúnu y Patasta, Tacotalpa, $17^{\circ} 27^{\prime} 57^{\prime}$ N, 92 ${ }^{\circ} 48^{\prime} 57$ ” W, 3/IV/2007, col. De La Cruz P. A., ex. Mimosa albida var. strigosa (Willd.) B.L. Rob. (Leguminosae: Mimosoideae) (10 ex).

Discusión. A. difficilis y A. mimosicola son especies similares; sin embargo, a A. difficilis se puede separar fácilmente debido a que los ojos son 1.4 veces el ancho de la frente, el escutelo es cuadrado y las antenas alcanzan 0.25 la longitud de los élitros, también los escleritos del saco interno de la genitalia del macho son muy característicos.

\section{Acanthoscelides elevatus (Sharp), 1885}

Diagnosis. Longitud (pronoto-élitros) 2.2-2.6 mm, ancho 1.5-1.8 mm; pronoto usualmente con el integumento café rojizo contrastando con élitros café obscuro; pigidio con pubescencia densa y uniforme de color blanco amarillento, interrumpida por pequeñas máculas de color marrón a los lados de la línea media cerca de 0.4 de la base; espina subapical del fémur posterior cerca de 1.6 veces más larga que el ancho de la base de la tibia; genitalia del macho con la base de la valva ventral cerca de 0.9 tan ancha como el ápice del lóbulo medio; armadura del saco interno de la genitalia del macho como en las Figs. 18-19.

Hospedero. Pavonia schiedeana.

Distribución. Belice, Costa Rica, Guatemala, Honduras, México (Chiapas, Oaxaca, Puebla, San Luis Potosí, Tabasco y Veracruz), Nicaragua y Panamá.

Material examinado. TABASCO. Teapa, 23/VI/1963, col. Doyen J., (1 ex, CEAM); Ejido Villa de Guadalupe, Huimanguillo, 17²1’38” N, 93³5’59” W, 19/X/2007, col. De La Cruz P. A., ex. Pavonia sp. (Malvaceae) (9 ex).

Discusión: Johnson (1983) colocó tentativamente a A. elevatus en el grupo Albopygus dentro del género Acanthoscelides, debido a que su morfología es más afin con las otras especies del grupo, aunque este grupo se distingue entre el género debido a que todos los integrantes tienen genitalias muy particulares.

\section{Acanthoscelides flavescens (Fähraeus), 1839}

Diagnosis. Longitud (pronoto-élitros) 1.7-2.7 mm, ancho 1.1-1.8 mm; cabeza, cuerpo y apéndices con integumento generalmente rojo-naranja; anchura entre los ojos igual 


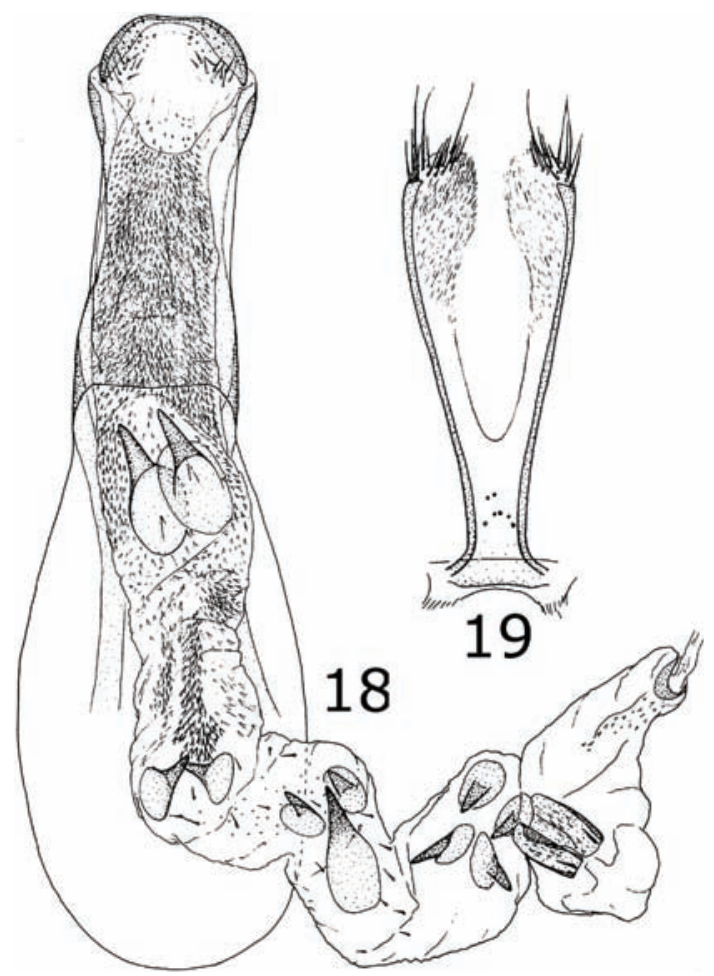

Figuras 18-19. Acanthoscelides elevatus, vista ventral de la genitalia del macho: 18) lóbulo medio, 19) lóbulos laterales.

a la anchura de la frente; antenas extendiéndose a la base de los élitros; metafémur con una espina grande cerca de 2 veces el ancho de la base de la metatibia, seguida por 2 espinas más pequeñas 0.3 de la longitud de la espina grande; con 3 espinulas coronales, la dorsal más larga y con pequeño sinus; mucro 0.3 de la longitud del primer tarsómero; genitalia con la base de la valva ventral del lóbulo medio cerca de 0.9 tan ancho como el ápice de esta estructura; armadura del saco interno de la genitalia del macho como en las Figs. 20-21.

Hospedero. Crotalaria mollicula, Eriosema violaceum, Galactia striata, Rhynchosia longeracemosa, $R$. minima, $R$. phaseoloides, $R$. precatória, $R$. pyramidalis, Tephrosia cinerea. En la coleccion TAMU se encuentra un especimen colectado en Ecuador (1 km S Babahoyo, Guayas, 8/IX/1983, Johnson C.D. col.) que fue obtenido de la leguminosa Aeschynomene americana L. (EX: CDJ\#2796-83) y constituye también un nuevo registro de hospedero, aunque por el número de especímes emergidos se puede considerar como un hospedero marginal. 


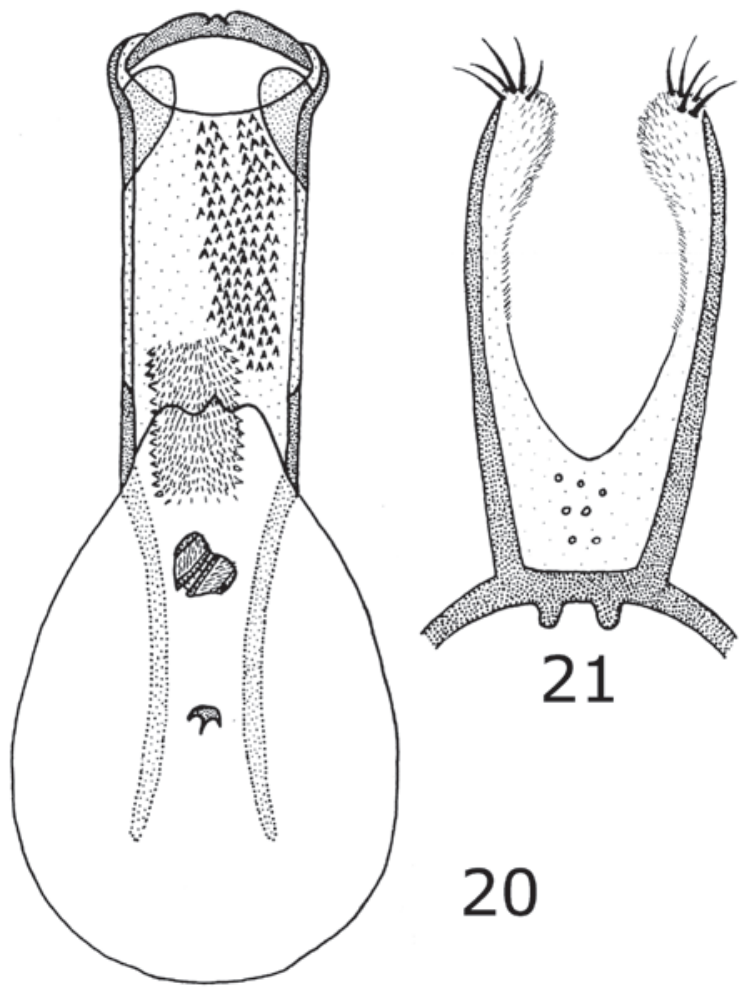

Figuras 20-21. Acanthoscelides flavescens, vista ventral de la genitalia del macho: 20) lóbulo medio, 21) lóbulos laterales.

Distribución. Antigua, Bahamas, Bonaire, Brasil, Colombia, Costa Rica, Ecuador, Estados Unidos, Guatemala, Guayana Francesa, Granada, Granadinas, Guadalupe, Guatemala, Guyana, Honduras, Islas Cayman, Islas Vírgenes, Jamaica, México (Campeche, Chiapas, Colima, Guerrero, Jalisco, Michoacán, Morelos, Nayarit, Nuevo León, Oaxaca, Quintana Roo, San Luis Potosí, Sinaloa, Tabasco, Veracruz y Yucatán), Montserrat, Nicaragua, Panamá, Perú, Puerto Rico y República Dominicana, San Vicente y Las Granadinas, Trinidad \& Tobago y Venezuela.

Material examinado: TABASCO. $500 \mathrm{~m}$ hacia el centro de Balancan, $17^{\circ} 46^{\prime} 37^{\prime \prime}$ N, 91³1’49” W, 8/II/2007, col. De La Cruz P. A., ex. Crotalaria mollicula Kunth (Leguminosae: Papilionoideae) (9 ex); El Bajío 2da sección, Cárdenas, 1758’22” N, 93²0’53” W, 28/III/2007, col. De La Cruz P. A., ex. Rhynchosia minima L. (D.C) (Leguminosae: Papilionoideae) (72 ex). 
Discusión. Este brúquido es muy similar A. campeche, A. distinguendus, A. burkei y A. zeteki; sin embargo, por la estructura de la genitalia se puede separar fácilmente de las otras especies. A. flavescens se alimenta principalmente de especies del género Rhynchosia; aunque, en este estudio se registra a Crotalaria mollicula como un nuevo hospedero. Kingsolver (1969), registró a la malvácea Abutilon hypoleucum como hospedero; sin embargo, esta información es ambigua ya que se indica como "in Abutilon hypoleucum" sin especificar claramente si se encontró entre el follaje de la planta o se obtuvieron a partir de las semillas, por lo que esta información deberá corroborarse en el futuro.

\section{Acanthoscelides guazumae Johnson \& Kingsolver, 1971}

Diagnosis. Longitud (pronoto-élitros) 1.3-2.2 mm, ancho 0.8-1.4 mm; integumento de la cabeza, pronoto y escutelo usualmente negra, algunas veces labro y vértex rojo naranja; los segmentos de las antenas pueden ser todos rojo-naranja o con los cinco o seis segmentos basales rojo-naranja y el resto cafés; pronoto y élitros con pubescencia moderadamente densa a densa de color blanca o dorada; las antenas alcanzan el húmero; élitro casi dos veces el ancho de éste; estrías profundas, puntedas, intervalos estriales punteados; metafémur armado con una espina grande de la longitud de la base de la tibia, seguida de dos espinas más pequeñas de 0.25 a 0.3 la longitud de la base de la tibia; corona tibial con 3 o 4 espínulas, mucro casi 1/6 o menos la longitud del primer tarsómero sin sinus en la base de la espina; genitalia con lóbulo medio corto, armadura del saco interno de la genitalia del macho como en las Figs. 22-23.

Hospedero. Guazuma tomentosa, Guazuma ulmifolia, Leucaena leucocephala. Se registra como nuevo hospedero a L. leucocephala y también su rango de alimentación se amplía para este insecto, ya que para éste sólo se habían registrado plantas de la familia Sterculiaceae como hospederos y ahora incursiona en leguminosas; aunque por la baja densidad de organismos emergidos de las semillas de esta planta se puede inferir que se trata de un hospedro marginal para este brúquido.

Distribución. Colombia, Costa Rica, El Salvador, Guatemala, Honduras, México (Campeche, Chiapas, Jalisco, Morelos, Nayarit, Oaxaca, Sonora, Tabasco, Tamaulipas y Veracruz), Nicaragua y Panamá.

Material examinado. TABASCO. $500 \mathrm{~m}$ hacia el centro de Balancan, $12 \mathrm{~m}$, 1746’37’ N, 91³1’49” W, 8/II/2007, col. De La Cruz P. A., ex. Leucaena leucocephala (Lam.) De Wit (Leguminosae: Mimosoideae) (1 ex); Campo Experimental COLPOS, km 21 carr. federal Cárdenas, Tabasco-Coatzacoalcos, 10 m, 17³7’19” N, 92²7’56” W, 29/III/2007, col. De La Cruz P. A., ex. Guazuma ulmifolia Lam. 


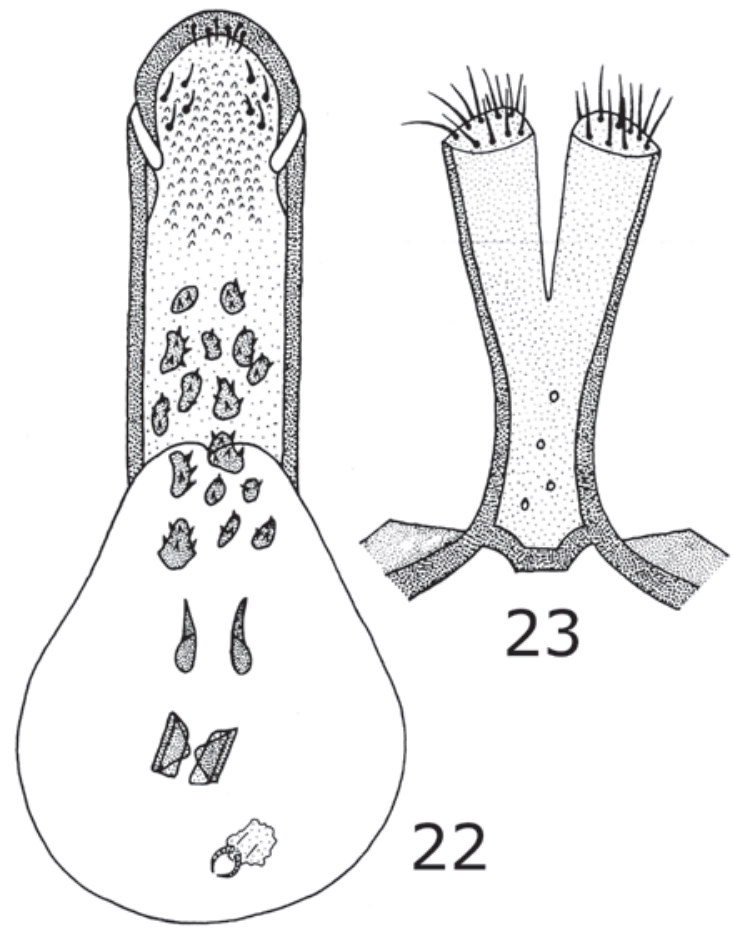

Figuras 22-23. Acanthoscelides guazumae, vista ventral de la genitalia del macho: 22) lóbulo medio, 23) lóbulos laterales.

(Sterculiaceae) (12 ex); Ejido Río Seco, Cárdenas, 10 m; 1802’34” N, 93²2’44” W, 16/V/2007, col. De La Cruz P. A., atraído en trampa de alcohol en cacaotal (1 ex); Km 30 carr. El Ceibo, Ej. Benito Juárez, Emiliano Zapata, 17²1’00” N, 91¹1’23” W, 17/VII/2007, col. De La Cruz P. A., ex. Leucaena leucocephala (Lam.) De Wit (Leguminosae: Mimosoideae) (1 ex).

Discusión. Johnson (1983) considera que A. aequalis, A. anoditus, A. elkinsae, A. guazumae, A. guerrero, A. merida y A. tepic forman un subgrupo debido a que la genitalia del macho presenta la valva ventral redondeada con un lóbulo ventral medio o quilla ya que la armadura del saco interno tiene muchas espinas, aunque éstas son distintas para cada especie.

\section{Acanthoscelides hectori Kingsolver, 1980}

Diagnosis. Longitud (pronoto-élitros) 2.3-2.75 mm, ancho 1.6-1.9 mm; integumento de la cabeza rojo-naranja en la base y café-rojiza de la frente hacia el ápice, antena 
de anaranjado a café, pronoto y élitros café rojizo, aunque pueden variar de negro a rojo-naranja; élitros con pubescencia en los intervalos entre las estrías 1- 2 marrón, manchas marrón aproximadamente 0.2 de la base entre la estría 1- 4 y 6- 8, cerca de 0.5 de la base entre la estría 1- 4 y 4- 9; ápice completamente cubierto por pubescencia marrón; estría 3 y 4 con pequeñas espinas en la base; armadura del saco interno de la genitalia del macho como en las Figs. 24-25.

Hospederos. Calopogonium caeruleum, Macroptilium atropurpureum, Rhynchosia minima.

Distribución. Colombia, Costa Rica, El Salvador, México (Tabasco, Veracruz) y Panamá.

Material examinado. TABASCO. El Bajío 2da sección, Cárdenas, 1758’22” N, 93²0’53” W, 28/III/2009, col. De La Cruz P. A., ex. Calopogonium caeruleum (Leguminosae: Papilionoideae) (37 ex); Teapa, 1/III/1908, col. Salvin (3 ex, USNM).

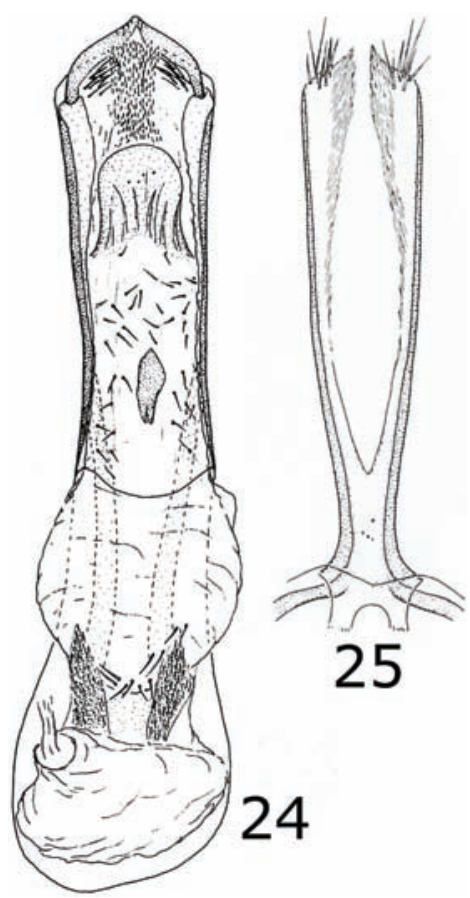

Figuras 24-25. Acanthoscelides hectori, vista ventral de la genitalia del macho: 24) lóbulo medio, 25) lóbulos laterales. 
Discusión. Es una especie similar a A. flavescens pero se puede separar por las características en la clave y por la armadura de la genitalia.

\section{Acanthoscelides macrophthalmus (Schaeffer), 1907}

Diagnosis. Longitud (pronoto-élitros) 2.3-3.6 mm, ancho 1.6-2.2 mm; integumento de la cabeza, cuerpo y apéndices rojo-naranja o marrón rojizo; antena con los segmentos expandidos lateralmente o flabelada, alcanzando de 0.5 a 0.8 la longitud de los élitros; con una carina media fuerte sobre la frente; ojos cerca de 12 veces la anchura de la frente; vestidura de la superficie dorsal variegada; genitalia del macho con lóbulos medios alargados; armadura del saco interno de la genitalia del macho como en las Figs. 26-27.

Hospederos. Falcataria moluccana, Leucaena collinsii, L. glauca, L. guatemalensis, L. leucocephala, L. pulverulenta, L. retusa, L. shannoni.

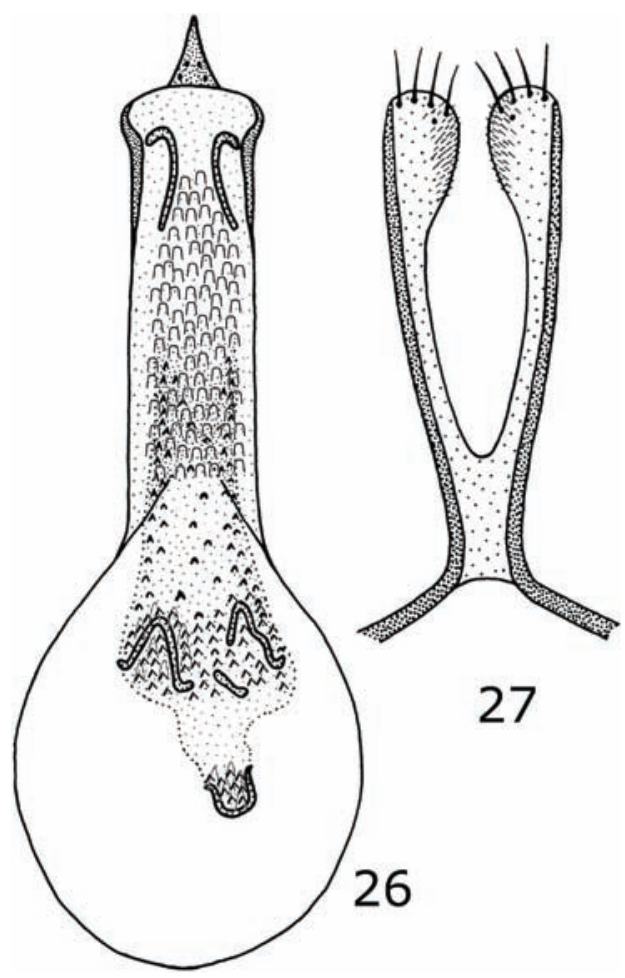

Figuras 26-27. Acanthoscelides macrophthalmus, vista ventral de la genitalia del macho: 26) lóbulo medio, 27) lóbulos laterales. 
Distribución. Bahamas, Islas Cayman, Costa Rica, El Salvador, Estados Unidos, Guatemala, Honduras, México (Baja California Sur, Campeche, Chiapas, Guerrero, Guanajuato, Hidalgo, Jalisco, Morelos, Nuevo León, Oaxaca, Puebla, Quintana Roo, San Luis Potosí, Sinaloa, Sonora, Tabasco, Tamaulipas, Veracruz y Yucatán), Nicaragua, Trinidad y Tobago. Esta especie ahora se encuentra en Asia, Africa y Europa, en algunos casos se debe a que se ha introducido accidentalmente y en otros a que se ha considerado como un agente de control biológico para combatir especies de Leucaena, a las cuales se les considera como plantas invasivas. Tuda et al. (2009) indican que al ser introducio A. macrophthalmus a Taiwan para control biológico de L. leucocephala, también se empezó a alimentar de las semillas de otra leguminosa introducida, Falcataria moluccana.

Material examinado. TABASCO. Carr. fed. El Ceibo, Tenosique, 12 m, 17¹6' '34'” N, 9103' '53', W, 17/VII/2007, col. De la Cruz P. A. (2 ex); Champechito, Huimanguillo, 13 m, 1755’11” N, 93²2’13” W, 22/VII/2007, col. De La Cruz P. A., ex. Leucaena leucocephala (Lam.) De Wit (Leguminosae: Mimosoideae) (2 ex); El Bajío 2da sección, Cárdenas, 11 m, 1758’22” N, 93²0’53” W, 29/I/2007, col. De La Cruz P. A., ex. Leucaena leucocephala (Lam.) De Wit; (Leguminosae: Mimosoideae) (3 ex); Hacia el centro de Balancan, orilla del Río Usumacinta, 1746’37” N, 91³1'49” W, 8/II/2007, col. De La Cruz P. A., ex. Leucaena leucocephala (Lam.) De Wit (Leguminosae: Mimosoideae) (19 ex); Km 30 carr. El Ceibo, Ej. Benito Juárez Emiliano Zapata, 17²1'00” N, 91¹1’23” W, 17/VII/2007, col. De La Cruz P. A., ex. Leucaena leucocephala (Lam.) De Wit (Leguminosae: Mimosoideae) (6 ex); Km 30 carr. El Ceibo, Ej. Benito Juárez Emiliano Zapata, 17²1’00” N, 91¹1’23” W, 17/VII/2007, col. De La Cruz P. A., ex. Leucaena leucocephala (Lam.) De Wit (Leguminosae: Mimosoideae) (2 ex).

Discusión. Esta especie es similar a A. boneti, pero se caracteriza porque tiene ojos muy grandes, 12 veces tan anchos como la frente y las antenas se extienden 0.4 a 0.5 la longitud de los élitros, a diferencia de $A$. boneti que tiene los élitros rojo naranja con estrías negras en los márgenes laterales entre las estrías 6 y 10.

\section{Acanthoscelides mundulus (Sharp), 1885}

Diagnosis. Longitud (pronoto-élitros) 1.7-3.0 mm, ancho 1.1-2.0 mm; integumento con la cabeza, protórax, élitros y cuerpo de café obscuro a negro, patas rojo-naranja; pronoto con una mancha triangular media de pubescencia densa blanca en la base; pigidio con un mancha moderadamente ancha de pubescencia densa blanca sobre la línea media, extendiéndose de la base aproximadamente 0.5 la longitud del pigidio; estrías elitrales 3, 4 y 5 abreviadas en la base; estría 4 y 5 más cercanas una a la otra 
que la estría adyacente; armadura del saco interno de la genitalia del macho como en las Figs. 28-29.

Hospedero. Chaetocalux latisiliqua, Nissolia fruticosa, N. schottii, N. wislizeni.

Distribución. El Salvador, Estados Unidos, México (Chiapas, Guanajuato, Guerrero, Jalisco, Michoacán, Morelos, Oaxaca, Puebla, San Luis Potosí, Sonora, Tabasco, Veracruz y Yucatán) y Panamá.

Material examinado. TABASCO. $1 \mathrm{~km}$ de Zúnu y Patasta, Tacotalpa, $560 \mathrm{~m}$, 17²8’11” N, 9249’16” W, 3/IV/2007, col. De La Cruz P. A., ex. Nissolia fruticosa Jacq. (Leguminosae: Papilionoideae) (1 ex).

Discusión. De acuerdo con Johnson (1990) A. mundulus y A. pygidiolineatus integran el grupo Mundulus, ambas especies muy parecidas; sin embargo no comparten

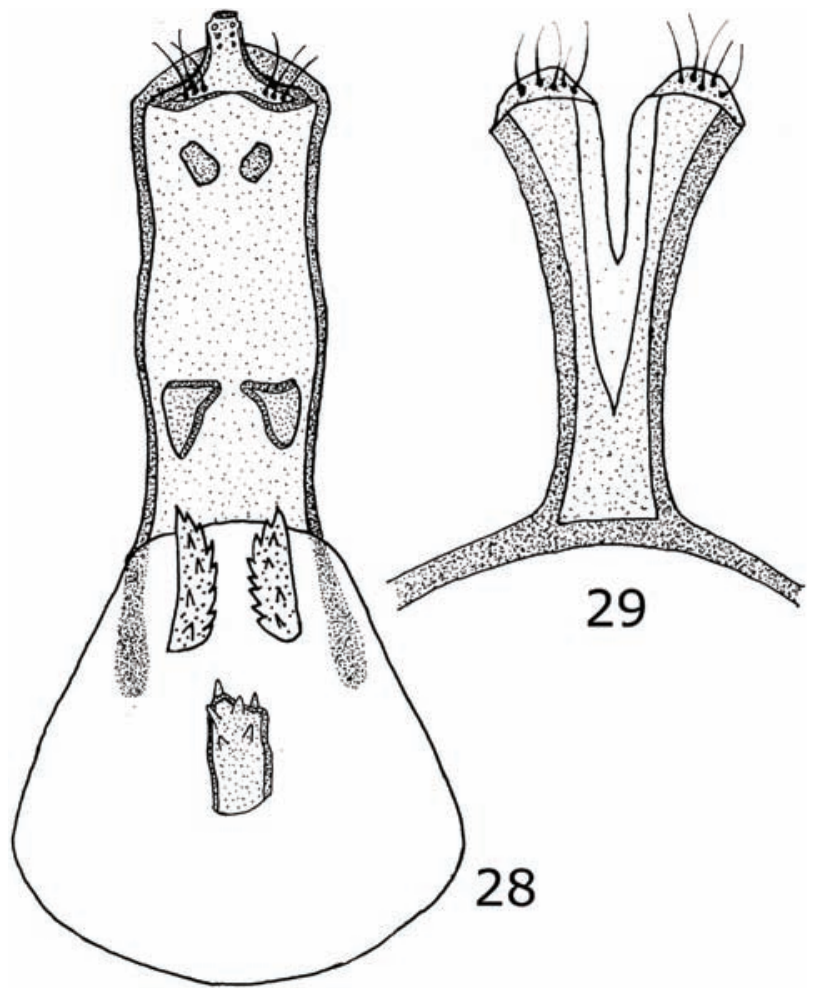

Figuras 28-29. Acanthoscelides mundulus, vista ventral de la genitalia del macho: 28) lóbulo medio, 29) lóbulos laterales. 
muchas características del género Acanthoscelides, por lo que pueden ser fácilmente confundidas con otros géneros. Ambas especies son especialistas en plantas del género Nissolia y entre ellas se pueden separar sólo con las estructuras de la genitalia.

\section{Acanthoscelides oblongoguttatus (Fähraeus). 1839}

Diagnosis. Longitud (pronoto-élitros) 1.7-2.5 mm, ancho 1.0-1.6 mm; mandíbulas largas y rectas cruzándose en el ápice, en las hembras son más grandes que en los machos; mucro de 1-6 veces más largo que el primer tarsomero; pigidio sin una mancha de pubescencia obscura en forma de "V"; insecto grande de más de $5.2 \mathrm{~mm}$ de largo; armadura del saco interno de la genitalia del macho como en las Figs. 30-31.

Hospedero. Acacia collinsii, A. cornigera, A. sphaerocephala. A. collinsii constituye un nuevo registro de hospederos para esta especie de brúquido.

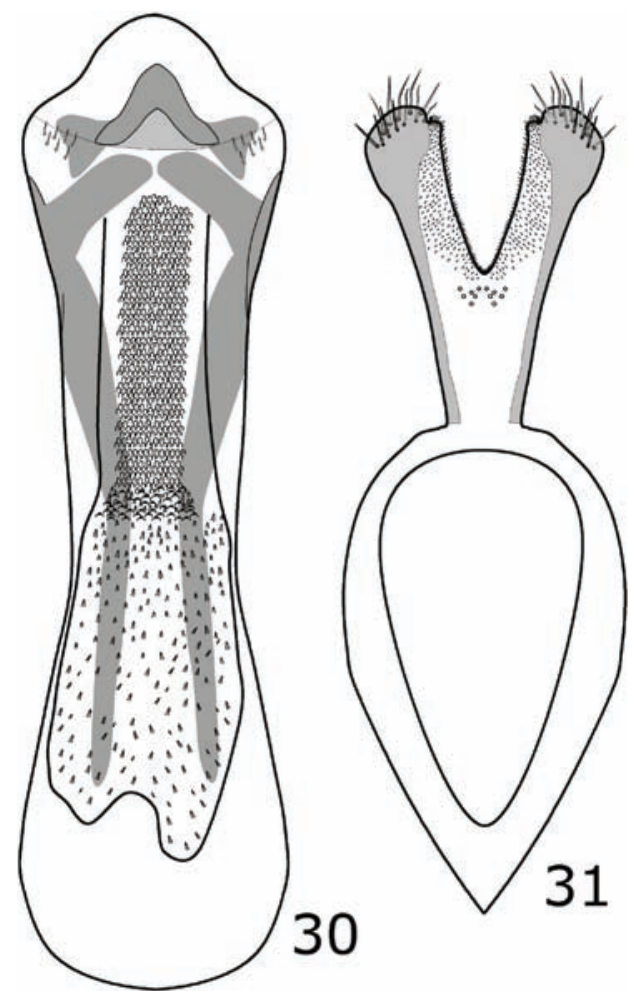

Figuras 30-31. Acanthoscelides oblongoguttatus, vista ventral de la genitalia del macho: 30) lóbulo medio, 31) lóbulos laterales. 
Distribución. Belice, El Salvador, Guatemala, Honduras, México (Campeche, Guerrero, Hidalgo, Oaxaca, San Luis Potosí, Tabasco, Tamaulipas y Veracruz).

Material examinado. TABASCO. Arroyo El Triunfo, 2da Sec. Balancan, 1743'29', N, 91 ${ }^{\circ} 02^{\prime} 46^{\prime}$ ' W, 17/VII/2007, col. De la Cruz P. A., ex. Acacia cornigera (L.) Willd. (Leguminosae: Mimosoideae) (50 ex); Campo Experimental COLPOS, km 21 carr. Federal Cárdenas, Tabasco-Coatzacoalcos, 12 m, 17 59’ 10” N, 93 35’ 11” W, 23/ IX/2007, col. De La Cruz P. A., ex. Acacia cornigera (L.) Willd (Leguminosae: Mimosoideae) (27 ex.); Carr. fed. El Ceibo, Tenosique, 12 m, 17²16’34’' N, 9103'53', W, 17/VII/2007, col. De la Cruz P. A., ex. Acacia collinsii Saff. (Leguminosae: Mimosoideae) (100 ex); Carr. fed. El Ceibo Tenosique, 12 m, 17¹6’34” N, 9103’53” W, 17/VII/2007, col. De La Cruz P. A., ex. Acacia collinsii Saff. (Leguminosae: Mimosoideae) (11 ex); Km 21 carr. Fed. Cárdenas-Coatzacoalcos, Campo Exp. COLPOS, 10 m, 1759'10'’ N, 93³5’11’' W, 23/IX/2007, col. De La Cruz P. A., ex. Acacia cornigera (L.) Willd. (Leguminosae: Mimosoideae) (6 ex); Laguna Colorada, Balancan, 1744'30'’ N, 91³1'34'’ W, 8/II/2007, col. De la Cruz P. A., ex. Acacia cornigera (L.) Willd. (Leguminosae: Mimosoideae) (75 ex).

Discusión. Esta especie fácilmente se puede confuindir con $A$. sauli, debido a que en ocasiones se les puede observar emerger de la misma planta; sin embargo, las mandíbulas grandes de las hembras de $A$. oblongoguttatus contrastan notablemente con las mandíbulas pequeñas de las hembras de $A$. sauli.

\section{Acanthoscelides obtectus (Say), 1831}

Diagnosis. Longitud (pronoto-élitros) 2.0-3.7 mm, ancho 1.3-2.2 mm; integumento de las patas posteriores rojo-naranja, excepto la mitad de la cara ventral del fémur posterior negra; segmentos de la antena 1-4, 11 y 0.5 del 5 de color rojo-naranja, el resto de los segmentos café; cuerpo con pubescencia recumbente blanca, amarillo dorado y café claro formando un patrón poco contrastante; metafémur armando con una espina subapical grande 1.2 veces el tamaño del ancho de la base de la metatibia, seguida de dos espinas más pequeñas 0.5 veces la longitud de la primera; corona de la metatibia con 4 espínulas; mucro 1/6 o menos de la longitud del primer tarsómero; armadura del saco interno de la genitalia del macho como en las Figs. 32-33.

Hospedero. Cajanus indicus, Cicer arietinum, Lathyrus odoratus, Lens esculenta, Mucuna pruriens, Phaseolus glabellus, P. mungo, P. acutifolius latifolius, P. coccineus, $P$. lunatus, $P$. vulgaris, Sesbania sesban, Vicia faba, V. sativa, Vigna caracalla, $V$. sesquipedalis, V. caracalla, V. umbellata, V. unguiculata, Voandzeia subterranea. 


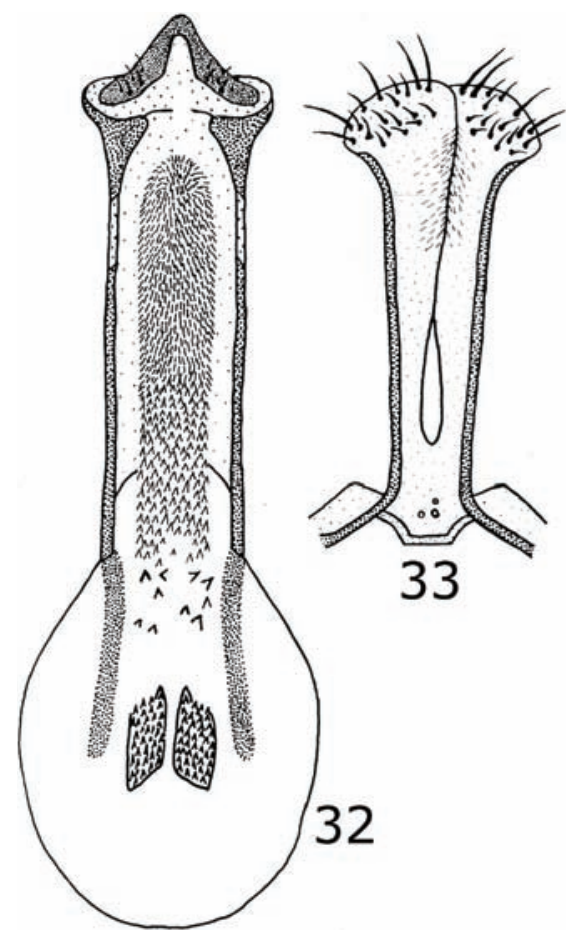

Figuras 32-33. Acanthoscelides obtectus, vista ventral de la genitalia del macho: 32) lóbulo medio, 33) lóbulos laterales.

Distribución. Se trata de una especie endémica de América, pero que debido al comercio intenso ahora se considera con una plaga de productos almacenados con una distribución cosmopolita.

Material examinado. TABASCO. Inf. Deportiva, Cárdenas, 2/III/2007, col. De La Cruz P. A., ex. Phaseolus vulgaris L. (Leguminosae: Papilionoideae) (6 ex).

Discusión. A. obtectus está relacionado con A. argillaceus y A. obvelatus, se diferencia de éstas porque los segmentos antenales del 1- 4 y 11 son rojo naranjas, la pata posterior es rojo-naranja excepto la mitad de la cara ventral que es de color negro y el pigidio rojo-naranja.

\section{Acanthoscelides quadridentatus (Schaeffer), 1907}

Diagnosis. Longitud (pronoto-élitros) 2.2-2.8 mm, ancho 1.4-1.7 mm; integumento de cabeza, cuerpo y apéndices rojo-naranja; protórax, élitros y pigidio con pubescencia 
blanca, amarilla y café formando un patrón variegado; antenas cortas, extendiéndose cerca de la base de los élitros; estría elitrales profundamente impresas, punteadas, con los intervalos estriales punteados; estría 3-4 y 5-6 más cerca una de otras en la base que las estrías adyacentes; metafémur armando con una espina subapical grande 1.2 veces tan larga como el ancho de la base de la metatibia, seguida de 4 espinas 0.5 del largo de la primera espina; armadura del saco interno de la genitalia del macho como en las Figs. 34-35.

Hospederos. Mimosa asperata, Mimosa pigra, M. pigra var. berlandieri, M. pigra var. pigra, M. strigillosa, M. vellosiella.

Distribución. Bolivia, Brasil, Colombia, Costa Rica, Cuba, Estados Unidos, Guatemala, Honduras, México (Campeche, Chiapas, Guerrero, Morelos, Oaxaca, Tabasco, Tamaulipas y Veracruz), Nicaragua, Panamá, Paraguay y Venezuela. Esta especie

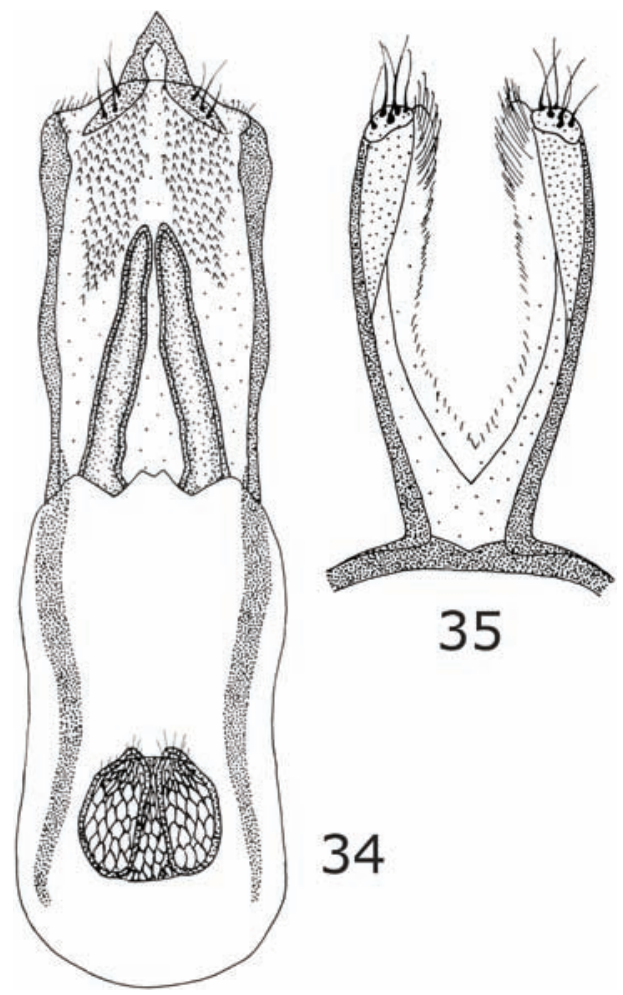

Figuras 34-35. Acanthoscelides quadridentatus, vista ventral de la genitalia del macho: 34) lóbulo medio, 35) lóbulos laterales. 
ahora se encuentra en Australia y Tailandia, debido a que se ha considerado como un agente de control biológico para combatir especies de Mimosa, a las cuales se les considera como plantas invasivas en estos países.

Material examinado. TABASCO. Carlos A. Madrazo, Huimanguillo, $17^{\circ} 22^{\prime} 14^{\prime \prime}$ N, 9337’ 12” W, 19/X/2007, col. De La Cruz P. A., Redeo sobre malváceas (1 ex); Laguna Colorada, Balancan, $17^{\circ} 44^{\prime} 30^{\prime \prime}$ N, 91³1'34” W, 8/II/2007, col. De La Cruz P. A., ex. Mimosa pigra L. (Leguminosae: Mimosoideae) (1 ex); Las Flores, Huimanguillo, $17^{\circ} 21^{\prime}$ 59” N, 93 35’ 44” W, 19/X/2007, col. De La Cruz P. A., Redeo sobre malváceas (38 ex); Reserva de la Biosfera Pantanos de Centla, Estación 3 Brazos, 0 m, 18 28’ 17” N, 92 32’ 16” W, 4/VI/2007, col. De La Cruz P. A., ex. Mimosa pigra L. (Leguminosae: Mimosoideae) (101 ex); Villa Ocuiltzapotlan, R/A Miramar, 10/IV/1994, Niño S. \& R. Castro (1 ex, MIFA); 10 mi. W Villahermosa, 17/VIII/1965, Raske A. G. (45 ex, TAMU).

Discusión. Según Johnson (1983) el grupo Quadridentatus está formado por ocho especies, aunque las siguientes cinco forman un subgrupo que es muy difícil de separar: A. devriesi, A. pigricola, A. puniceus, A. quadridentatus y A. zebratus; sin embargo, con la estructura de la genitalia es posible identificarlas fácilmente.

\section{Acanthoscelides sauli Romero, Cruz y Kingsolver, 2009}

Diagnosis. Longitud (pronoto-élitros) 4.4-5.0 mm, ancho 2.7-3.1 mm; integumento de la cabeza, cuerpo y apéndices rojo-naranja a marrón rojizo; élitros con pubescencia variegada blanca, amarilla y café; pigidio con una mácula de pubescencia oscura en forma de "V"; mandíbulas cortas y curvas, nunca se cruzan en el ápice en ambos sexos; mucro de 2-6 veces más largo que el primer tarsómero; armadura del saco interno de la genitalia del macho como en las Figs. 36-37.

Hospedero. Acacia cornigera, Acacia collinsii.

Distribución. México (Chiapas, Tabasco y Veracruz).

Material examinado. TABASCO. Arrollo El Triunfo $2^{\circ}$ Secc., Balancan, $12 \mathrm{~m}$, 17²5'56', N, 9102'46'’ W, 17/VII/2007, col. De la Cruz P. A., ex. Acacia cornigera (L.) Willd. (Leguminosae: Mimosoideae) (10 ex); carr. fed. al Ceibo, Tenosique, 12 m, 17²16’34' N, 9103'53'’ W, 17/VII/2007, col. De la Cruz P. A., ex. Acacia collinsii Saff. (Leguminosae: Mimosoideae) (16 ex); Ejido Miraflores, Sierra de Tapijulapa, Tlacotalpa, 20 m, 17²7’44' ' N, 9241'47' ' W, 26/IX/2007, col. De La Cruz P. A., ex. Acacia cornigera (L.) Willd. (Leguminosae: Mimosoideae) (14 ex); Km 21 carr. fed. Cárdenas-Coatzacoalcos, Campo Exp. COLPOS, 10 m, 1759’10”' N, 


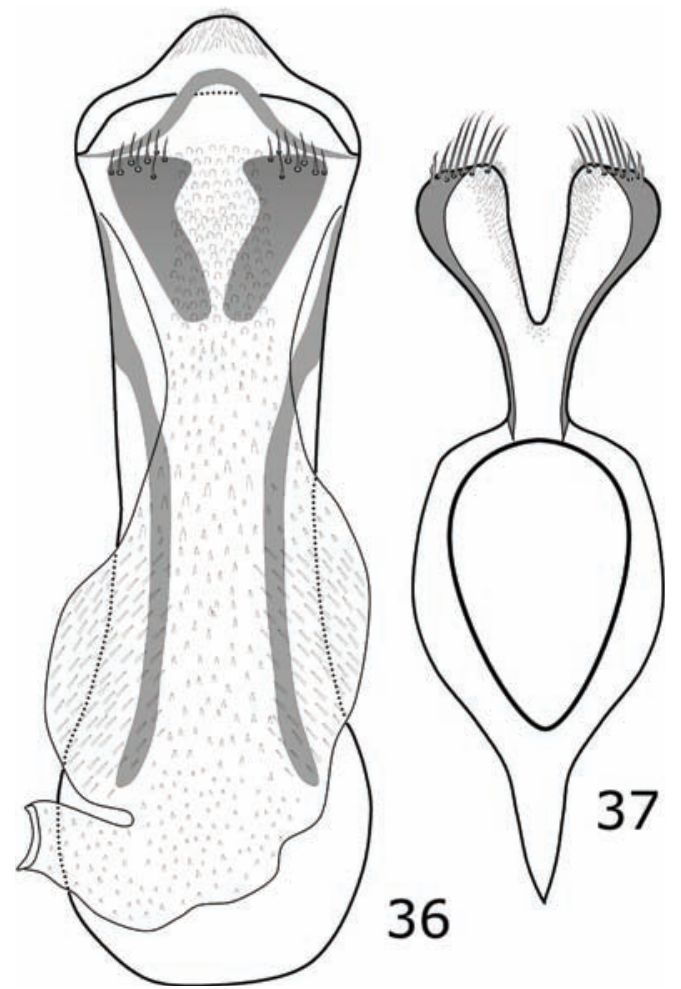

Figuras 36-37. Acanthoscelides sauli, vista ventral de la genitalia del macho: 36) lóbulo medio, 27) lóbulos laterales.

93³5’11’’ W, 23/IX72007, col. De la Cruz P. A., ex. Acacia cornigera (L.) Willd. (12 ex).

Discusión. A. sauli por mucho tiempo permaneció como especie críptica junto con A. oblongoguttatus compartiendo el mismo nicho; sin embargo, después de su descripción se tienen algunas características que permiten separarlas con morfología externa. Machos y hembras de $A$. sauli tienen mandíbulas cortas, redondeadas en forma de "herradura” y nunca se entrecruzan en el ápice y el patrón de pubescencia en los élitros es muy contrastante; en $A$. oblongoguttatus las hembras tienen mandíbulas muy largas, rectas y se cruzan en el ápice; también a nivel de genitalia de hembras es posible separar las especies, las hembras de $A$. sauli presentan una genitalia membranosa y poco quitinizada, en contraste con A. oblongoguttatus que la genitalia está muy quitinizada y transformada en ovipositor que le sirve para introducir los huevos al interior de la vaina. 


\section{Acanthoscelides schubertae Johnson, 1983}

Diagnosis. Longitud (pronoto-élitros) 1.4-1.9 mm, ancho 0.9-1.1 mm; pronoto y élitros con pubescencia blanca, amarilla y café en patrones muy contrastantes; antenas extendiéndose de 0.25 a 0.3 la longitud de los élitros; metafémur armando con una espina subapical 1.5 veces la longitud del ancho de la base de la metatibia, seguida de dos espinas 0.3 la longitud de la primera espina; mucro 0.4 la longitud del primer tarsómero, con un sinus poco pronunciado en la base del mucro; primer esternito abdominal del macho ligeramente o medianamente cóncavo, concavidad pubescente, con pelos más largos en el ápice; armadura del saco interno de la genitalia del macho como en las Figs. 38-39.

Hospedero. Desmodium incanum.

Distribución. Belice, Guatemala; Honduras; México (Quintana Roo, San Luis Potosí, Tabasco, Veracruz y Yucatán).

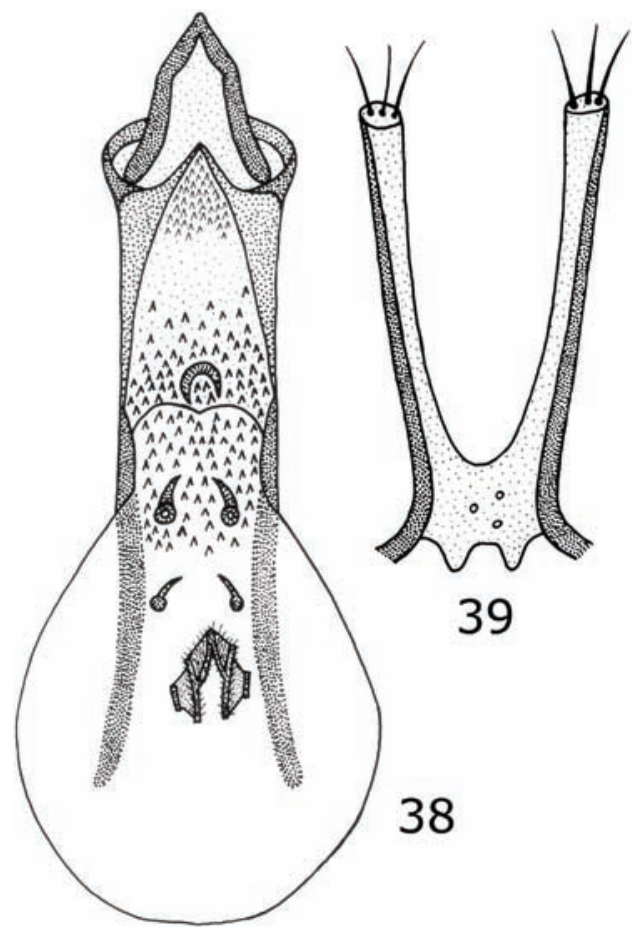

Figuras 38-39. Acanthoscelides schubertae, vista ventral de la genitalia del macho: 38) lóbulo medio, 39) lóbulos laterales. 
Material examinado. TABASCO. Ejido El Bajío 2da sección, Cárdenas, 10 m, 1758’09” N, 93²0’55” W, 28/III/2007, col. De La Cruz P. A., ex. Desmodium incanum DC. (Leguminosae: Mimosoideae) (22 ex); Emiliano Zapata; 17²1’00” N, 91¹1’23” W, 8/II/2007, col. De La Cruz P. A., (1 ex); La Candelaria, Huimanguillo, 17²1939” N, 93³6’08” W, 13/III/2007, col. De La Cruz P. A., ex. Desmodium incanum DC. (Leguminosae: Mimosoideae) (34 ex); Reserva de la Biósfera Pantanos de Centla, Estación 3 Brazos, 0 m, 18²4’23” N, 92³8’47” W, 4/VI/2007, col. De La Cruz P. A. (7 ex).

Discusión. Esta especie se encuentra en el grupo Pertinax y se diferencia entre las otras fácilmente debido al patrón del dorso que es único y además está fuertemente contrastante, también presenta en el primer esternito abdominal del macho una concavidad media con pubescencia y unas setas largas en la parte apical.

\section{Acanthoscelides sousai Johnson, 1983}

Diagnosis. Longitud (pronoto-élitros) 3.1-4.0 mm, ancho 2.0-2.5 mm; integumento de la cabeza, pronoto y la mayor parte del élitro café rojizo; pronoto con una mancha mesal en forma de "V" invertida de pubescencia densa amarilla; antenas extendiéndose a la base de los élitros; escutelo transversal; carina protoráxica lateral extendiéndose de la base hasta 0.6 de la distancia a la cavidad coxal; metafemur armando con una espina subapical 1.7 veces la longitud del ancho de la base de la metatibia, seguida de dos espinas 0.4 la longitud de la primera espina; corona tibial con 4-5 espinulas; mucro 0.25 la longitud del primer tarsómero, sin sinus en la base del mucro; armadura del saco interno de la genitalia del macho como en las Figs. 40-41.

Hospedero. Acacia collinsii, Acacia cornigera, Acacia gentlei y Mimosa dormiens. A. collinsii es un nuevo registro de hospedero para este brúquido.

Distribución. Costa Rica, Guatemala, México (Chiapas, Tabasco y Veracruz).

Material examinado. TABASCO. Campo Exp. Colegio de Postgraduados, km 21 carr. Cárdenas-Coatzacoalcos, 11 m, 1759'10’' N, 93³5’11’’ W, 23/X/2007, col. De la Cruz P. A., ex. Acacia cornigera (L.) Willd. (1 ex); carr. fed. El Ceibo, Te-

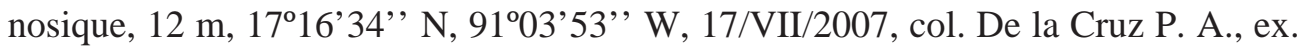
Acacia collinsii Saff. (1 ex).

Discusión. De acuerdo a Johnson $(1983,1990)$ A. sousai se encuentra en el grupo Albopygus junto con otras nueve especies más, todas se caracterizan por tener cuerpos 


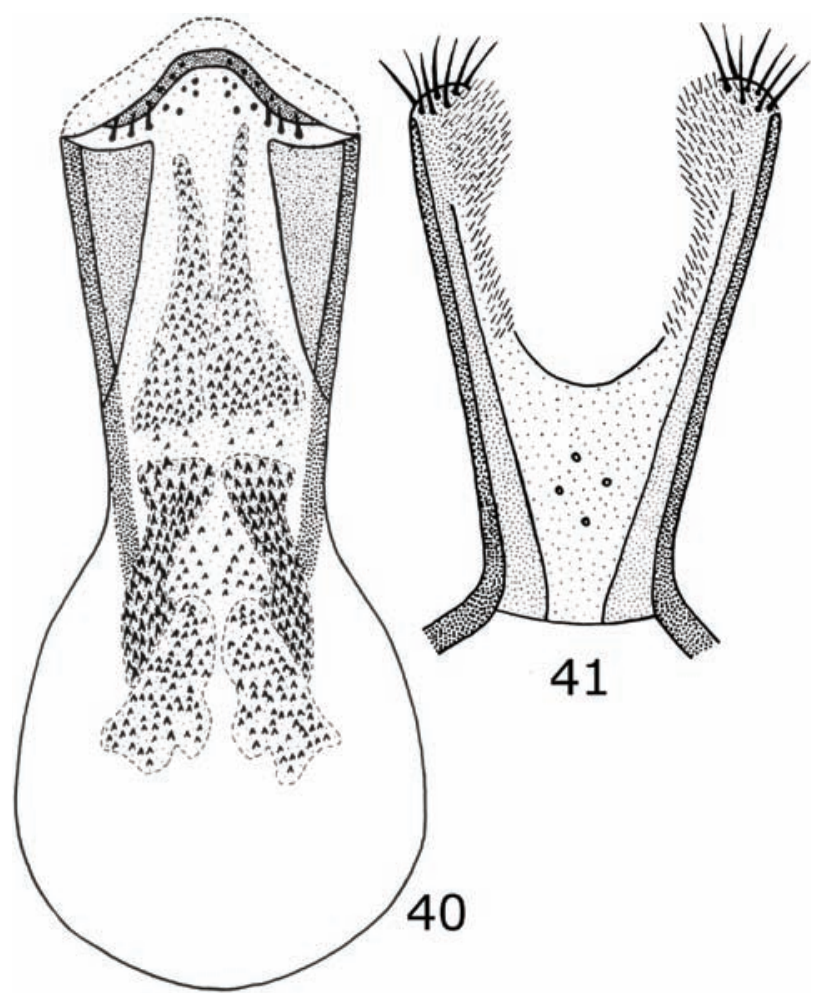

Figuras 40-41. Acanthoscelides sousai, vista ventral de la genitalia del macho: 40) lóbulo medio, 41) lóbulos laterales.

robustos y patrones de pubescencia contrastantes, aunque el patrón de pubescencia que presenta el protorax de $A$. sousai es particular de la especie.

\section{Acanthoscelides taboga Johnson, 1983}

Diagnosis. Longitud (pronoto-élitros) 2.0-2.6 mm, ancho 1.2-1.8 mm; integumento del pronoto, pigidio, abdomen, antenas y patas rojo-naranja; élitros siempre con maculas largas marrón o negras entre las estrías 4-10, cerca de 0.5 de la base; metafémur armando con una espina subapical 1.6 veces la longitud del ancho de la base de la metatibia, seguida de dos espinas 0.3 la longitud de la primera espina; mucro 0.33 la longitud del primer tarsómero, con un sinus poco pronunciado en la base del mucro; primer esternito abdominal con una pequeña concavidad cubierta con pubescencia blanca densa en la línea media; armadura del saco interno de la genitalia del macho como en las Figs. 42-43. 


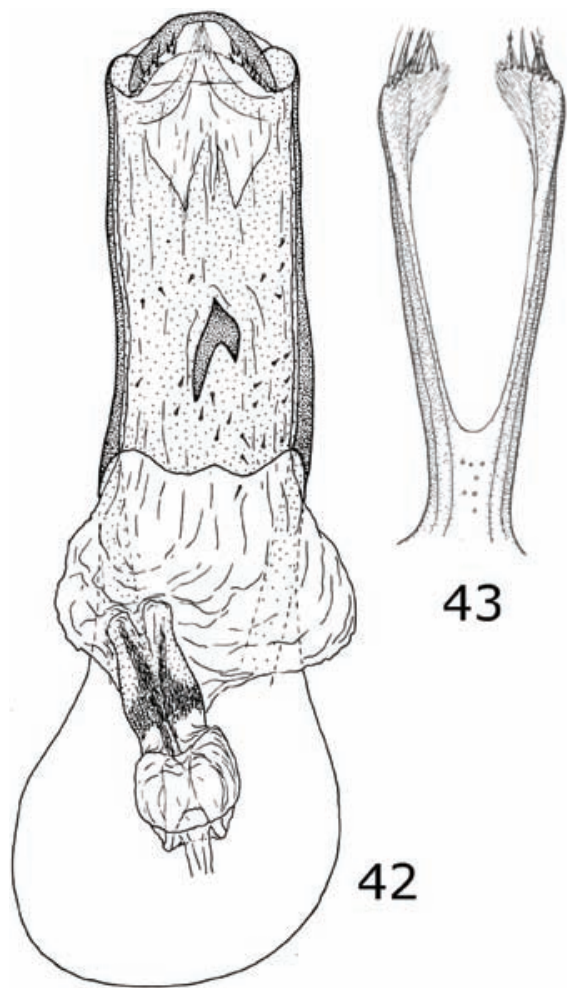

Figuras 42-43. Acanthoscelides taboga, vista ventral de la genitalia del macho: 42) lóbulo medio, 43) lóbulos laterales.

Hospedero. Calopogonium caeruleum, C. mucunoides, Macroptilium sp., Pachyrhizus erosus, $P$. tuberosus, Tephrosia sp.

Distribución. Belice, Colombia, Costa Rica, El Salvador, Honduras, México (Tabasco, Veracruz y Yucatán), Peru, Panamá, Surinam, Tobago y Venezuela.

Material examinado. TABASCO. Ejido el Bajío 2da sección, Cárdenas, $11 \mathrm{~m}$, 1758’22” N, 93²0’53” W, 28/III/2007, col. De La Cruz P. A., ex. Calopogonium caeruleum (ex 49).

Discusión. A. taboga está incluido en el grupo Puellus, que es uno de los más grandes y actualmente cuenta con 30 especies. Johnson (1983) dividió al grupo en 7 subgrupos, de tal manera que A. taboga y A. aureolus forman un subgrupo debido a la similitud en la genitalia; aunque la primera especie es de distribución tropical, en tanto que la segunda sólo se le ha registrado en Norteamérica. 


\section{Acanthoscelides zeteki Kingsolver, 1969}

Diagnosis. Longitud (pronoto-élitros) 1.8-2.6 mm, ancho 1.2-2.0 mm; integumento de la cabeza, pronoto, élitros y pigidio café rojizo; antenas extendiéndose en la base de los élitros o ligeramente más allá, espina coronal dorsal de la tibia posterior más larga que otras espinas coronales, con sinus en la base, pronoto y élitros rojo naranja a marrón rojizo; genitalia del macho con lóbulos medios de longitud moderada, en vista ventral valva ventral corta, lados convexos, ápice con una protuberancia sobresaliente, base de la valva ventral cerca de 0.9 tan ancha como el ápice del lóbulo medio, ligeramente arqueado en vista lateral; armadura del saco interno de la genitalia del macho como en las Figs. 44-45.

Hospederos. Cajanus cajan, Fleminga strobilifera, Rhynchosia calycosa, R. longeracemosa, $R$. minima, $R$. pyramidalis, $R$. reticulata, $R$. schomburgkii.

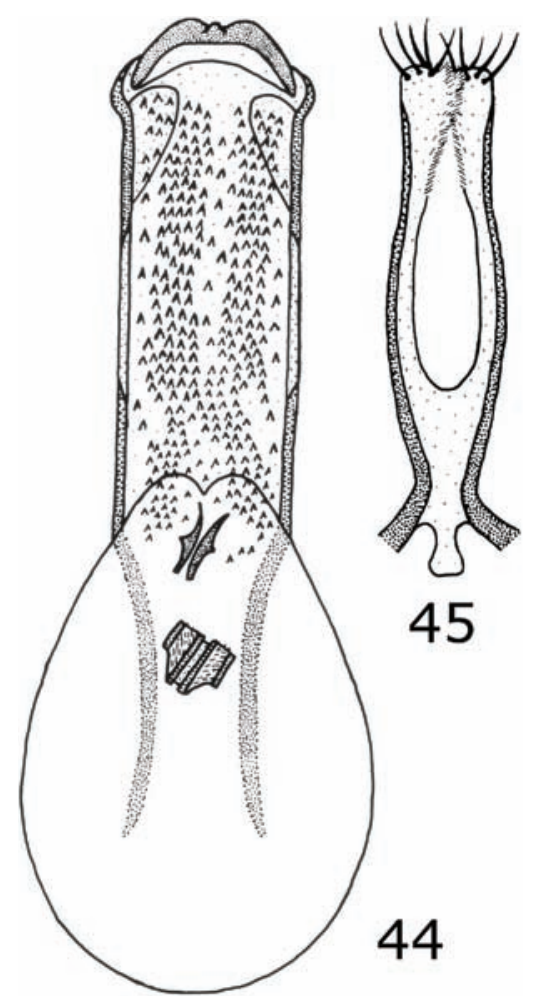

Figuras 44-45. Acanthoscelides zeteki, vista ventral de la genitalia del macho: 44) lóbulo medio, 45) lóbulos laterales. 
Distribución. Colombia, Costa Rica, Estados Unidos, Guatemala, Honduras, México (Campeche, Guerrero,Jalisco,Michoacán, Querétaro, QuintanaRoo,Sinaloa,Sonora,Tabasco, Veracruz y Yucatán), Nicaragua, Trinidad \& Tobago, Panamá y Venezuela.

Material examinado. TABASCO. Miahuatlán, Cunduacán, $16 \mathrm{~m}, 18^{\circ} 03$ ’12” N, 93 11’41” W, 3/V/2007, col. De La Cruz P. A., ex. Rhynchosia minima (L.) DC. (6 ex).

Discusión. El grupo Flavescens está integrado por 14 especies; sin embargo, las especies estrechamente relacionadas y similares son: A. burkei, $A$. campeche, A. distinguendus y A. zeteki, de tal manera que se requiere del análisis de la genitalia para poder separarlas.

\section{Caryedes clitoriae (Gyllenhal), 1839}

Diagnosis. Longitud 2.5-3.2 mm, ancho 1.6-2.0 mm; integumento del cuerpo rojizo; pronoto con una mancha de pubescencia café o café obscuro; élitro con pubescencia variegada gris y amarilla; pata posterior cubierta uniformemente con pubescencia amarilla; cabeza pequeña y ovalada; ojos grandes prominentes; mandíbulas cortas; estría elitral tres sin tocar el gibosito basal; lóbulo postocular abreviado; radio interocular de más de $0.22 \mathrm{~mm}$; armadura del saco interno de la genitalia del macho como en las Figs. 46-47.

Hospedero. Calopogonium caeruleum, C. velutinum.

Distribución. Belice, Bolivia, Brasil, Colombia, El Salvador, Guatemala, México (Tabasco), Nicaragua, Panama, Peru, Surinam, Trinidad \& Tobago y Venezuela.

Material examinado. TABASCO. El Bajío 2da sección, Cárdenas, 1758’22” N, 93²0’53” W, 28/III/2007, col. De La Cruz P. A., ex. Calopogonium caeruleum (Benth.) Sauvalle (5 ex).

Discusión. El registro de C. clitoriae para México, es el primer reporte de la especie para el estado y para el país; al parecer se trata de una especie con afinidad Neotropical y su distribución más al norte justamente es el estado de Tabasco. A esta especie se le encontró de manera simpátrica con C. paradisensis en las semillas de Calopogonium caeruleum.

\section{Caryedes helvinus (Motschulsky), 1874}

Diagnosis. Longitud 2.8-3.7 mm, ancho 1.9-2.4 mm; integumento del cuerpo obscuro o rojizo, o rojo obscuro con el húmero elitral obscuro; patas de color castaño, excepto 


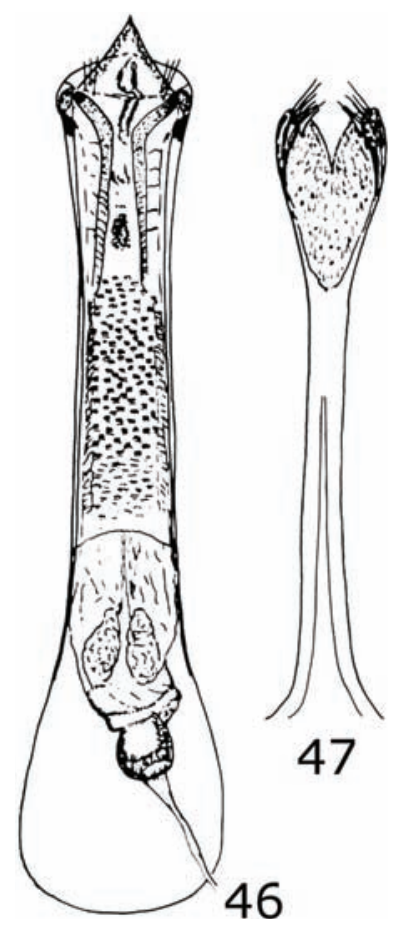

Figuras 46-47. Caryedes clitoriae, vista ventral de la genitalia del macho: 46) lóbulo medio, 47) lóbulos laterales.

metatibia rojiza; vestidura en general de color blanca amarillenta, áreas laterales sin contrastar con pubescencia café y negro, dorso con pubescencia variegata amarillo y café; metatibia con mucro alrededor de la anchura del ápice de la tibia; corona tibial con el diente lateral fuerte; metacoxa uniformemente punteada; armadura del saco interno de la genitalia del macho como en las Figs. 48-49.

Hospederos. Centrosema macrocarpa, C. pubescens, C. virginianum.

Distribución. Belice, Bolivia, Brasil, Colombia, Costa Rica, Estados Unidos, Honduras, México (Oaxaca, Tabasco y Tamaulipas), Nicaragua, Panama, Perú, St. Vincent \& Grenadines, Trinidad y Venezuela.

Material examinado. TABASCO. Teapa (USNM, 1 ex).

Discusión. Kingsolver \& Whitehead (1974b) indican que los especímenes colectados en el sur de Brasil en promedio son notablemente mayores que espímenes colectados 


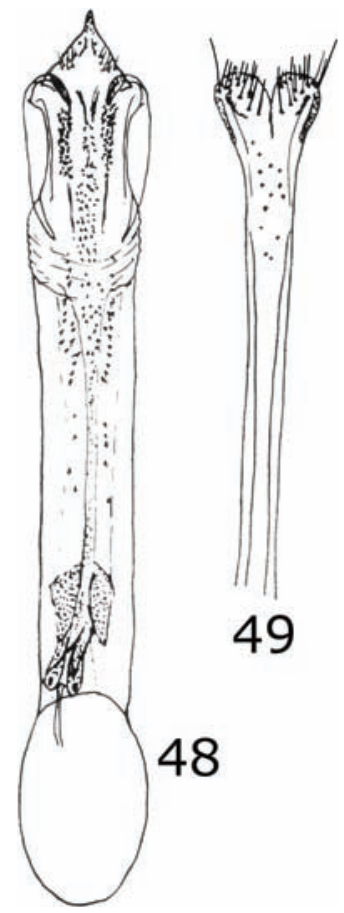

Figuras 48-49. Caryedes helvinus, vista ventral de la genitalia del macho: 48) lóbulo medio, 49) lóbulos laterales.

en cualquier otra parte de Sudamérica, además que tienden a ser de una coloración más obscura.

\section{Caryedes paradisensis Kingsolver y Whitehead, 1974}

Diagnosis. Longitud 2.7-3.2 mm, ancho 1.9-2.2 mm; integumento mayormente de color rojizo, antenas amarillentas excepto los segmentos 7-10 que son obscuros; cuerpo cubierto con pubescencia variegada, blanca, amarillenta y café obscuro; cabeza corta, con apariencia cuadrada, ojos prominentes, mandíbulas pequeñas y redondeadas; metasterno poco profundo, ligeramente arqueado en vista lateral, gena corta, escrobo antenal glabro, disco elitral convexo mesalmente, gibosito basal levantado encima del plano del gibosito humeral; armadura del saco interno de la genitalia del macho como en las Figs. 50-51.

Hospedero. Rhynchosia sp., Calopogonium caeruleum, C. velutinum, Pachyrhizus sp., Phaseolus vulgaris. 


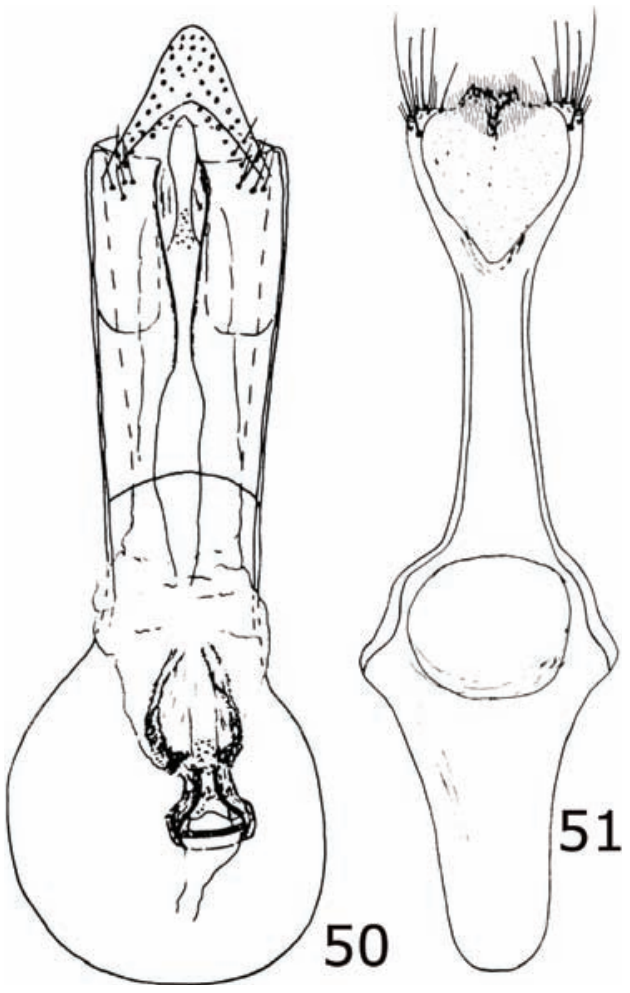

Figuras 50-51. Caryedes paradisensis, vista ventral de la genitalia del macho: 50) lóbulo medio, 51) lóbulos laterales.

Distribución. Colombia, Costa Rica, México (Tabasco) y Panamá.

Material examinado. TABASCO. El Bajío 2da sección, Cárdenas, 1758’22” N, 93²0’53” W, 28/III/2007, col. De La Cruz P. A., ex. Calopogonium caeruleum (15 ex).

Discusión. El registro de C. paradisensis para México, es el primer reporte de la especie para el estado y para el país; al parecer se trata de una especie con afinidad Neotropical y su distribución más al norte justamente es el estado de Tabasco.

\section{Ctenocolum podagricus (Fabricius), 1801}

Diagnosis. Longitud 2.0-3.4 mm, ancho 1.4-2.0 mm; el integumento del cuerpo puede variar de rojizo a café; ojos grandes, radio interocular 0.17-0.20; sinus ocular 
profundo, 4-5 hileras de facetas al ras de él; antena serrada, extendiéndose hasta el húmero elitral en hembras y hasta el primer tercio del élitro en los machos; base de la muesca entre el diente del gibosito basal elitral más cerca del ápice del diente interno que de la base del élitro; fémur posterior con pecten con 7-9 dientes, sin abertura entre el primero y el segundo diente, pero el segundo mucho más pequeño; armadura del saco interno de la genitalia del macho como en las Figs. 52-53.

Hospedero. Lonchocarpus costaricensis, L. eriocarinalis, L. hondurensis, L. margaritensis, L. minimiflorus, L. muehlbergianus, L. nitidus, L. parviflorus, L. pentaphyllus, L. rugosus, Piscidia carthagenensis, P. piscipula.

Distribución. Argentina, Bolivia, Brasil, Costa Rica, Cuba, Ecuador, El Salvador, Guatemala, Guyana, Jamaica, México (Campeche, Chiapas, Jalisco, Querétaro, Quintana Roo, Sinaloa, Tabasco, Veracruz), Nicaragua, Paraguay, Perú, Puerto Rico, Trinidad \& Tobago, Venezuela.

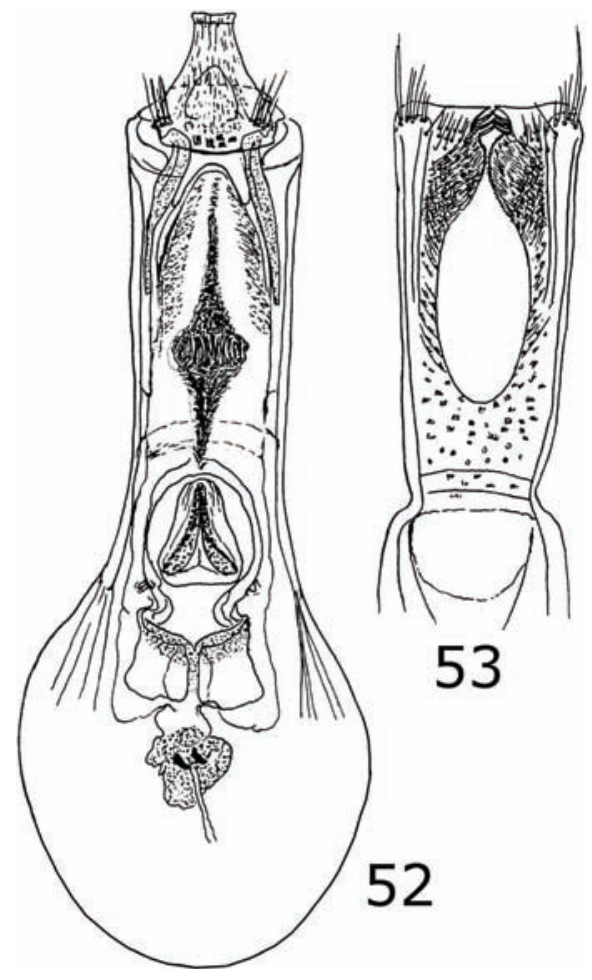

Figuras 52-53. Ctenocolum podagricus, vista ventral de la genitalia del macho: 52) lóbulo medio, 53) lóbulos laterales. 
Material examinado. TABASCO. Cascadas de Reforma, Balancan, 13 m, 17³7'19” N, 92²7’56” W, 17/VII/2007, col. De La Cruz P.A. ex. Piscidia piscipula (L.) Sarg, Det. (5 ex); Ejido Benito Juárez, Tenosique, 12 m, 17²3’35” N, 91¹1’46” W, 17/ VII/2007, col. De La Cruz P. A., ex. Lonchocarpus rugosus Benth. (13 ex); Emiliano Zapata, 1740’57” N, 91³9’07” W, 8/II/2007, col. De La Cruz P. A, ex. Lonchocarpus rugosus Benth. (2 ex).

Discusión. Según Kingsolver \& Whitehead (1974a) el grupo Crotonae está formado por C. crotonae, C.biolleyi, C. colburni y C. martiale; sin embargo, Johnson y Nilsson (1990) ponen en sinonimía a $C$. crotonae, de tal manera que consideran que la especie válida debe ser $C$. podagricus. Con el cambio anterior también se tiene que ajustar el nombre del grupo, por tal motivo el grupo Crotonae se substituye por grupo Podagricus.

\section{Gibbobruchus divaricatae Whitehead \& Kingsolver, 1975}

Diagnosis. Longitud 2.6-4.1 mm, ancho 1.8-2.6 mm; integumento mayormente de color obscuro; antena amarillenta, con los segmentos 7-10 ligeramente más obcuros; tarsos amarillos, excepto el basitarso posterior obscuro; profémur, mesofémur y tibias bandeadas; vestidura mayormente escasa, obscura, ligeramente variegada, de naranja a obscuro; sutura elitral con una banda de pubescencia obscura; élitros con gibositos y tubérculos fuertemente levantados; pecten con 3-4 dientes posteriores separados de un diente grande anterior por un espacio; metatibia arqueada; pigidio del macho con un gibosito en la parte media apical; pigidio de la hembra con un espejo (área lustrosa) grande, redondeado, convexo, micropunteado; armadura del saco interno de la genitalia del macho como en las Figs. 54-55.

Hospederos. Bauhinia divaricata, B. pes-caprae y B. ungulata.

Distribución. Estados Unidos, Honduras y México (Campeche, Estado de México, Guerrero, Nayarit, Oaxaca, Quintana Roo, San Luis Potosí, Tabasco, Tamaulipas y Veracruz).

Material examinado. TABASCO. 15 mi. NE Villahermosa, 13/VI/1965, Burke et al. (USNM, 1 ex); Villahermosa, 15 mi. NE, 5 mi. S, 13/VI/1965, ex. Bauhinia divaricata L. (USNM, 1 ex.).

Discusión. G. divaricatae y G. cristicollis son dos especies muy cercanas, aunque G. cristicollis no se registró en Tabasco, es muy posible que en el futuro se colecte, 


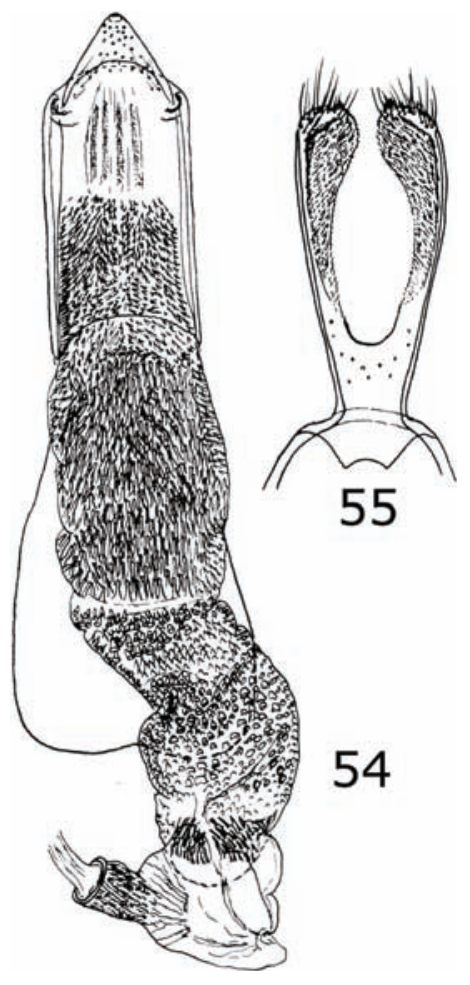

Figuras 54-55. Gibbobruchus divaricatae, vista ventral de la genitalia del macho: 54) lóbulo medio, 55) lóbulos laterales.

ya que existen registros en Veracruz y Chiapas; sin embargo se le podrá separar muy fácilmente por las estructuras de la genitalia.

\section{Gibbobruchus guanacaste Whitehead \& Kingsolver, 1975}

Diagnosis. Longitud 2.4-3.6 mm, ancho 1.6-2.4 mm; integumento con dimorfismo sexual, machos de color marrón rojizo, hembras amarillentas; élitros variegados con pubescencia blanca, café y negra, dorso del metafémur con un patrón de pubescencia blanca y café; primer esternito abdominal del macho con una mancha de pubescencia muy densa y notoria; pecten de metafémur con 3 a 4 dientes pequeños bien separados, seguido por un diente grande después de un espacio equivalente a la longitud de éste; pigidio de la hembra con un espejo grande, casi redondo, convexo, truncado o ligeramente emergiendo basalmente, micropunteado, con un fleco de pubescencia apicalmente; armadura del saco interno de la genitalia del macho como en las Figs. 56-57. 


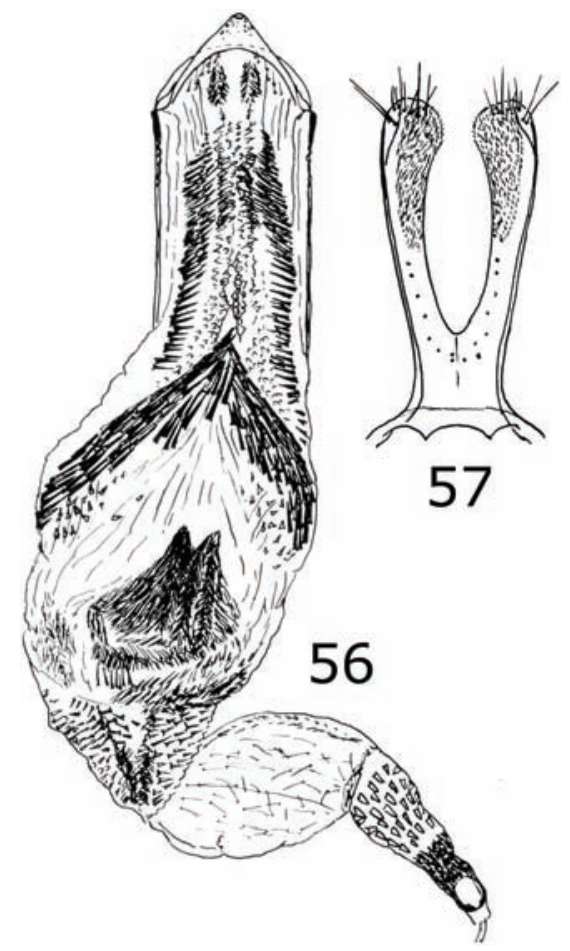

Figuras 56-57. Gibbobruchus guanacaste, vista ventral de la genitalia del macho: 56) lóbulo medio, 57) lóbulos laterales.

Hospederos. Bauhinia aculeata, B. divaricata, B. glabra, B. pauletia, B. pes-caprae, B. pringeli, B. ungulata, Lonchocarpus rugosus. L. rugosus es un nuevo registro de hospedero para este brúquido.

Distribución. Costa Rica, El Salvador, Jamaica a México (Chiapas, Guerrero, Jalisco, Sinaloa, Tabasco y Veracruz), Nicaragua y Venezuela.

Material examinado. TABASCO. Ejido Benito Juárez, Tenosique, 12 m, 17²3’35” N, 91¹1'46” W, 17/VII/2007, col. De La Cruz P. A., ex. Lonchocarpus rugosus Benth., CEAM (6 ex).

Discusión. A G. guanacaste sólo se le había registrado en hospederos del género Bauhinia; sin embargo, L. rugosus al parecer se trata de un hospedero marginal, como ocurre en muchas especies de la familia Bruchidae. 


\section{Meibomeus apicicornis (Pic), 1933}

Diagnosis. Longitud 1.4-2.2 mm, ancho 0.9-1.3 mm; integumento negro, no metálico; la mayoría de los segmentos antenales terminales amarillos en el macho y obscuros en la hembra; segmentos antenales basales 1-4 o 1-5, tibia anterior, media, tarsos, mitad apical o casi todo el fémur anterior, ápice del fémur medio, tarso posterior, excepto la mitad basal o más del basitarso, amarillos; vestidura elitral poco densa de color blanco, por lo general con una mancha de pubescencia densa blanca sobre el intervalo elitral 3; élitro con un gibosito basal vago, estría elitral 4 notablemente abreviada basalmente y terminando con un diente fuerte, estrías 3 y 5 menos abreviadas; metafémur con diminutos dientes basales, pecten con un diente grande seguidos inmediatamente por 3 a 5 dientes más pequeños; armadura del saco interno de la genitalia del macho como en las Figs. 58-59.

Hospedero. Desmodium incanum.

Distribución. Belice, Costa Rica, El Salvador, Estados Unidos, Guatemala, Honduras, México (Aguascalientes, Campeche, Campeche, Chiapas, Hidalgo, Oaxaca,

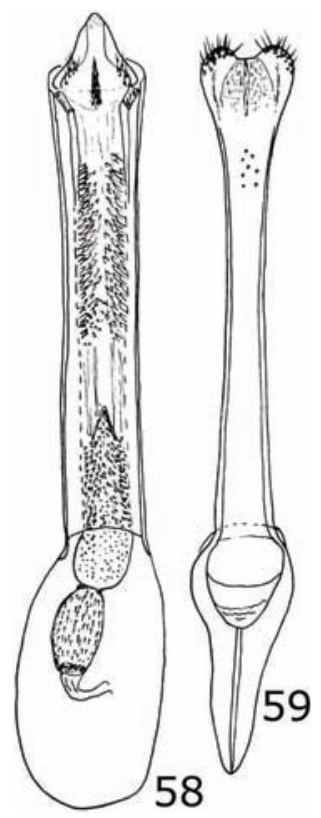

Figuras 58-59. Meibomeus apicicornis, vista ventral de la genitalia del macho: 58) lóbulo medio, 59) lóbulos laterales. 
Querétaro, Quintana Roo, San Luis Potosí, Sinaloa, Tabasco, Tamaulipas, Veracruz), Nicaragua y Panamá.

Material examinado. TABASCO. Ej. Miraflores, Sierra de Tapijulapa, Tacotalpa, 26/IX/2007, 17²7’44” N, 9241’47’ W, col. De La Cruz P. A., redeando sobre malváceas CEAM (1 ex); Las Delicias, Teapa, 27/XII/2007, 20 m, 1759’23” N, 93³7’09” W, col. De La Cruz P. A., ex. Desmodium sp. (Leguminosae: Papilionoideae), CEAM (2 ex).

Discusión. M. apicicornis fue la única especie registrada para el estado de Tabasco; sin embargo, en el futuro se incrementará el número de especies de este género ya que éste tiene una distribución principalmente en áreas tropicales. De acuerdo a Kingsolver y Whitehead (1976) esta especie puede ser colectada en cualquier época del año, se le ha colectado en Honduras en flores de mango en los meses de febrero y marzo.

\section{Merobruchus columbinus (Sharp), 1885}

Diagnosis. Longitud 4.0-5.4 mm, ancho 2.3-2.9 mm; integumento obscuro rojizo a amarillento, antena rojo-café excepto los segmentos 8-10 que son amarillentos; pubescencia gris, café y bronceado formando un patrón variegado tenue en pronoto y élitros; base de las estrías elitrales 3, 4 y 5 con dientes; margen basal de las estrías 3 y 4 sin gibosidades; estría 6 y 7 conectadas basalmente con una carina en forma de "U"; metafémur con un diente basal grande, seguido inmediatamente de 3 dientes más pequeños; metatibia ligeramente arqueada; armadura del saco interno de la genitalia del macho como en las Figs. 60-61.

Hospedero. Samanea saman.

Distribución: Colombia, Costa Rica, El Salvador, Guatemala, Honduras, México (Chiapas, Quintana Roo y Tabasco), Nicaragua, Panamá, Trinidad \& Tobago, Venezuela,

Material examinado: TABASCO. Av. Lázaro Cárdenas Infonavit deportiva, Cárdenas, 10 m, 25/III/2007, Col. De La Cruz P. A., ex. Samanea saman (Jacq) Merrill, CEAM (2 ex); Campo Experimental COLPOS, km 21 carr. Federal Cárdenas, Tabasco-Coatzacoalcos, 10 m, 17³7’19” N, 92²7’56” W, 14/IV/2007, col. Pérez De La Cruz M., atraido en trampa de alcohol en cacaotal, CEAM (1 ex); Campo Experimental COLPOS, km 21 carr. Federal Cárdenas, Tabasco-Coatzacoalcos, 10 m, 17³7’19” N, 92²7’56” W, 19/IV/2007, col. Pérez De La Cruz M., atraido en trampa de alcohol en cacaotal, CEAM (3 ex); Cascadas de Agua Blanca, Macuspana, 17³7’19” N, 92²7’56” W, 7/V/2007, col. De La Cruz P. A., ex. Samanea saman 


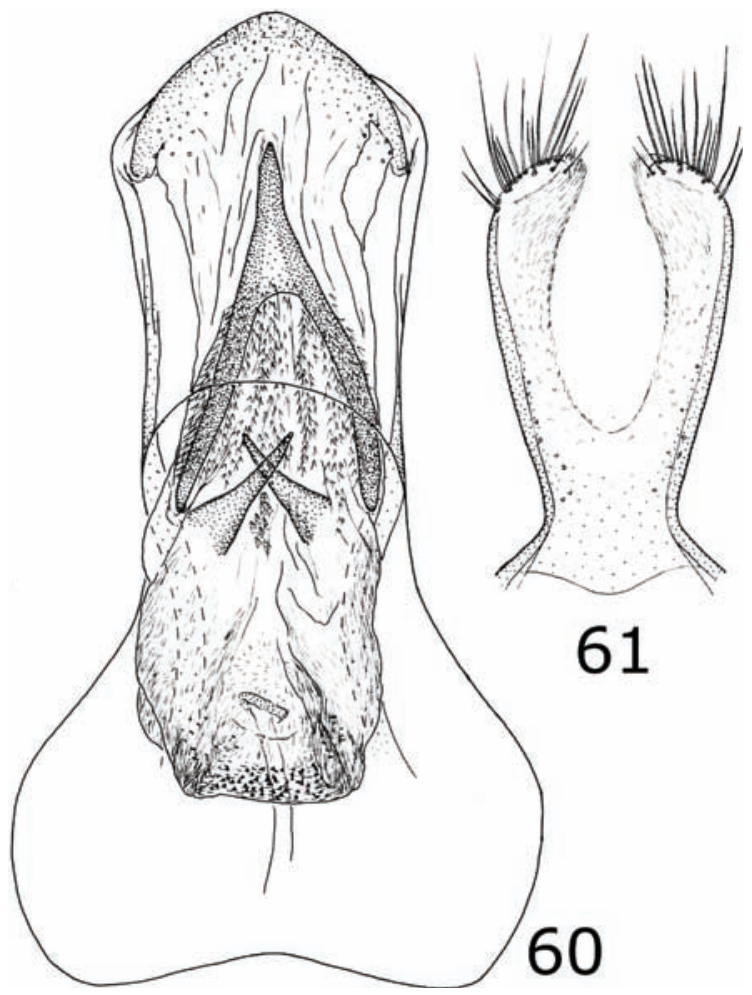

Figuras 60-61. Merobruchus columbinus, vista ventral de la genitalia del macho: 60) lóbulo medio, 61) lóbulos laterales.

(Jacq) Merrill, Det. Romero Nápoles J. 3 ind., Colecc. CEAM. Ejido las Delicias, Teapa, 20 m, $17^{\circ} 33^{\prime} 16.5$ ” N, 92 56’ 51.4” W, 16/VI/2007, Col. De La Cruz P. A., Atraido en trampa de alcohol en cacaotal, CEAM (1 ex); Ejido las Delicias, Teapa, 20 m, 17³3’16.5” N, 9256’51.4” W, 31/VIII/2007, col. De La Cruz P. A., atraido en trampa de alcohol en cacaotal, CEAM (1 ex).

Discusión. Hasta el momento la única especies de Merobruchus que ha sido registrada en Samanea saman es M. columbinus; sin embargo, si se han citado cinco especies de Stator para Centro y Sudamérica en este mismo hospedero.

\section{Merobruchus placidus (Horn), 1873}

Diagnosis. Longitud 1.8-2.8 mm, ancho 1.1-1.8 mm; integumento café-rojizo a obscuro con algunas áreas esternales amarillas; vestidura con pubescencia corta gris-amari- 
llenta, blanca-grisácea con maculas cafés en los élitros, pubescencia blanca-grisácea sobre las áreas ventrales del cuerpo y patas; escutelo cuadrado, profundamente emerginado; estrías elitrales poco profundas, estrías 3 y 4 ligeramente desviadas lateralmente de los dentículos basales; metafémur con el pecten con un diente basal grande seguido de 3 dientes más pequeños; armadura del saco interno de la genitalia del macho como en las Figs. 62-63.

Hospedero. Acacia angustissima, A. angustissima var. texensis, A. angustissima var. hirta, A. angustissima var. suffrutescens, A. genistifolia, A. goldmanii, A. hayesii, A. rosei, A. villosa. En la coleccion TAMU se encuentra un especimen colectado en Colombia (Cundinamarca 5 km SW Anapoima, 17/X/1984, Johnson C.D. col.) que fue obtenido de la leguminosa Leucaena leucocephala (Lam.) de Wit (Ex: CDJ\#354284) y constituye también un nuevo registro de hospedero. Por el número reducido de indivíduos emergidos de este hospedero se puede considerar marginal para este insecto.

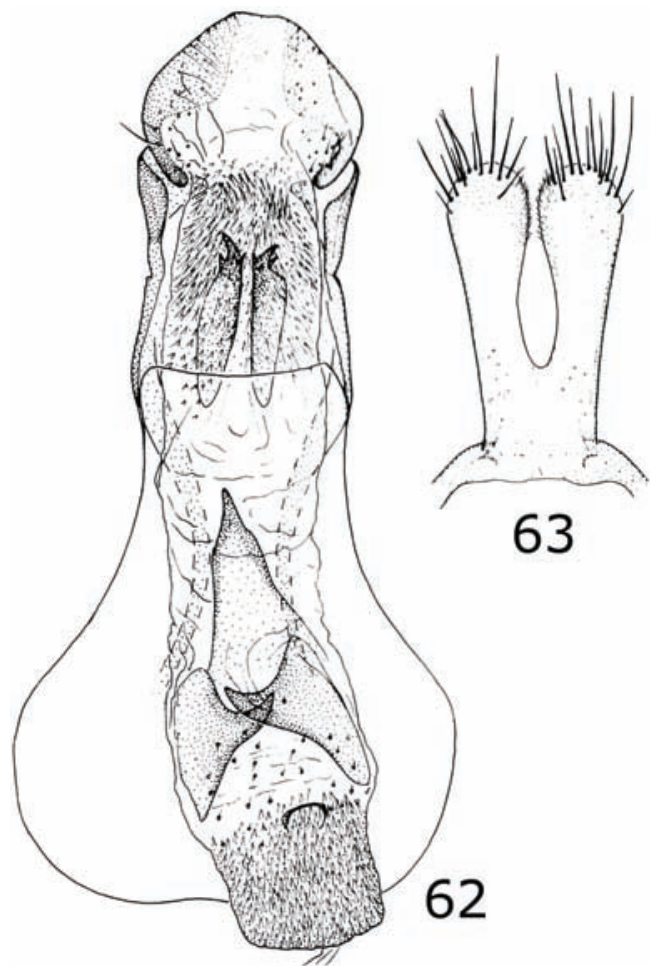

Figuras 62-63. Merobruchus placidus, vista ventral de la genitalia del macho: 62) lóbulo medio, 63) lóbulos laterales. 
Distribución. Belize, Colombia, Costa Rica, Estados Unidos, Guatemala, Honduras, México (Baja California Sur, Campeche, Chiapas, Chihuahua, Colima, Durango, Estado de México, Guanajuato, Guerrero, Jalisco, Morelos, Nayarit, Nuevo León, Oaxaca, San Luis Potosí, Sinaloa, Sonora, Tabasco, Veracruz, Yucatán) y Venezuela.

Material examinado. TABASCO. Agua Blanca, TAMU (2 ex); Agua Blanca, Macuspana, 17³7’19” N, 92²3’56” W, 7/V/2007, col. De La Cruz P. A., ex. Acaciella angustissima var. angustissima (Mill.) Kuntze, CEAM (2 ex); Ejido el Bajío 2da sección, Cárdenas, 10 m, 1758’22” N, 93²0’53” W, 28/III/2007, col. De La Cruz P. A., ex. Acaciella angustissima var. Angustissima (Mill.) Kuntze, CEAM (3 ex); La Candelaria, Agua selva, Huimanguillo, 17²19’39” N, 93³6’08” W, 13/III/2007, col. De La Cruz P. A., ex. Acaciella angustissima var. Angustissima (Mill.) Kuntze, CEAM (24 ex).

Discusión. De acuerdo con Kingsolver (1988) esta especie tiene poca variación en la morfología externa entre los especímenes colectados en Estados Unidos y Costa Rica; sin embargo, la genitalia es muy variable ya que los escleritos apicales pueden o no tener espinas accesorias y el ápice de las espinas puede ser recto o curvo; el esclerito medio siempre con la base amplia pero variable en su forma; los escleritos basales siempre con espinas grandes, pero difieren en su ápice.

\section{Merobruchus sonorensis Kingsolver, 1980}

Diagnosis. Longitud 2.9-3.5 mm, ancho 1.6-2.0 mm; la mayor parte del integumento es café rojizo, con algunas pequeñas áreas en la cabeza, pronoto y pigidio amarillo, antena amarillo rojizo con los segmentos 8-10 obscuros, patas anteriores y medias amarillo rojizo; escutelo con pubescencia densa de color blanco, pigidio con un triángulo basal de pubescencia densa blanca, estrechamente conectado con una mancha blanca media en forma de diamante; ápice del quinto esternito abdominal con una muesca ancha, con carinas laterales moderadamente prominentes; armadura del saco interno de la genitalia del macho como en las Figs. 64-65.

Hospederos. Albizia adinocephala, A. caribaea, A. lebbek, A. occidentales A. ortegae, A. tomentosa, A. sinaloenses, Acacia occidentales, Chloroleucon mangense, Ch. tenuiflorum, Havardia sonorae, Lysiloma divaricata.

Distribución. Colombia, Costa Rica, El Salvador, Honduras, México (Campeche, Chiapas, Guanajuato, Guerrero, Jalisco, Nayarit, Oaxaca, Quintana Roo, Sinaloa, Sonora, Tabasco, Veracruz) y Nicaragua. 


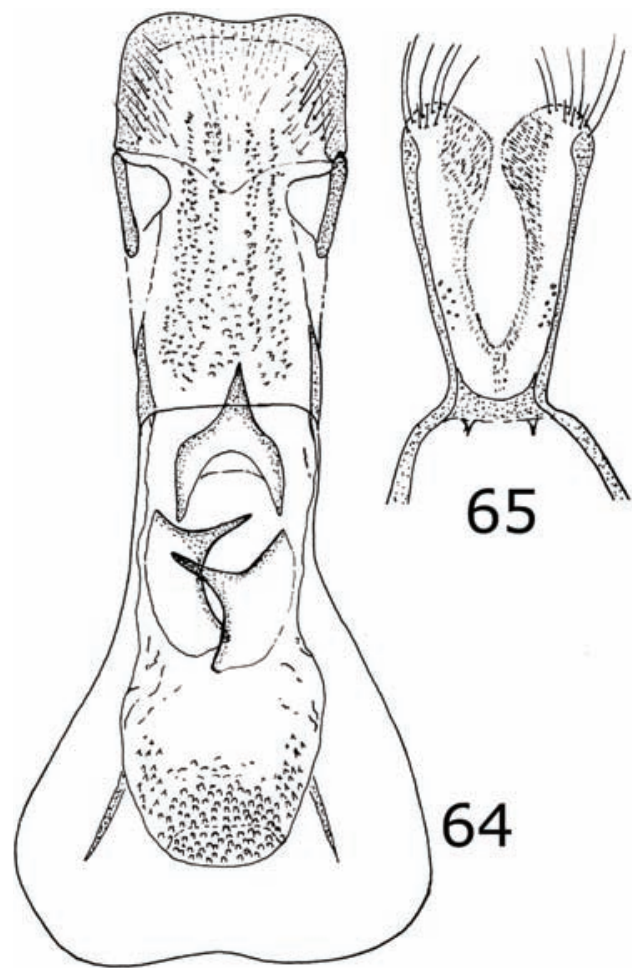

Figuras 64-65. Merobruchus sonorensis, vista ventral de la genitalia del macho: 64) lóbulo medio, 65) lóbulos laterales.

Material examinsado. TABASCO. Periférico Carlos A. Molina, Cárdenas, $10 \mathrm{~m}$, 1758’43” N, 93²3’00” W, 2/III/2007, col. De La Cruz P. A., ex. Albizia lebbeck (L.) Benth., CEAM (784 ex); Poblado C-20, Plan Chontalpa, Cárdenas, 12 m, 22/ IV/2007, col. Romero N. J., CEAM (1 ex).

Discusión. Actualmente el género Merobruchus cuenta con 26 especies, de las cuales sólo tres son citadas para este trabajo; en todos los casos las plantas hospederas del grupo son leguminosas. Dado que es un género que se encuentra principalmente en áreas xéricas de regiones tropicales y subtropicales, con toda seguridad el número de especies se incrementará en el futuro para el estado de Tabasco.

\section{Mimosestes cinerifer (Fahraeus), 1839}

Diagnosis. Longitud 3.0-3.9 mm, ancho 1.9-2.3 mm; el integumento del cuerpo varía de rojo-anaranjado a negro, aunque por lo general café rojizo, antenas con los cuatro 
segmentos basales rojo-naranja, segmentos restantes negros; vestidura de pubescencia blanca uniforme o amarillo y dorado mezclado sin formar patrones específicos; ocular sinus 0.50 a 0.66 la longitud del ancho del ojo; espinas en la base de la estría 3 y 4 fuertes, espinas en la base de la estría 5 y 6 vestigiales; metafémur con un canal profundo en la superficie ventral de 0.33 a 0.50 la longitud del metafémur; metafémur armado basalmente con una mesoventral espina grande, seguida de 2 a 4 (generalmente 3 ) espinas más pequeñas 0.33 de la longitud de la primera; armadura del saco interno de la genitalia del macho como en las Figs. 66-67.

Hospederos. Acacia cornigera, A. macracantha y A. collinsii. A. collinsii constituye un nuevo registro de hospedero para el brúquido.

Distribución. Guatemala, México (Campeche, Chiapas, Guerrero, Jalisco, Oaxaca, Puebla, Tabasco, Tamaulipas, Veracruz).

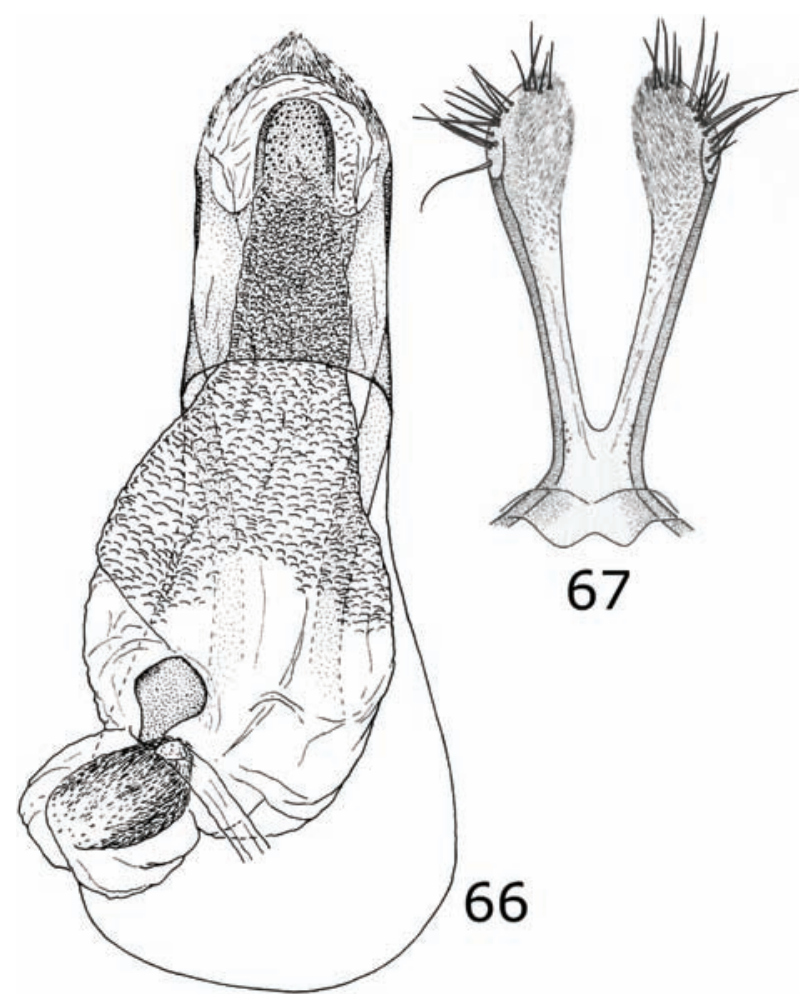

Figuras 66-67. Mimosestes cinerifer, vista ventral de la genitalia del macho: 66) lóbulo medio, 67) lóbulos laterales. 
Material examinado. TABASCO. carr. fed. El Ceibo, Tenosique; 12 m, 17¹6’34', N, 91ํㅇ'53', W, 17/VII/2007, col. De la Cruz P. A., ex. Acacia collinsii Saff, CEAM (18 ex); carr. fed. El Ceibo, Tenosique, 12 m, 17¹6’34” N, 9103’53” W, 17/VII/2007, col. De La Cruz P. A., ex. Acacia collinsii Saff., CEAM (2 ex); Ejido Miraflores Tacotalpa, 53 m, 17²7’44” N, 9241’47” W, 26/IX/2007, col. De La Cruz P.A., ex. Acacia cornigera (L.) Willd., CEAM (27 ex); Ejido Miraflores, Sierra de Tapijulapa, Tlacotalpa, 20 m, 17²7’44'’ N, 9241'47'’ W, 26/IX/2007, col. De la Cruz P. A., ex. Acacia cornigera (L.) Willd., CEAM (14 ex); Km 21 carr. fed. Cárdenas-Coatzacoalcos, Campo Exp. COLPOS, 10 m, 1759'10' N, 9135'11' ' W, 23/IX72007, col. De la Cruz P. A., ex. Acacia cornigera (L.) Willd., CEAM (3 ex); Laguna Colorada, Balancan, 1744’30'’ N, 91³1'34'’ W, 8/II/2007, col. De la Cruz P. A., ex. Acacia cornigera (L.) Willd., CEAM (9 ex).

Discusión. Según Kingsolver y Johnson (1978) esta especie es muy similar a $M$. mimosae; sin embargo, los escleritos del saco interno de la genitalia permiten separar fácilmente a estas especies.

\section{Mimosestes obscuriceps (Sharp), 1885}

Diagnosis. Longitud 3.5-4.7 mm, ancho 2.6-3.3 mm; integumento de cuerpo y apéndices variando de rojo-naranja a negro; antena con los cuatro segmentos basales rojonaranja, resto de los segmentos negros; pronoto generalmente con vestidura densa y uniforme de pubescencia amarilla, élitro ligeramente variegado de pubescencia café, amarilla y blanca; élitros con estrías profundas, punteadas, ocasionalmente los intervalos estriales con pequeñas espinas seguidas por punturas; estrías subiguales en la base, espinas débiles en la base de las estrías 3-5 y algunas veces en la estría 6; metafémur con un canal profundo en la superficie ventral de 0.50 la longitud del metafémur; metafémur armado con una espina grande subapical, tan larga como 1.33 la longitud del ancho de la base de la metatibia, seguida de 3 espinas más pequeñas 0.33 a 0.50 de la longitud de la primera espina; armadura del saco interno de la genitalia del macho como en las Figs. 68-69.

Hospedero. Acacia cornigera, A. collinsii, A. sphaerocephala.

Distribución. Honduras, México (Chiapas, Tabasco, Tamaulipas, Veracruz).

Material examinado. TABASCO. Carlos A. Madrazo, Huimanguillo, 17²2’14” N, 93³7’12” W, 19/X/2007, col. De La Cruz P. A., CEAM (1 ex); carr. fed. El Ceibo, Tenosique, 12 m, 17²16’34'” N, 9103’53'” W, 17/VII/2007, col. De la Cruz P. A., ex. Acacia collinsii Saff., CEAM (2 ex); carr. fed. El Ceibo Tenosique, 17¹6’34” N, 


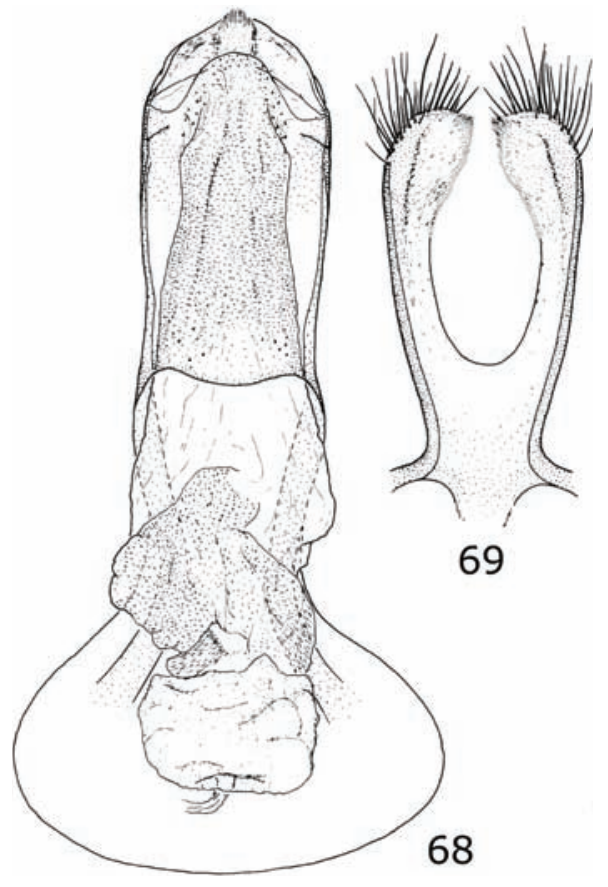

Figuras 68-69. Mimosestes obscuriceps, vista ventral de la genitalia del macho: 68) lóbulo medio, 69) lóbulos laterales.

9103’53” W, 17/VII/2007, col. De La Cruz P. A., ex. Acacia collinsii Saff., CEAM (1 ex); Ejido Miraflores Tacotalpa, 17²7’44” N, 9241’47” W, 26/IX/2007, col. De La Cruz P. A., ex. Acacia cornigera (L.) Willd., CEAM (3 ex).

Discusión. Según Romero et al. (2009) esta especie es poco abundante, debido principalmente a la competencia que existe en los hospederos que son compartidos por más de una especie de Bruchidae, tal es el caso de Acacia cornigera en donde se registraron de manera simpátrica a Acanthoscelides sauli y M. obscuriceps; sin embargo, los mismos autores indican que la planta puede ser atacada hasta por 10 especies diferentes de brúquidos de tres géneros, aunque las combinaciones entre las diferentes especies puede variar dependiendo del área geográfica y el tiempo de fructificación de la planta.

\section{Sennius auricomus Johnson \& Kingsolver, 1973}

Diagnosis. Longitud 1.6-2.5 mm, ancho 1.1-1.4 mm; integumento del protórax rojo-naranja a negro, élitros variando de negro con una pequeña mancha media ro- 
jo-naranja a élitros totalmente naranjas, mayormente negro con una mancha basal -rojo-naranja; cuerpo con pubescencia blanca y dorada o entremezclada; élitros con la estría 3 y 4 más cercana una de otra en la base que el resto; metafémur armando con una espina subapical 0.5 del ancho de la metatibia; corona tibial con tres espinulas, mucro 0.10 de la longitud del basitarso; armadura del saco interno de la genitalia del macho como en las Figs. 70-71.

Hospederos. Cassia leptocarpa, Senna galegifolia, S. holwayana, S. multijuga, S. mutisiana, Senna pallida var. quiedondilla, S. polyphylla. S. multijuga constituye un nuevo registro de hospedero para el brúquido.

Distribución. Colombia, Costa Rica, El Salvador, Guatemala, México (Guerrero, Michoacán, Morelos, Nayarit, Oaxaca, Sinaloa, Sonora, Tabasco y Yucatán) y Venezuela.

Material examinado. TABASCO. Poblado Zúnu y Patasta, Tacotalpa, 17²7’57” N, 9248’57” W, 3/IV/2007, col. De La Cruz P. A., ex. Senna multijuga (L. C. Rich) Irwin y Barneby (Leguminosae: Caesalpinioideae), CEAM (3 ex).

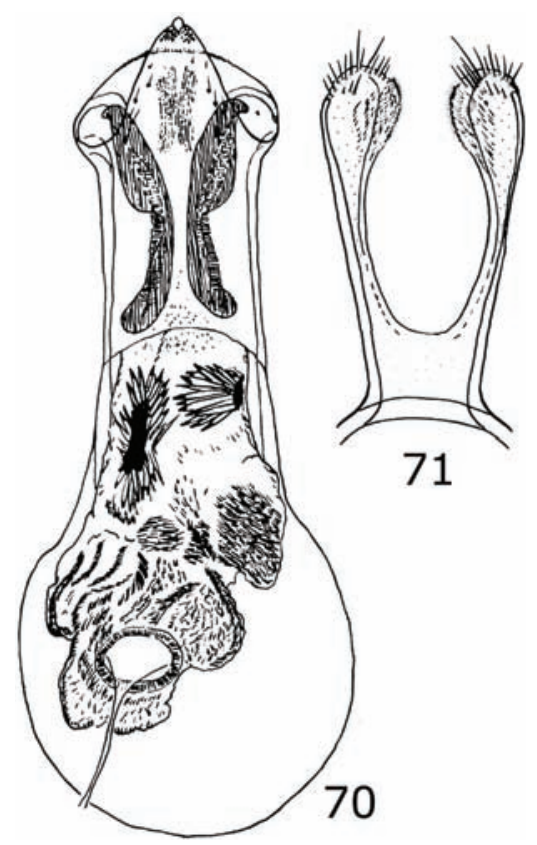

Figuras 70-71. Sennius auricomus, vista ventral de la genitalia del macho: 70) lóbulo medio, 71) lóbulos laterales. 
Discusión. Sennius es un género complicado debido a la similitud entre las especies y a la variabilidad de las mismas, también es importante indicar que muchas especies comparten hospederos, por lo que en ocasiones se torna complicado su separación; sin embargo el uso de la genitalia es indispensable para discriminar a las especies. Precisamente el epiteto genérico Sennius hace referencia a especies que se encuentran de plantas del género Senna.

\section{Sennius fallax (Boheman), 1839}

Diagnosis. Longitud 1.3-2.5 mm, ancho 0.8-1.7 mm; integumento del protórax negro, procoxa y todas las patas café claro a rojo-naranja, último tarsómero generalmente café obscuro o negro; élitro generalmente negro con una banda media rojo-naranja extendida hacia el ápice, algunas veces élitro negro con una mancha rojo-naranja en la base; cuerpo con pubescencia blanca, dorada y café o ésta entremezclada; escutelo transverso con dientes posteriores laterales; metafémur armado con una espina subapical grande 0.33 de la longitud del ancho de la base de la metatibia; corona tibial con tres o cuatro espinulas, mucro 0.16 de la longitud del basitarso; armadura del saco interno de la genitalia del macho como en las Figs. 72-73.

Hospederos. Cassia hintonii, Senna bicapsularis, S. foetidissima, S. guatemalensis var. chiapensis, S. fruticosa, S. galegifolia, S. hayesiana, S. occidentales, S. obtusifolia, S. pendula var. advena, S. polyantha, S. reticulata, S. siamea, S. Tora, S. wislizeni. En la colección TAMU se encuentra un especimen colectado en Michoacán, 16 mi. E Jiquilpan, 9/VII/1968, Johnson C.D., que fue obtenido de la leguminosa Acacia riparia Kunth (Ex: CDJ\#256-68) y constituye un nuevo registro de hospedero; por el número reducido de indivíduos emergidos de este hospedero se puede considerar marginal para este insecto.

Distribución. Cuba, Estados Unidos, Guatemala, Honduras, Jamaica, México (Chiapas, Colima, Estado de México, Guanajuato, Guerrero, Hidalgo, Jalisco, Michoacán, Nayarit, Oaxaca, San Luis Potosí, Sinaloa, Tabasco y Veracruz) y Panamá.

Material examinado. TABASCO. Aquiles Serdán, Paraíso, 4/VI/2007, 18²4’46” N, 9300’47” W, col. De La Cruz P. A., ex. Senna occidentalis (L.) Link (Leguminosae: Caesalpinioideae), CEAM (309 ex).

Discusión. Comentario indicado en Sennius auricomus.

\section{Sennius guttifer (Sharp), 1885}

Diagnosis. Longitud 1.9-2.7 mm, ancho 1.3-2.0 mm; integumento del protórax generalmente rojo-naranja con márgenes laterales negros; élitro uniformemente ro- 


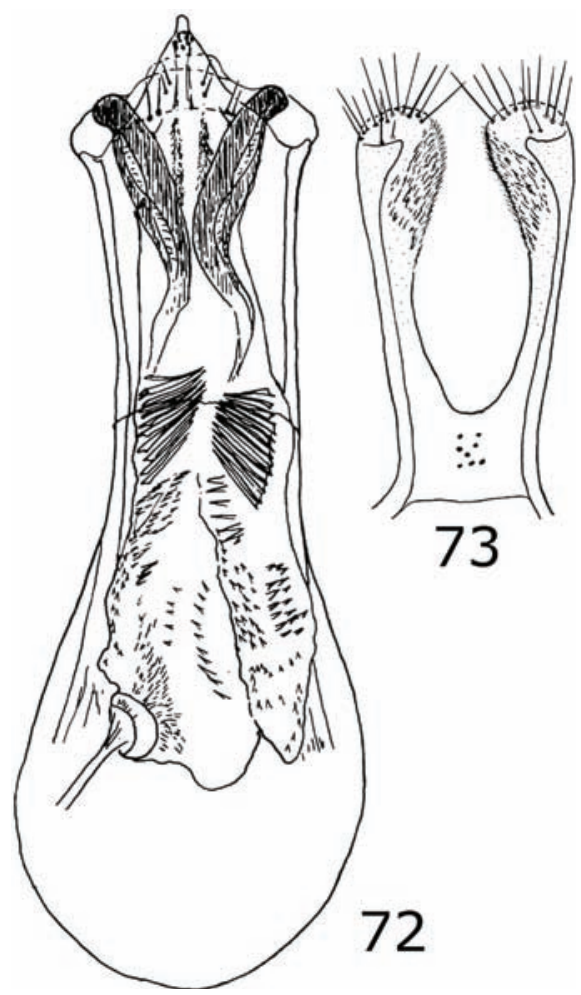

Figuras 72-73. Sennius fallax, vista ventral de la genitalia del macho: 72) lóbulo medio, 73) lóbulos laterales.

jo-naranja, café rojizo, ocasionalmente café obscuro, patas y pigidio generalmente rojo-naranja; vestidura del cuerpo con pubescencia blanca y dorada, algunas veces se presentan péqueñas manchas de pubescencia densa blanca en la base de los élitros; estrías 2-3 y 4-5 más cercanas unas de otras en la base que las estrías adyacentes, con una espina pequeña en la base de la estría 2, 3, 4 y a veces en la 5; metafémur armado con una espina subapical grande de longitud similar al ancho de la base de la metatibia o ligeramente más pequeña, la espina con el margen posterior con una a tres serrulaciones; corona tibial con tres espinulas; mucro más largo que las espinulas, 0.10 de la longitud del basitarso; armadura del saco interno de la genitalia del macho como en las Figs. 74-75.

Hospederos. Cassia sp., Senna bicapsularis, S. nicaraguensis, S. pendula var. advena. 


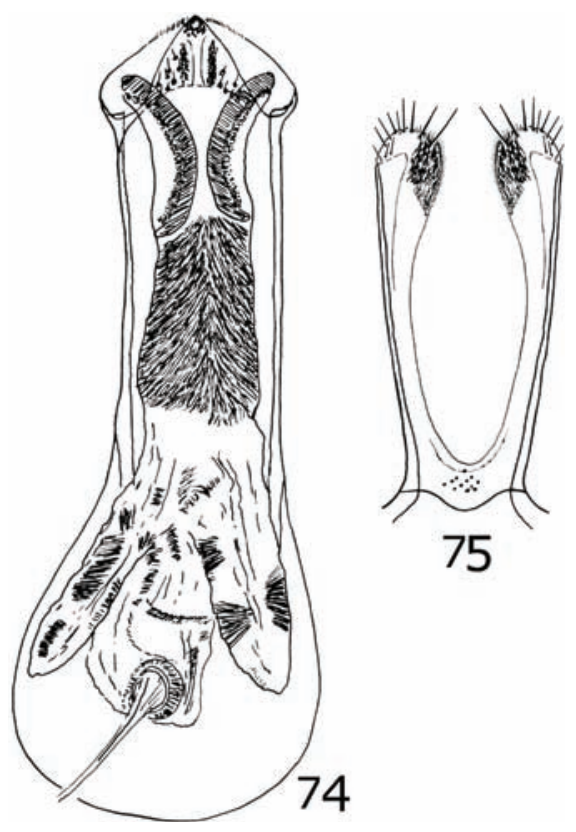

Figuras 74-75. Sennius guttifer, vista ventral de la genitalia del macho: 74) lóbulo medio, 75) lóbulos laterales.

Distribución. Belice, Guatemala y México (Campeche, Chiapas, Campeche, Jalisco, Oaxaca, Sinaloa y Veracruz).

Material examinado. TABASCO. Pozo Costero 24, Frontera, Centro, 1/IV/2009, UTM X-552474, Y-2059548, col. Pérez De La C. M., ex. Senna bicapsularis (L.) Roxb., CEAM (25 ex).

Discusión. Comentario indicado en Sennius auricomus.

\section{Sennius lebasi (Fähraeus), 1839}

Diagnosis. Longitud 1.5-2.8 mm, ancho 0.9-1.9 mm; integumento de los élitros variando de café a negro con una banda media que llega a los márgenes laterales, ocacionalmente alcanza la estría 3 medialmente; pigidio rojo-naranja a negro; vestidura del cuerpo con pubescencia blanca y dorada mezclada; élitro con una banda densa de pubescencia blanca cubriendo la banda roja; estrías 3 y 4 más cercana una de otras en la base que las estrías adyacentes; metafémur armado con una espina subapical grande con una longitud similar al ancho de la base de la metatibia; corona tibial con 
tres espinulas, mucro 0.12 de la longitud del basitarso; armadura del saco interno de la genitalia del macho como en las Figs. 76-77.

Hospedero. Cassia leptocarpa, Senna bicapsularis, S. cobanensis, S. hirsuta var. leptocarpa, S. occidentalis, S. obtusifolia, S. pendula var. advena, S. septemtrionalis, S. sophera, S. uniflora, Sesbania herbacea.

Distribución. Belice, Brasil, Colombia, Chile, Costa Rica, El Salvador, Estados Unidos, Guatemala, Honduras, México (Campeche, Chiapas, Colima, Guanajuato, Guerrero, Jalisco, Michoacán, Morelos, Nayarit, Oaxaca, Puebla, Querétaro, San Luis Potosí, Sinaloa, Sonora, Tabasco, Veracruz y Yucatán), Nicaragua, Panamá, Trinidad \& Tobago y Venezuela.

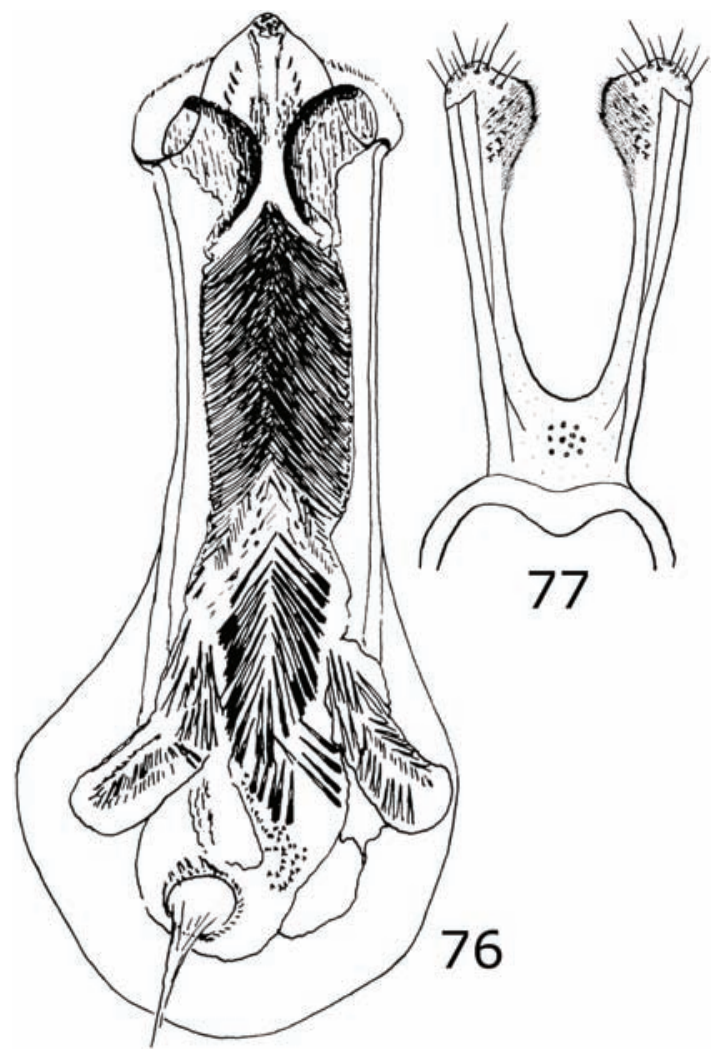

Figuras 76-77. Sennius lebasi, vista ventral de la genitalia del macho: 76) lóbulo medio, 77) lóbulos laterales. 
Material examinado. TABASCO. Boulevar, al lado de Aurrerá, Teapa, 26/IX/2007, 17³3’16.5” N, 9256’51.4” W, 42 m, col. De La Cruz P. A., ex. Senna occidentalis (L.) Link., CEAM (12 ex).

Discusión. Comentario indicado en Sennius auricomus.

\section{Sennius morosus (Sharp), 1885}

Diagnosis. Longitud 1.3-2.6 mm, ancho 0.9-1.7 mm; integumento del protórax negro, patas usualmente rojo-naranja excepto la base del metafémur que es negra, antena con todos los segmentos rojo naranja o negros, algunas veces el segmento apical de color más claro que el resto de los segmentos; vestidura del cuerpo de pubescencia blanca y dorada mezclada o amarillenta; estrías 3 y 4 más cercana una de otras en la base que las estrías adyacentes; metafémur armado con una espina subapical grande con una longitud similar al ancho de la base de la metatibia, margen posterior de la espina generalmente crenulado o serrado; corona tibial con cuatro espinulas, mucro 0.16 de la longitud del basitarso o menor; armadura del saco interno de la genitalia del macho como en las Figs. 78-79.

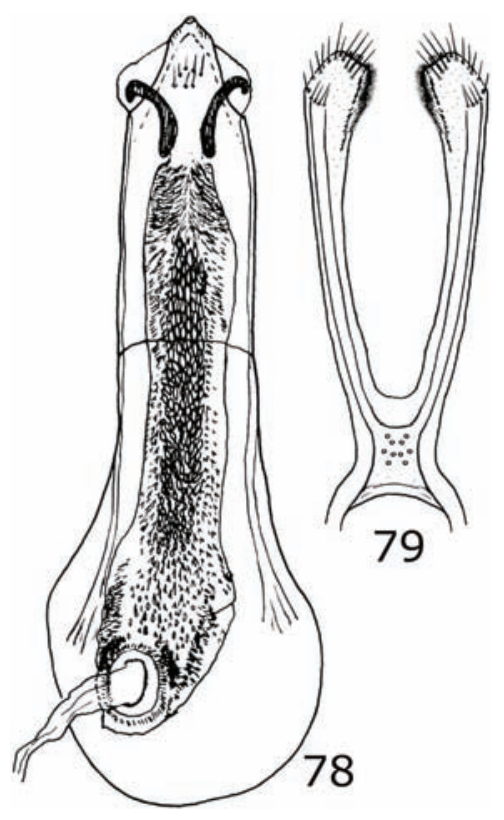

Figuras 78-79. Sennius morosus, vista ventral de la genitalia del macho: 78) lóbulo medio, 79) lóbulos laterales. 
Hospederos. Cassia leptocarpa, Lysiloma acapulcense, Senna bauhinioides, S. covesii, S. durangensis, S. hirsuta var. leptocarpa, S. obtusifolia, S. polyphylla, S. roemeriana, S. uniflora, S. villosa, S. wislizeni. L. acapulcense y S. wislizeni constituyen nuevos registros de hospedero para el brúquido.

Distribución. Colombia, Costa Rica, El Salvador, Estados Unidos, Guatemala, Honduras, México (Campeche, Chiapas, Chihuahua, Coahuila, Colima, Durango, Estado de México, Guerrero, Hidalgo, Jalisco, Michoacán, Morelos, Nayarit, Nuevo León, Oaxaca, Puebla, Quintana Roo, San Luis Potosí, Sinaloa, Sonora, Tabasco, Tamaulipas, Veracruz y Yucatán), Nicaragua, Panamá y Taboga.

Material examinado. TABASCO. Pichucalco a $6 \mathrm{~km}$ de Teapa, Villahermosa, 6/ IV/1985, Vertiz M., (CNIN 1ex).

Discusión. Comentario indicado en Sennius auricomus.

\section{Sennius rufomaculatus (Motschulsky), 1874}

Diagnosis. Longitud 1.5-2.4 mm, ancho 1.0-1.6 mm; integumento del protórax, procoxa, área ventral y pigidio negros; élitros negros con una mancha rojo-naranja del tamaño de la mitad del élitro y se extiende de la estría 2 a la 9, ocasionalmente los élitros completamente negros o rojo-naranja; vestidura del cuerpo de pubescencia blanca, café y dorada; estrías 3 y 4 más cercana una de otras en la base que las estrías adyacentes; metafémur armado con una espina subapical grande con una longitud similar al ancho de la base de la metatibia o más pequeña; corona tibial con tres espinulas, mucro 0.16 de la longitud del basitarso o menor; armadura del saco interno de la genitalia del macho como en las Figs. 80-81.

Hospederos. Cassia leptocarpa, Senna alata, S. bicapsularis, S. cobanensis, S. galegifolia, S. hirsuta var. leptocarpa, S. hirsuta var. hirta, S. obtusifolia, S. occidentalis, S. polyphylla, S. uniflora.

Distribución. Colombia, Costa Rica, El Salvador, Granada, Guadalupe, Guatemala, Honduras, Hispaniola, Jamaica, México (Chiapas, Chihuahua, Colima, Durango, Guanajuato, Guerrero, Jalisco Michoacán, Morelos, Nayarit, Oaxaca, Puebla, San Luis Potosí, Sinaloa, Sonora, Tabasco, Tamaulipas, Veracruz, Yucatán y Zacatecas), Nicaragua, Panamá, Puerto Rico, República Dominicana, San Vicente y Las Granadinas, Trinidad \& Tobago y Venezuela.

Material examinado. TABASCO. Boulevard al lado de Aurrerá, Teapa, 26/IX/2007, 17³3’16.5” N, 9256’51.4” W, 42 m, col. De La Cruz P. A., CEAM (17 ex).

Discusión. Comentario indicado en Sennius auricomus. 


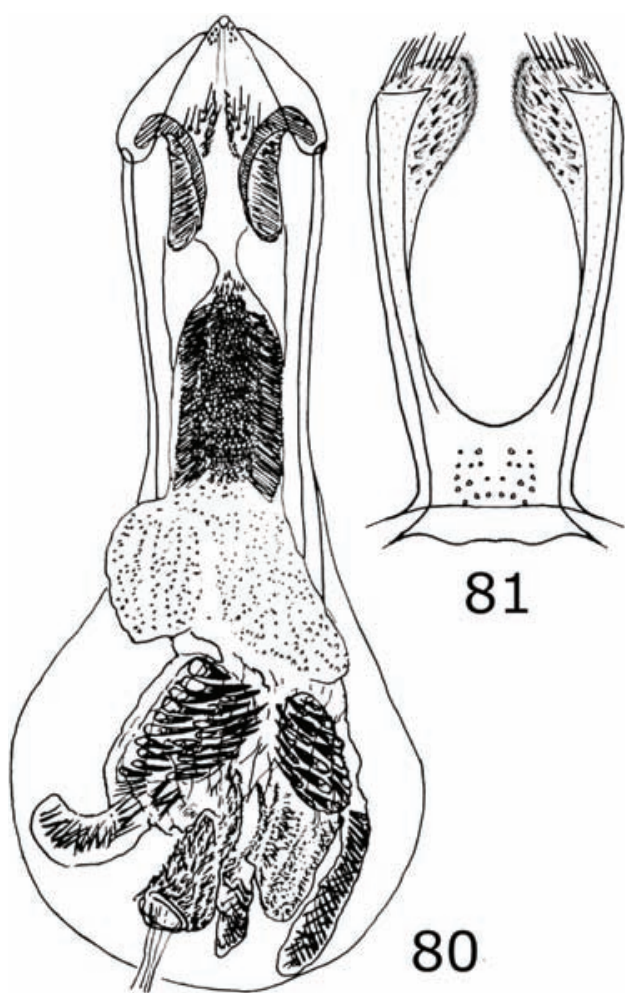

Figuras 80-81. Sennius rufomaculatus, vista ventral de la genitalia del macho: 80) lóbulo medio, 81) lóbulos laterales.

\section{Sennius trinotaticollis (Pic), 1930}

Diagnosis. Longitud 1.8-2.4 mm, ancho 1.5-1.7 mm; integumento del protórax negro, aunque algunas veces puede ser café rojizo; procoxa y patas generalmente rojo naranja, aunque pueden presentarse rojo obscuro; dos quintos de la parte basal de los élitros rojo naranja, excepto húmeros y área entre la estría 3 y margen medio café claro o café, intervalos entre la estria 1 y 2 rojo naranja casi hasta el ápice de los élitros; vestidura del cuerpo de pubescencia blanca, café y dorada; estría 2 con punturas profundas en la base; estrías 3 y 4 más cercana una de otras en la base que las estrías adyacentes, algunas veces estría 2 muy cerca de la estría 3, esta última con una espina pequeña en la base; metafémur armado con una espina subapical grande 1.33 veces la longitud del ancho de la base de la metatibia, margen posterior de la espina serrulado; corona tibial con tres espinulas, mucro 0.16 de la longitud del basitarso; armadura del saco interno de la genitalia del macho como en las Figs. 82-83. 


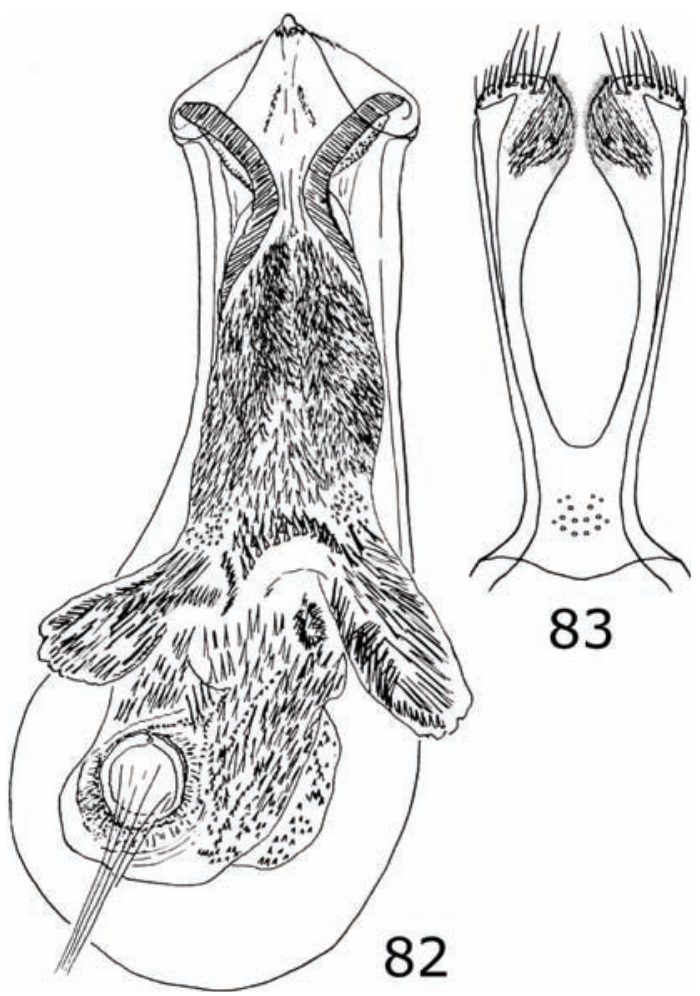

Figuras 82-83. Sennius trinotaticollis, vista ventral de la genitalia del macho: 22) lóbulo medio, 83) lóbulos laterales.

Hospederos. Senna hayesiana, S. oxyphylla.

Distribución. Colombia, Costa Rica, Guatemala, México (Tabasco), Panamá, Trinidad y Venezuela.

Material examinado. TABASCO. Villa Ocuilatzapotla R/A Miramar, 1/II/1994, Niño S. \& J.A. Castro, CEAM (1 ex).

Discusión. Comentario indicado en Sennius auricomus.

Stator limbatus (Horn), 1873

Diagnosis. Longitud 1.6-2.7 mm, ancho 1.1-2.0 mm; integumento de los élitros variando de completamente anaranjados a negros con manchas naranjadas en la porción 
apical y basal, el resto del cuerpo puede variar entre negro y naranja; cuerpo cubierto por pubecencia blanca moderadamente densa; estrías elitrales profundas y punteadas, intervalos estriales punteados, estría 3-4 y 5-6 más cercanas unas de otras en la base que las estrías adyacentes; estrías 3-6 algunas veces abreviadas en la base; metfémur armada con una espina subapical grande, con una longitud similar al ancho de la base de la metatibia; armadura del saco interno de la genitalia del macho como en las Figs. 84-85.

Hospederos. Acacia acatlensis, A. angustissima, A. adinocephala, A. angustissima, A. baileyana, A. berlandieri, A. confusa, A. coulteri, A. cultriformis, A. farnesiana, A. furcatispina, A. gaumeri, A. greggii, A. glomerosa, A. goldmanii, A. greggii, A. koa, A. macmurphyi, A. melanoxylon, A. millefolia, A. picachensis, A. polyphylla, A. occidentales, A. retinodes, A. retusa, A. riparia, A. roemeriana; A. tenuifolia, A. willardiana, A. wrightii, Albizia adinocephala, A. caribaea, A. chinensis, A. guacha-

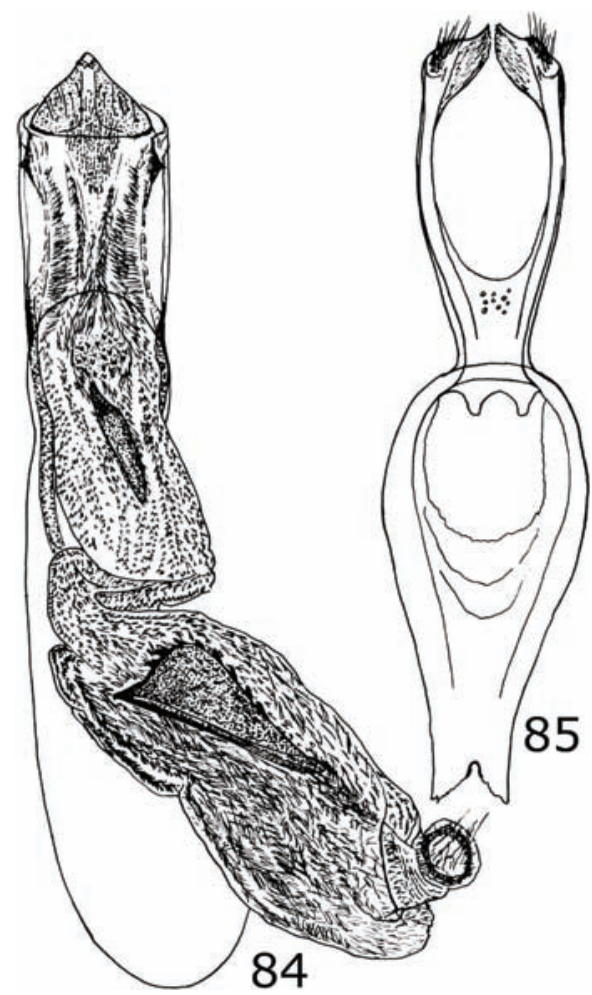

Figuras 84-85. Stator limbatus, vista ventral de la genitalia del macho: 84) lóbulo medio, 85) lóbulos laterales. 
pele, A. lebbek, A. niopoides var. niopoides, A. plurijuga, A. sinaloensis, Calliandra houstoniana, Cercidium floridum, C. microphyllum, C. torreyanum, Chloroleucon tenuiflorum, Ebenopsis confinis, Havardia acatlensis, $H$. mexicana, $H$. pallens, $H$. sonorae, Leucaena leucocephala, L. pulverulenta, L. trichandra, Lysiloma acapulcense, L. divaricata, L. latisiliquum, L. microphyllum, L. tergeminum, Parkinsonia aculeata, P. praecox, P. texana var. macra, Pithecellobium brevifolium, P. dulce, P. excelsum, $P$. flexicaulis, $P$. fragrans, $P$. oblongum, Piptadenia flava, Pseudopiptadenia inaequalis, Samanea saman, Sesbania sp. Sphinga platyloba.

Distribución. Antillas, Argentina, Brasil, Colombia, Costa Rica, Curacao, Ecuador, Granada, Guatemala, El Salvador, Estados Unidos, Honduras, Jamaica, México (Baja California Sur, Campeche, Coahuila, Chiapas, Chihuahua, Colima, Guanajuato, Guerrero, Hidalgo, Jalisco, Michoacán, Morelos, Nayarit, Nuevo León, Oaxaca, Puebla, Querétaro, Quintana Roo, San Luis Potosí, Sinaloa, Sonora, Tabasco, Tamaulipas, Veracruz y Yucatán), Nicaragua, Panamá, Perú, San Vicente y Las Granadinas, Trinidad \& Tobago, Uruguay y Venezuela.

Material examinado. TABASCO. Ra. José Ma. Morelos y Pavón, Teapa, 26/ IX/2007, 1759’23” N, 93³7’09” W, 20 m, col. De La Cruz P. A., ex. Albizia lebbeck, CEAM (15 ex).

Discusión. S. limbatus es la especie más polífaga en el género y la más ampliamente distribuida. El trabajo elaborado por Morse y Farrell (2005) nos brinda un excelente explicación sobre los procesos de especiación en el grupo y como esta especie dio origen a su especie hermana S. geali.

\section{Stator subaeneus (Schaeffer), 1907}

Diagnosis. Longitud 2.4-2.8 mm, ancho 1.8-2.0 mm; integumento del cuerpo totalmente negro, excepto patas anteriores, medias y antenas anaranjadas; vestidura de color cobre, con setas blancas en bandas irregulares y manchas sobre pronoto y élitros; margen caudal y dorsal de los ojos contiguos con el vertex y lados de la cabeza; la antena se extiende a la mitad del metepisterno; metacoxa uniformemente punteada; metafémur armado con una espina subapical grande, con una longitud similar al ancho de la base de la metatibia; armadura del saco interno de la genitalia del macho como en las Figs. 86-87.

Hospederos. Acacia collinsii, A. cornigera, A. farnesiana.

Distribución. Colombia, Honduras, Estados Unidos, México (Chiapas, Oaxaca, Puebla, San Luis Potosí, Tabasco, Tamaulipas, Veracruz, y Yucatán). 


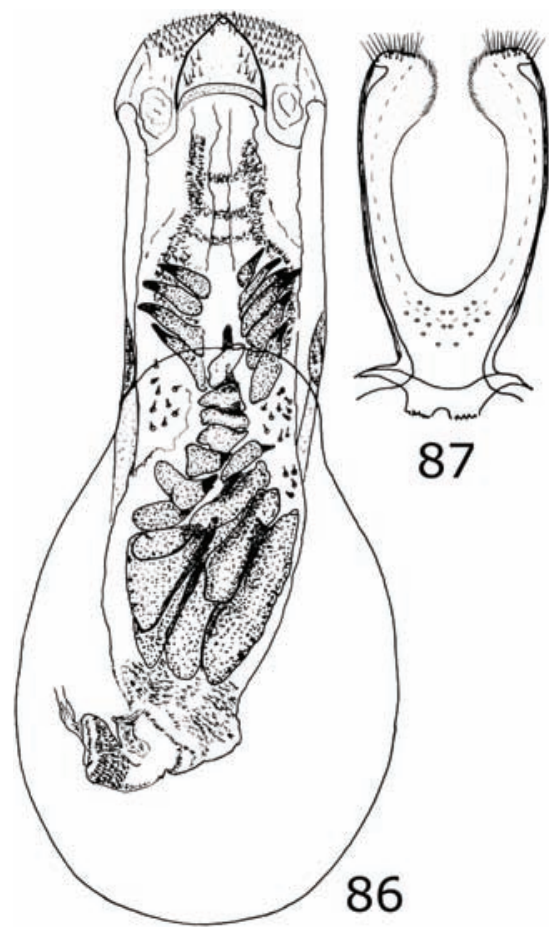

Figuras 86-87. Stator subaeneus, vista ventral de la genitalia del macho: 86) lóbulo medio, 87) lóbulos laterales.

Material examinado. TABASCO. Carr. El Ceibo Tenosique, 17/VII/2007, 17²16’34” N, 9103’53” W, 12 m, col. De La Cruz P. A., ex. Acacia cornigera (L.) Willd. CEAM (1 ex); carr. El Ceibo Tenosique, 17/VII/2007, 17²16’34” N, 9103’ 53” W, 12 m, col. De La Cruz P. A., ex. Acacia collinsii Saff, CEAM (3 ex); Laguna Colorada, Balancan, 8/II/2007, 1744’30’' N, 91³1'34’’ W, Col. De la Cruz P. A., Acacia cornigera (L.) Willd, CEAM (8 ex).

Discusión. De acuerdo con Johnson y Kingsolver (1976) S. subaeneus pertenece al grupo Subaeneus, junto con las especies $S$. mexicanus, $S$. chalcodermus y S. bottimeri; difícil de separar de las dos primeras, en contraste con $B$. bottimeri que presenta el metafémur anaranjado y se puede identificar con mayor facilidad.

\section{Stator vachelliae Bottimer, 1973}

Diagnosis. Longitud 2.0-2.8 mm, ancho 1.4-1.9 mm; integumento del cuerpo totalmente negro, excepto los cuatro segmentos antenas basales, patas anteriores y medias, 
y 0.2 de las patas posteriores que son anaranjado; vestidura de pronoto y élitros con pubescencia amarilla y matizada con pubescencia café y gris; metasterno densamente punteado, con punturas grandes y conspicuas lateralmente; metacoxa uniformemente punteada; metafémur armada con una espina subapical grande, con una longitud ligeramente más ancha que la base de la metatibia; carina lateroventral emerginada apicalmente y con una angulación roma; armadura del saco interno de la genitalia del macho como en las Figs. 88-89.

Hospederos. Acacia cochliacantha, A. collinsii, A. farnesiana, A. macracantha, A. pennatula, A. roemeriana, A. tortuosa, Mimosa arenosa, Parkinsonia aculeata, Samanea saman.

Distribución. Brasil, Colombia, Costa Rica, El Salvador, Estados Unidos, Honduras, México (Aguascalientes, Baja California Sur, Chiapas, Coahuila, Colima, Durango,

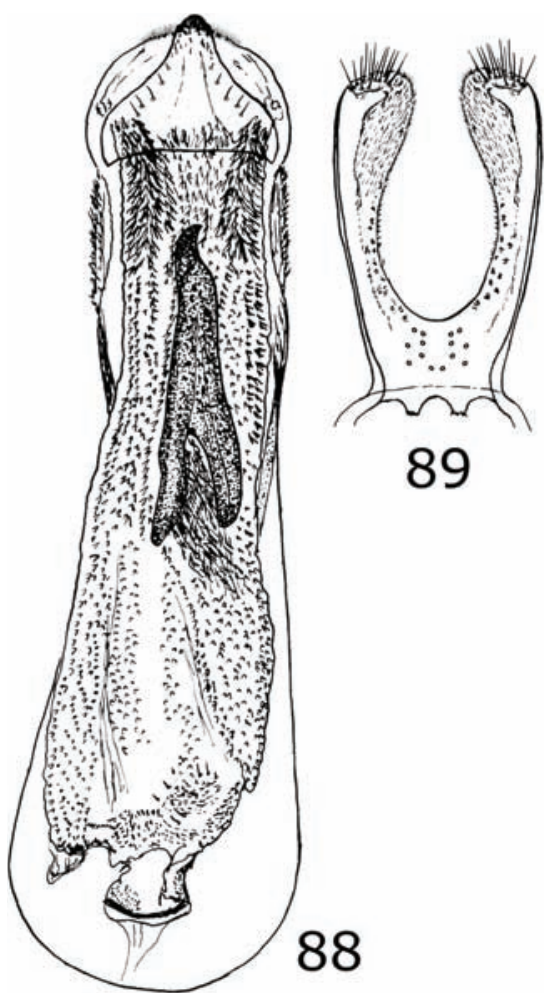

Figuras 88-89. Stator vachelliae, vista ventral de la genitalia del macho: 88) lóbulo medio, 89) lóbulos laterales. 
Estado de México, Guanajuato, Guerrero, Hidalgo, Jalisco, Michoacán, Morelos, Nayarit, Nuevo León, Oaxaca, Puebla, Querétaro, Sinaloa, Sonora, Tabasco, Tamaulipas y Veracruz), Nicaragua, Panamá y Venezuela.

Material examinado. TABASCO. Ocotlán, (Macuspana), col. Weld L.H., CAS (1 ex).

Discusión. De acuerdo con Johnson y Kingsolver (1976) S. vachelliae se encuentra en el grupo Sordidus junto con S. chihuahua, S. coconino, S. pygidialis y S. sordidus; sin embargo, $S$. vachelliae es fácil separarla de las otras especies debido a que presenta la metacoxa totalmente punteada, además de sus características específicas de la genitalia.

\section{TRIBU BRUCHIDIINI}

\section{Callosobruchus maculatus (Fabricius), 1775}

Diagnosis de formas normales o no voladoras. Longitud 2.7-3.1 mm, ancho 1.5-1.9 $\mathrm{mm}$; integumento de la cabeza negro, con una mancha rojiza atrás de los ojos, antena mayormente rojo oscuro, pronoto amarillento con márgenes rojizos, élitro rojo con una pequeña mácula sobre el húmero y margen lateral, patas amarillo rojizo; vestidura amarillenta sobre la superficie dorsal, área ventral con pubescencia blanca, lóbulo basal del pronoto con una mancha blanca densa, pigidio con una linea media blanca; machos con antenas pectinadas y en la hembras serradas; pronoto convexo con el lóbulo basal prominente y surcado mesalmente; escutelo diminuto y lobulado; estría 3 y 4 con una gibosidad basal; margen ventral del metafémur surcado con la carina ventrolateral y ventromesal dentada; armadura del saco interno de la genitalia del macho como en las Figs. 90-91.

Diagnosis de formas anormales o voladoras. Longitud y anchura similar a las formas normales; en general estos especímenes se parecen mucho a la forma normal, excepto el color del integumento del área ventral que es más obscuro, los ocho o nueve segmentos antenales distales amarillentos, patas posteriores amarillentas con el margen dorsal café amarillento, patas anteriores y medio amarillentas y la mácula del élitros es más grande; la armadura del saco interno de la genitalia del macho tiene una variante y se ilustra en las Figs. 92-93.

Hospederos. Acacia nilotica, Cajanus cajan, Cicer arietinum, Dolichos biflorus, $D$. lablab, D. monachalis, Glycine max, Lablab niger, L. purpureus, Lathyrus aphaca, L. clymenum, L. odoratus, L. sativus, Lens culinaris, Phaseolus acutifolius, P. au- 


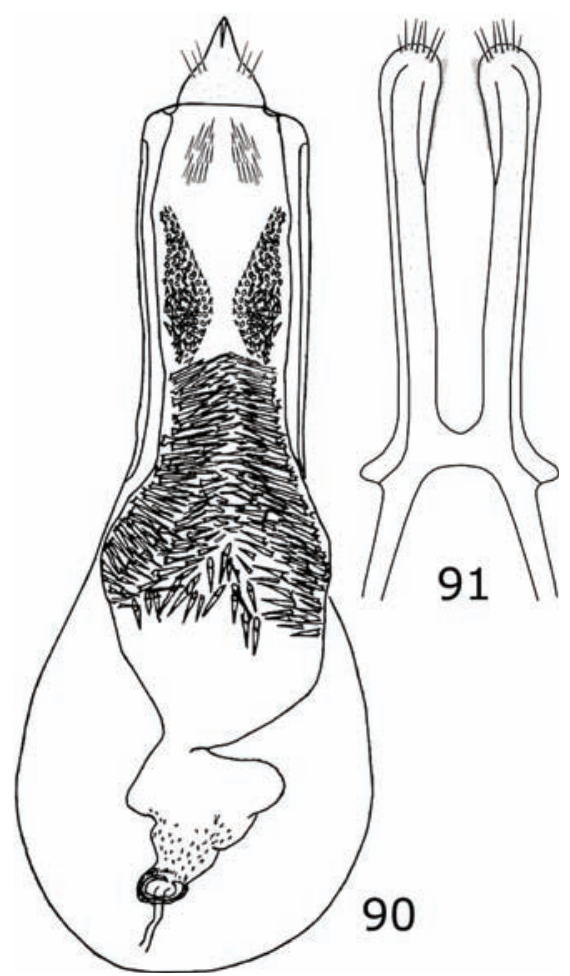

Figuras 90-91. Callosobruchus maculatus, vista ventral de la genitalia del macho de la forma normal: 90) lóbulo medio, 91) lóbulos laterales.

reus, P. lunatus, P. mungo, P. vulgaris, Pisum sativum, Pueraria lobata, Sphenostylis stenocarpa, Vicia ervilia, V. faba, V. lutea, V. sativa, Vigna angularis, V. luteola, V. radiata, $V$. subterranea, $V$. umbellata, $V$. unguiculata. Esta especie tiene la habilidad de infestar y reinfestar muchas especies de granos almacenados y ocasionar grandes pérdiadas en éstos; en México sólo se le ha registrado en Cicer arietinum y Vigna unguiculata subsp. unguiculata.

Distribución. Se trata de una especie cosmopolita, originaria del continente Africano (Southgate 1964).

Material examinado. TABASCO. Cárdenas, 21/VI/2007, col. De La Cruz P. A., ex. Vigna sp. (Leguminosae: Papilionoideae), CEAM (186 ex); Ejido las Delicias, Ranchería José Ma. Morelos y Pavón, Teapa, 29/IX/2007, 1759’23” N, 93³7’09” W, 20 m, col. De La Cruz P. A., Vigna sp., CEAM (6 ex); Teapa, 29/IX/2007, 17³3’16.5” N, 9256’51.4” W, 20 m, col. De La Cruz P. A., ex. Vigna sp., CEAM (2 ex). 


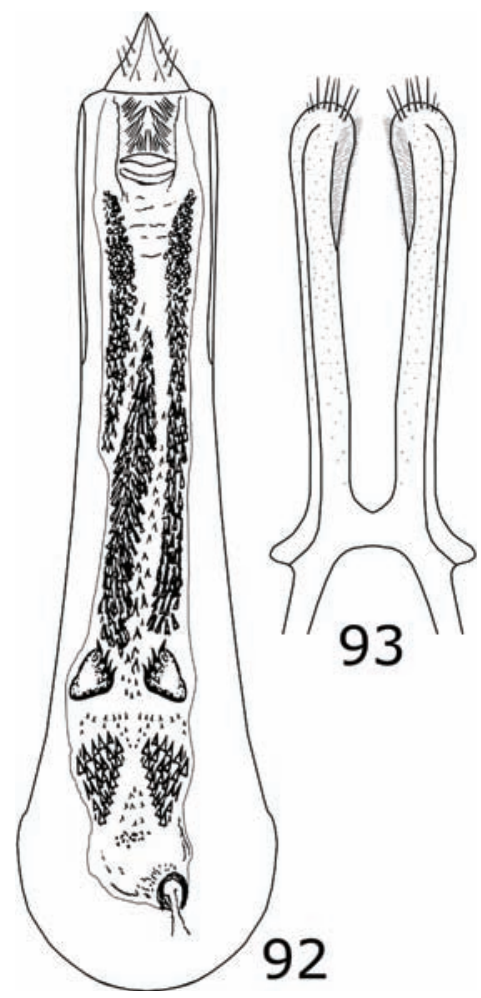

Figuras 92-93. Callosobruchus maculatus, vista ventral de la genitalia del macho de la forma anormal: 92) lóbulo medio, 93) lóbulos laterales.

Discusión. Las formas normales presentan alas y son capaces de volar pero prefieren permanecer en el substrato de las semillas en relativa obscuridad; sin embargo, una alta infestación por lo general resulta en una sobrepoblación en un granero y debido al incremento en la temperatura ocasionado por la actividad metabólica larvaria, se dispara un mecanismo a través del cual aparecen las formas anormales que son voladoras y que buscan la luz. Las hembras voladoras tienen un peso menor y sus ovariolas están pobremente desarrolladas y sus abdómenes están llenos de grasa y posteriormente desarrollan pocos huevos fértiles; por otro lado los testículos de los machos voladores también son inmaduros después de la emergencia, pero gradualmente se transforman en individuos fértiles (Kingsolver 2004). Los términos "forma voladora” y "forma no voladora” fueron utilizados por primera vez por Utida (1954, 1981); en tanto que los términos "normal” y "activa” o anormal fueron utilizados por Caswell (1960). 


\section{TRIBU MEGACERINI}

\section{Megacerus alabani Teran \& Kingsolver, 1977}

Diagnosis. Longitud $3.0 \mathrm{~mm}$, ancho $2.0 \mathrm{~mm}$; integumento negro, moderadamente brillante; vestidura en el lóbulo basal y ángulos posteriores del pronoto, escutelo, una pequeña mancha en la mitad de la primera interestría del élitro, mesoepímero, metasternon uroesternitos y pigidio con densa pubescencia blanca; élitros con estrías profundamente marcadas, intervalos estriales punteados, ligeramente rugoso y sinuosos, primer intervalo dilatado en su parte media; metatibia con mucro largo; armadura del saco interno de la genitalia del macho como en las Figs. 94-95.

Hospedero. Ipomoea seducta. Esta planta es el primer registro para este brúquido, además es la primera vez que se documenta la asociación de la planta con este grupo de insectos.

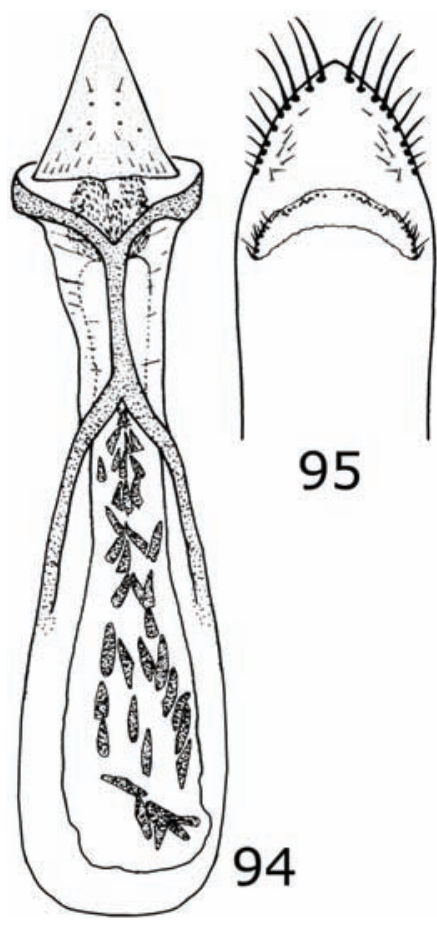

Figuras 94-95. Megacerus alabani, vista ventral de la genitalia del macho: 94) lóbulo medio, 95) lóbulos laterales. 
Distribución. México (Colima, Morelos, Nayarit, Oaxaca, Oaxaca, Quintna Roo, Tabasco).

Material examinado: TABASCO. 1 km de Zúnu y Patasta, Tacotalpa, 3/IV/2007, 17²7’57’ N, 9248’57’ W, col. De La Cruz P. A., ex. Ipomoea seducta House, Convolvulaceae, CEAM (1 ex); Agua Blanca Macuspana, 7/V/2007, 17³7’19” N, 92²7’56” W, col. De La Cruz P. A., CEAM (37 ex).

Discusión. M. alabani es una especie rara, muy poco representada en las colecciones, debido principalmente a que no se le conocían sus planta hospedras, hasta el momento es una especie endémica de México.

\section{Megacerus cubiculus (Casey), 1884}

Diagnosis. Longitud 1.5-2.5 mm, ancho 0.8-1.7 mm; integumento de la cabeza negro, protórax rojo con manchas negras, élitros rojos con algunas manchas negras, aunque la coloración puede tener una amplia variabilidad; vestidura de pubescencia amarilla y blanca en diferentes densidades en el cuerpo; ojos casi contiguos, con carina frontal ocupando la totalidad del espacio interocular; escotadura ocular llegando hasta la mitad de la longitud del ojo; élitros con húmeros no tan salientes, sin aspecto constreñido detrás del área humeral; sexto intervalo elitral de la misma anchura en toda su longitud; en vista lateral los élitros no sobrepasan al abdomen; ancho máximo del metafémur sensiblemente mayor que la mitad del ancho de la metacoxa; armadura del saco interno de la genitalia del macho como en las Figs. 96-97.

Hospederos. Convolvulus sp., Ipomoea batatas, I. cordatotriloba, I. cholulensis, I. hederifolia, I. incarnata, I. lacunosa, I. nil, I. purpurea, I. trifida, I. triloba, Merremia aegyptia, $M$. cissoides, $M$. quinquefolia. I. cholulensis es un nuevo hospedero que se registró para Honduras; también I. cordatotriloba es un nuevo hospedero pero para Estados Unidos; material de ambas especies se encuentra depositado en FSCA.

Distribución. Bahamas, Estados Unidos, Honduras, México (Campeche, Chiapas América Central, Campeche, Chiapas, Guerrero, Jalisco, Michoacán, Morelos, Nayarit, Oaxaca, Querétaro, Sinaloa, Tabasco, Tamaulipas y Yucatán), Nicaragua, Tobago y Venezuela. Bahamas y Tobago constituyen nuevos registros de distribución para este brúquido, el material de referencia se encuentra depositado en FSCA.

Material examinado. TABASCO. Agua Blanca, Macuspana, 7/V/2007, 17³7'19” N, 92²7’56” W, col. De La Cruz P. A., CEAM (38 ex). 


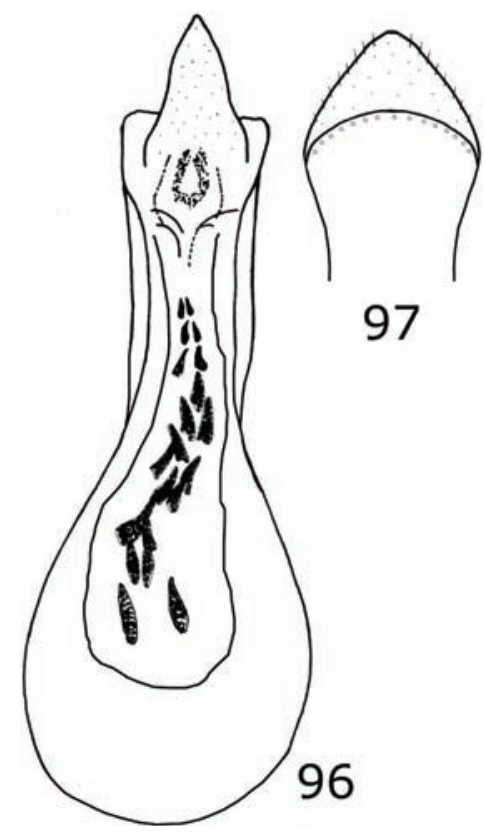

Figuras 96-97. Megacerus cubiculus, vista ventral de la genitalia del macho: 96) lóbulo medio, 97) lóbulos laterales.

Discusión. Esta especie se encuentra muy íntimamente relacionada con $M$. impiger; aunque esta última no se ha registrado para Tabasco, con toda seguridad en el futuro se podrá documentar debido a que se le ha colectado en áreas adyascentes al estado; sin embargo, con las características indicadas en la diagnosis se podrá separa fácilmente a la especie.

\section{Megacerus leucospilus (Sharp), 1885}

Diagnosis. Longitud 3.0-3.2 mm, ancho 2.0-2.2 mm; integumento rojo, excepto cabeza, antenas, patas anteriores, patas medias, tarso posterior y cara externa de la metatibia negros; gran parte del pronoto, mitad anterior del borde sutural de los élitros, parte anterior del lóbulo epipleural, mesoepímero y la mitad anterior del metaespisterno cubiertos por una densa pubscencia amarilla; élitros con 2/3 del intervalo elitral 1 , intervalo 2, 4/5 de la parte anterior de la intervalo 4, base y $3 / 4$ de la parte apical del intervalo 6 y la mitad posterior del intervalo 8 con una densa pubescencia blanquecina; mucro de la metatibia más largo que el ancho del ápice de ese segmento; armadura del saco interno de la genitalia del macho como en las Figs. 98-99. 


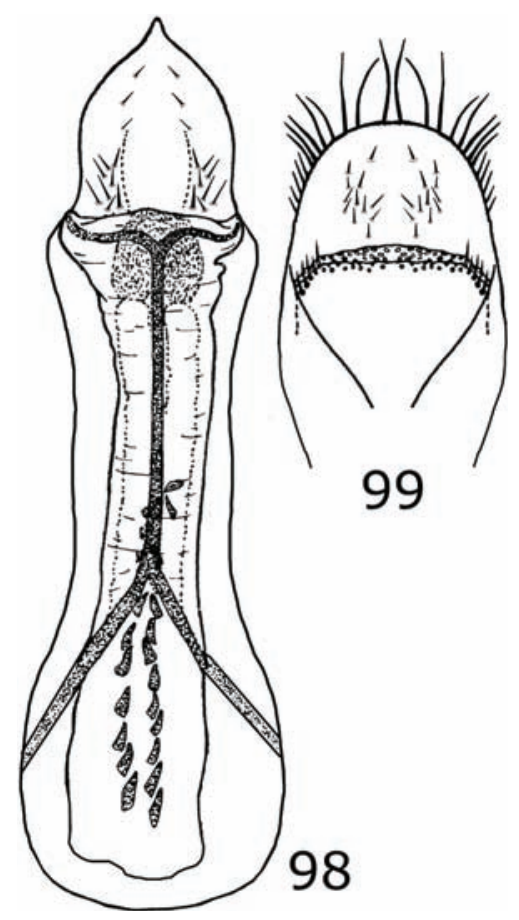

Figuras 98-99. Megacerus leucospilus, vista ventral de la genitalia del macho: 98) lóbulo medio, 99) lóbulos laterales.

Hospedero. Ipomoea cairica, I. carnea subsp. fistulosa, I. carnea subsp. carnea, I. pes-caprae.

Distribución. Colombia, Costa Rica, El Salvador, Estados Unidos, Guayana Francesa, Honduras, México (Campeche, Chiapas, Guerrero, Michoacán, Nayarit, Oaxaca, Puebla, Quintana Roo, Tabasco, Tamaulipas y Veracruz), Nicaragua y Panamá.

Material examinado. TABASCO. 3 mi. N Chable, 4/VIII/1974, col. O’Brien C. W. L. B. O’Brien y G. B. Marshall, CEAM (1 ex).

Discusión. Esta especie es muy característica debido a los patrones de su pubescencia, aunque su genitalia presenta muy pocos caracteres de diagnosis.

\section{Megacerus tricolor (Suffrian), 1870}

Diagnosis. Longitud 1.8-2.7 mm, ancho 1.2-1.8 mm; integumento del cuerpo negro, excepto bordes laterales y anteriores del clípeo y patas anteriores que son castañas, 
élitros rojo violáceao bordeados de negro; vestidura de pubescencia blanca y amarilla; pigidio con densa pubescencia blanca, excepto en dos pequeñas áreas glabras medias y otras dos periapicales que tocan los bordes laterales; estrías elitrales profundas, con puntos grandes, redondeados, no confluentes y de diámetro mayor que el ancho de aquellas; interestrías con la superficie finamente punteada, los bordes ondulantes y una línea de puntos sólo en la novena estría; armadura del saco interno de la genitalia del macho como en las Figs. 100-101.

Hospedero. Argyreia nervosa, Calystegia sepium, Convolvulus sp., Ipomoea alba, I. arborescens, I. cairica, I. carnea, I. crinicalyx, I. cholulensis, I. hederifolia, I. meyeri, I. murucoides, I. nil, I. purpurea, I. tricolor, I. triloba, Merremia aegyptia, M. quinquefolia, Turbina corymbosa, T. racemosa.

Distribución. Antillas, Bolivia, Brasil, Colombia, Costa Rica Cuba, Estados Unidos, República Dominicana, Ecuador, Guatemala, Honduras, México (Baja California Sur,

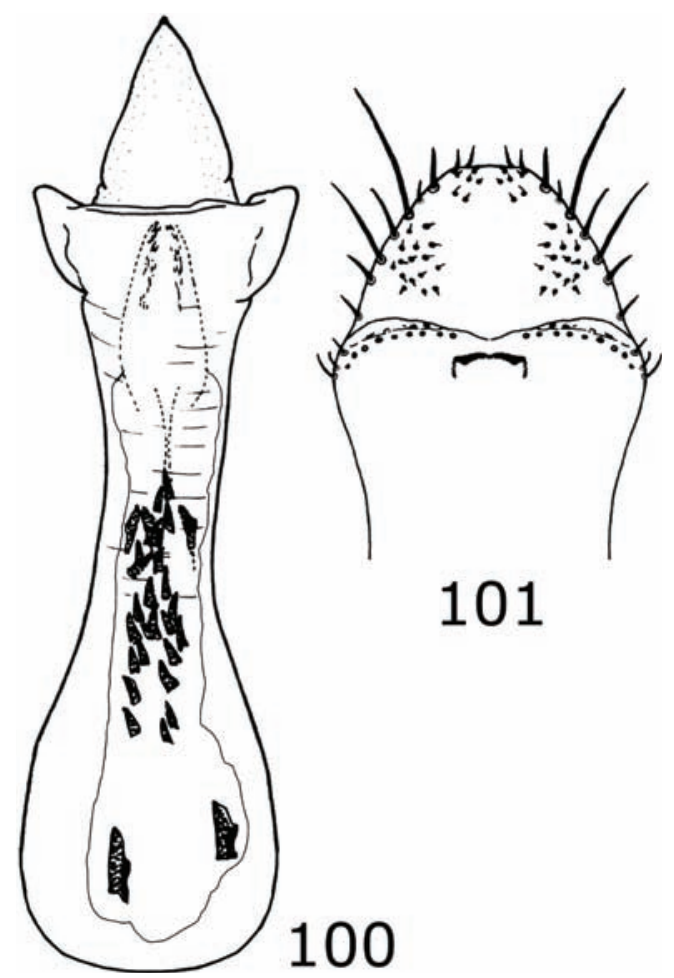

Figuras 100-101. Megacerus tricolor, vista ventral de la genitalia del macho: 100) lóbulo medio, 101) lóbulos laterales. 
Chiapas, Distrito Federal, Guerrero, Jalisco, Michoacán, Morelos, Nayarit, Oaxaca, Puebla, Quintana Roo, Sinaloa, Tabasco, Tamaulipas y Yucatán), Nicaragua, Panamá, Paraguay, Perú, Trinidad \& Tobago y Venezuela.

Material examinado. TABASCO. El Bajío 2da sección, Cárdenas, 1758’22” N, 93²0’53” W, 28/III/2009, Col. De La Cruz P. A., ex. Ipomoea purpurea (L.) Roth Convolvulaceae, CEAM (1 ex).

Discusión. Esta especie es muy característica debido al patron de su pubescencia, principalmente el pigidio que presenta una pubescencia densa de color blanco, excepto en dos pequeñas áreas glabras medias y otras dos periapicales que tocan los bordes laterales; su genitalia presenta muy pocos caracteres de diagnosis.

\section{SUBFAMILIA PACHYMERINAE}

Se considera como la subfamilia más primitiva, las especies adjudicadas a este grupo son de tamaño mediano a grande y se les localiza principalmente en áreas subtropicales y tropicales de todo el mundo, excepto en Australia; está integrada por tres tribus: Caryopemini, Caryedini y Pachymerini. Las dos primeras tribus son endémicas del Viejo Mundo y se alimentan principalmente de especies de la familia Leguminosae y Combretaceae; en tanto que Pachymerinae es endémica del Nuevo Mundo y se alimenta casi exclusivamente se semillas de palmas (Nilsson \& Johnson 1993).

\section{TRIBU CARYEDINI}

Como se indicó anteriormente la tribu Caryedini es endémica del Viejo Mundo y está integrada por cinco géneros: Afroredon, Caryedon, Caryotrypes, Exoctenophorus, Mimocaryedon; sin embargo, una especie del género Caryedon se introdujo accidentalmente al Nuevo Mundo, misma que se indica a continuación.

\section{Caryedon serratus (Olivier), 1790}

Diagnosis. Longitud 3.5-6.8 mm, ancho 1.8-3.0 mm; integumento café obscuro con manchas negras; pubescencia amarillenta sobre las manchas negras; disco del pronoto generalmente circundado por una carina o línea marginal; borde elitral posterior glabro; proceso prosternal corto, sin separar a las coxas por completo, si las llega a separar entonces el proceso es muy delgado y agudo; carina lateral del pronoto indistinta lateralmente; metafémur con prepecten serrulado; pecten con la primera espina grande, seguda por 12-13 dientes más pequeños de un tamaño de 0.5 de la longitud del primer diente; armadura del saco interno de la genitalia del macho como en las Figs. 102-103. 


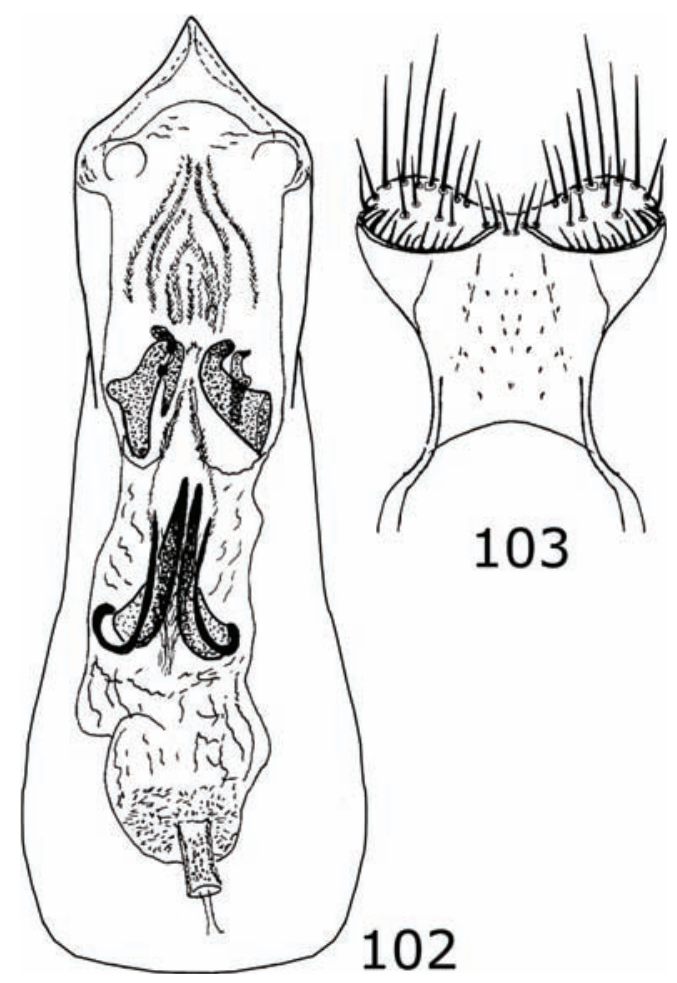

Figuras 102-103. Caryedon serratus, vista ventral de la genitalia del macho: 102) lóbulo medio, 103) lóbulos laterales.

Hospedero. Se trata de una especie altamente polífaga, de tal manera que a continuación sólo se indicarán las especies hospederas que se han registrado en México: Bauhinia variegata, Cassia moschata y Tamarindus indica.

Distribución. Originario del Viejo Mundo, pero se introdujo accidentalmente en el intercambio comercial del fruto del tamarindo al Nuevo Mundo y ahora presenta una distribución cosmopolita, principalmente en área subtropicales y tropicales.

Material examinado. TABASCO. Los Reyes Loma Alta, Cárdenas, 7/IV/1999, Sánchez S., ex. Tamarindus indica L. Caesalpinioideae, CEAM (2 ex); El Bajío 2da sección, Cárdenas, 28/III/2007, 1758’22” N, 93²0’53” W, 11 m, col. De La Cruz P. A., ex. Tamarindus indica L. Caesalpinioideae, CECT (2 ex).

Discusión. Clarence D. Johnson por primera vez reporta a esta especie en México en 1966, en posteriores citas se decribió paulatinamente su expansión en el territorio 
nacional y en general en América (Romero \& Johnson 2002b). Al parecer C. serratus cuenta actualmente con una especie hermana, C. gonagra; al respecto Delobel et al. (2003) indican que después de hacer exámenes de DNA y morfología de la genitalia de ambas especies, concluyen reviviendo la vieja sinonimía de C. serratus y ahora considerada como especie válida, C. gonagra. Ambas especies se pueden alimentar de semillas de tamarindo, pero al parecer $C$. gonagra no se alimenta de semillas de cacahuate (Arachis hypogaea), no así C. serratus, que en el Viejo Mundo si lo hace; sin embargo, la especie que se ha registrado para México es $C$. serratus y hasta el momento no existen registros de que se alimente de las semillas de esta planta. Tal vez sea necesario hacer un estudio en el futuro para determinar con exactitud que especie fue la que se introdujo al Nuevo Mundo.

\section{DISCUSIÓN GENERAL}

La fauna de brúquidos en Tabasco representan el 51.85\% (14) de los géneros y el 13.84\% (49) de las 354 especies y 27 generos registrados para México; en la base de datos BRUCOL, hasta antes del 2009, Tabasco se encontraba pobremente representado con 8 géneros y 12 especies (Romero \& Johnson 2002a). Actualmente, para el estado se ha registrado un incremento en géneros de $175 \%$ (14 géneros) y en especies de un 408\% (49 especies), este incremento indica que aun falta explorar este grupo de insectos en la parte sur del estado; ya que existen difererencias notables en cuanto al total de especies y géneros reportados para Tabasco al compararlos con otros estados como Querétaro, donde se han registrado 14 géneros y 57 especies (Luna et al. 2002), en Jalisco 14 géneros y 106 especies; sin embargo, esto no significa que la diversidad sea menor, pues aun hay zonas donde se debe explorar como la subregión Centro, Pantanos y Ríos. Además es importante reconocer que los efectos climatológicos que en los últimos años han afectado al estado de Tabasco también tienen efecto sobre los procesos biológicos de las plantas como floración y fructificación recorriendo los ciclos reproductivos de los Bruchidae. Las especies de brúquidos encontradas son una muestra representativa de la diversidad de esta familia en el estado, el registro de Aeschynomene scabra como nuevo hospedero para la familia Bruchidae nos indica que el sureste es un sitio que requiere de estudios más profundos sobre la representación real de los brúquidos, incluyendo el estudio de sus hospederos y aspectos biológicos y ecológicos para comprender mejor como interactúan con las plantas hospederas. En este trabajo se reportan 11 plantas hospederas no registradas anteriormente para las siguientes especies: Amblycerus cistelinus, Acanthoscelides oblongoguttatus, A. elevatus, A. flavescens, A. guazumae, A. taboga, G. guanacaste, Mimosestes obscuriceps, M. cinerifer, Merobruchus placidus, M. sonorensis, Sennius auricomus y Megacerus alabani. 
AGRADECIMIENTOS. Al CONACYT (Consejo Nacional de Ciencia y Tecnologia), por el financiamiento para la realización del postgrado y del trabajo de investigación; debe decir: a María de los Ángeles por su apoyo en la identificación de material botánico; a los revisores y editor por los comentarios para la mejora del manuscrito, en especial a Arturo Bonet.

\section{LITERATURA CITADA}

Caswell, G. H. 1960. Observations on an abnormal form of Callosobruchus maculatus (F.). Bulletin of Entomological Research, 50: 671-680.

Delobel, A., Sembène, M., Fédière, G. \& Roguet, D. 2003. Identity of the groundnut and tamarind seed-beetles (Coleoptera: Bruchidae: Pachymerinae), with the restoration of Caryedon gonagra (F.). Annales de la Societe Entomologique de France (n.s.), 39: 197-206.

Grether, R. 2005. La enciclopedia ilustrada de las leguminosas: Sistemática, Filogenia, Biogeografía y usos de las familias a nivel mundial. Bolletin Society Botanical, 77: 77-79.

Johnson, C. D. 1966. Caryedon gonagra (Fabricius) established in Mexico (Coleoptera: Bruchidae). Pan-Pacific Entomologist, 42: 162.

Johnson, C. D. 1983. Ecosystematics of Acanthoscelides (Coleoptera: Bruchidae) of Southern Mexico and Central America. Miscellaneous Publications of the Entomological Society of America, 56: 1-248.

Johnson, C. D. 1990. Systematics of the seed beetle genus Acanthoscelides (Bruchidae) of Northern South America. Transactions of the American Entomological Society, 116: 297-618.

Johnson, C. D. \& Kingsolver, J. M. 1973. A revision of the genus Sennius of North and Central America (Coleoptera: Bruchidae). U.S. Department of Agriculture, Technical Bulletin, 1462: 1-135.

Johnson, C. D. \& Kingsolver, J. M. 1976. Systematics of Stator of North and Central America (Coleoptera: Bruchidae). U.S. Department of Agriculture, Technical Bulletin,. 1537: 1-101.

Johnson, C. D. \& Kingsolver, J. M. 1981. Checklist of the Bruchidae (Coleoptera) of Canada, United States, Mexico, Central America, and the West Indies. The Coleopterists' Bulletin, 35: 409-422.

Johnson, C. D. \& Nilsson, J. A. 1990. New synonymy of Bruchus podagricus Fabricius and Bruchus crotonae Fahraeus, with a lectotype designation and a new combination for B. podagricus (Coleoptera: Bruchidae: Ctenocolum). Pan-Pacific Entomologist, 66: 171-172.

Johnson, C. D., Southgate, J. B. \& Delobel, A. 2004. A revision of the Caryedontini (Coleoptera: Bruchidae: Pachymerinae) of Africa and the Middle East. Memoirs of the American Entomological Society, 44: 1-126.

Kingsolver, J. M. 1969. A new species of Neotropical seed weevil affecting pigeon peas, with notes on two closely related species (Coleoptera: Bruchidae: Bruchinae). Proceedings of the Entomological Society of Washington, 71: 50-55.

Kingsolver, J. M. 1970. A study of male genitalia in Bruchidae (Coleoptera). Proceedings of the Entomological Society of Washington, 72: 370-386.

Kingsolver, J. M. 1988. Biosystematics of the genus Merobruchus of continental North America and the West Indies (Coleoptera: Bruchidae). U.S. Department of Agriculture, Technical Bulletin, 1744: 1-63.

Kingsolver, J. M. 2004. Handbook of the Bruchidae of the United States and Canada (Insecta, Coleoptera). U.S. Department of Agriculture, Technical Bulletin 1912, vol. 1: 1-324, and vol. 2: 1-198.

Kingsolver, J. M. \& Johnson, C. D. 1978. Systematics of the genus Mimosestes (Coleoptera: Bruchidae). U.S. Department of Agriculture, Technical Bulletin, 1590: 1-106.

Kingsolver, J. M. \& Whitehead, D. R. 1974a. Biosystematics of Central American species of Ctenocolum, a new genus of seed beetles (Coleoptera: Bruchidae). Proceedings of the Biological Society of Washington, 87: 283-312. 
de la Cruz Pérez et al.: Brúquidos de Tabasco

Kingsolver, J. M. \& Whitehead, D. R. 1974b. Classification and comparative biology of the seed beetle genus Caryedes Hummel (Coleoptera: Bruchidae). Transactions of the American Entomological Society (Philadelphia), 100: 341-436.

Kingsolver, J. M. \& Whitehead, D. R. 1976. The North and Central American species of Meibomeus (Coleoptera: Bruchidae: Bruchinae). U. S. Department of Agriculture, Technical Bulletin, 1523: 1-56.

Lot, A. \& Chiang, F. 1986. Manual de Herbario: Administración y manejo de colecciones, técnicas de recolección y preparación de ejemplares botánicos. Instituto de Biología. Universidad Nacional Autónoma de México. Consejo Nacional de la Flora de México. A. C. México, D.F.

Luna-Cortazar, J., Romero Nápoles, J. \& Jones R. W. 2002. Lista de Bruchidae del Estado de Querétaro, México (Insecta: Coleoptera). Acta Zoologica Mexicana, 87: 17-28.

Morse, G. E. \& Farrell, B. D. 2005. Interspecifc phylogeography of the Stator limbatus species complex: The geographic context of speciation and specialization. Molecular Phylogenetics and Evolution, 36: 201-213.

Nilsson, J. A. \& Johnson, C. D. 1993. A taxonomic revision of the palm bruchids (Pachymerini) and a description of the world genera of Pachymerinae (Coleoptera: Bruchidae). Memories of the American Entomological Society, 41: 1-104.

Romero N., J. 2002a. Five new species of Meibomeus Bridwell from the New World with host records for them and six named species (Coleoptera: Bruchidae). The Coleopterist Bulletin, 56: 182-202.

Romero N., J. 2002b. Bruchidae, pp. 513-534. In: J. Llorente B. and J. J. Morrone (Eds). Biodiversidad, Taxonomía y Biogeografía de Artrópodos de México, Hacia una Síntesis de su Conocimiento.Vol. III, UNAM.

Romero N., J. \& Johnson, C. D. 1999. Zabrotes sylvestris, a new species from the United States and Mexico related to Z. subfasciatus (Boheman) (Coleoptera: Bruchidae: Amblycerinae). The Coleopterist Bulletin, 53: 87-98.

Romero N., J. \& Johnson, C. D. 2000. Revision of the genus Zabrotes Horn of Mexico (Coleoptera: Bruchidae: Amblycerinae). Transactions of the American Entomological Society, 126: 221-274.

Romero N., J. \& Johnson, C. D. 2002a. BRUCOL. Una base de datos para Bruchidae (Insecta: Coleoptera), pp. 1: 520-524: In: J. Romero N., E. G. V. Estrada \& A. M. Equihua (Eds). Entomología Mexicana. Colegio de Postgraduados-SME. Montecillo, Edo. de México.

Romero N., J. \& Johnson ,C. D. 2002b. Cassia moschata H.B.K., new host for Caryedon serratus (Olivier) in the New World (Coleoptera: Bruchidae: Pachymerinae). Coleopterists Bulletin, 56: 95-96.

Romero N., J. \& Johnson, C. D. 2004. Sinopsis de los brúquidos de México (Insecta: Coleoptera), pp: 3: 758-763. In: M. Morales, A. M. G. Ibarra, A. del P. G. Rivera \& S. C. Stanford (Eds). Entomología Mexicana. Sociedad Mexicana de Entomologia.

Romero N., J., Johnson, C. D. \& Kingsolver, J. M. 1996. Revision of the genus Amblycerus of the United States and Mexico (Coleoptera: Bruchidae: Amblycerinae). United States Department of Agriculture Technical Bulletin, 1845: 1-166.

Romero N., J., Grether G., R., Camargo, S. L. R. \& Johnson, C. D. 2005. Método para la evaluación de daño de semillas por brúquidos (Insecta: Coleoptera) en el campo, con nuevos registros de hospederos y distribución para el grupo, pp. 4: 107-111. In: M. A. Morales, M. G. Ibarra, A. E. Mendoza, M. P. G. Ibarra \& S. C. Stanford (Eds). Entomología Mexicana. Colegio de Postgraduados-SME. Montecillo, Texcoco, Edo. de México.

Romero N., J., de la Cruz P., A. \& Kingsolver, J. M. 2009. Seed beetles (Coleoptera: Bruchidae) associated with Acacia cornigera (L.) Willd., with description of a new species of Acanthoscelides Schilsky. Insecta Mundi, 0093: 1-11. 
Secretaria de Desarrollo Social y protección al ambiente (SEDESPA). 2001. Atlas del Estado de Tabasco, SEDESPA. Gobierno del Estado.Villahermosa, Tabasco.

Southgate, B. J. 1964. Distribution and hosts of certain Bruchidae in Africa. Tropical Stored products Information Circular, 7: 277-279.

Teran, A. L. \& Kingsolver, J. M. 1977. Revisión del género Megacerus (Coleoptera: Bruchidae). Opera Lilloana, 25: 1-287.

Thomas, G. \& Clay, D. 2012. Biodap-ecological diversity and its measurement. Ed. Resource Conservation Fundy National Park. New Brunswick, Canada. Disponible en: http://nhsbig.inhs.uiuc. edu/wes/populations.html (consultado el 20 de junio de 2012).

Tuda, M., Wu, L., Tateishi, Y., Niyomdham, Ch., Buranapanichpan, S., Matimoto, K., Wang, Ch., Chen, Z., Zhu, H., Zhang, Y., Murugan, K., Chou, L. \& Johnson, C.D. 2009. A novel host shift and invaded range of a seed predator Acanthoscelides macrophthalmus (Col: Chrysomelidae: Bruchidae), of an invasive weed, Leucaena leucocepha. Entomological Science, 12: 1-8.

Utida, S. 1954. "Phase" dimorphism observed in the laboratory population of the cowpea weevil Callosobruchus quadri-maculatus. Japanese Journal of Applied Zoology, 18: 161-168.

Utida, S. 1981. Polymorphism and phase dimorphism in Callosobruchus. Series Entomologica, 19: 143-147.

Villaseñor, J. L. 2003. Diversidad y distribución de las Magnoliophyta de México. Interciencia, 28: 160-167.

Villaseñor, J. L. 2004. Los géneros de las plantas vasculares de la flora de México. Boletín de la Sociedad Botánica de México, 75: 105-135.

Weaver, P. L. 1989. Andira inermis (W. Wright) DC. SO-ITF-SM-20. New Orleans, L.A: U.S. Department of Agriculture, Forest Service, Southern Forest Experiment Station, 3-42.

Whitehead, D. R. \& Kingsolver, J. M. 1975. Biosystematics of the North and Central American species of Gibbobruchus (Coleoptera: Bruchidae: Bruchinae). Transactions of the American Entomological Society, 1001: 167-225.

Zacher, F. 1952. Die Nahrpflanzen der Samenkafer. Zeitschrift für angewandte Entomologie, 33: 460480. 